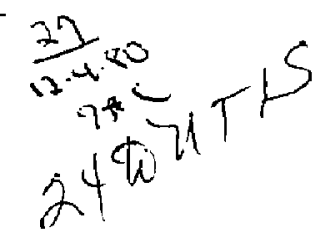

\title{
MASTER
}

J. V. Candy

N. Mao

\section{October 1980}

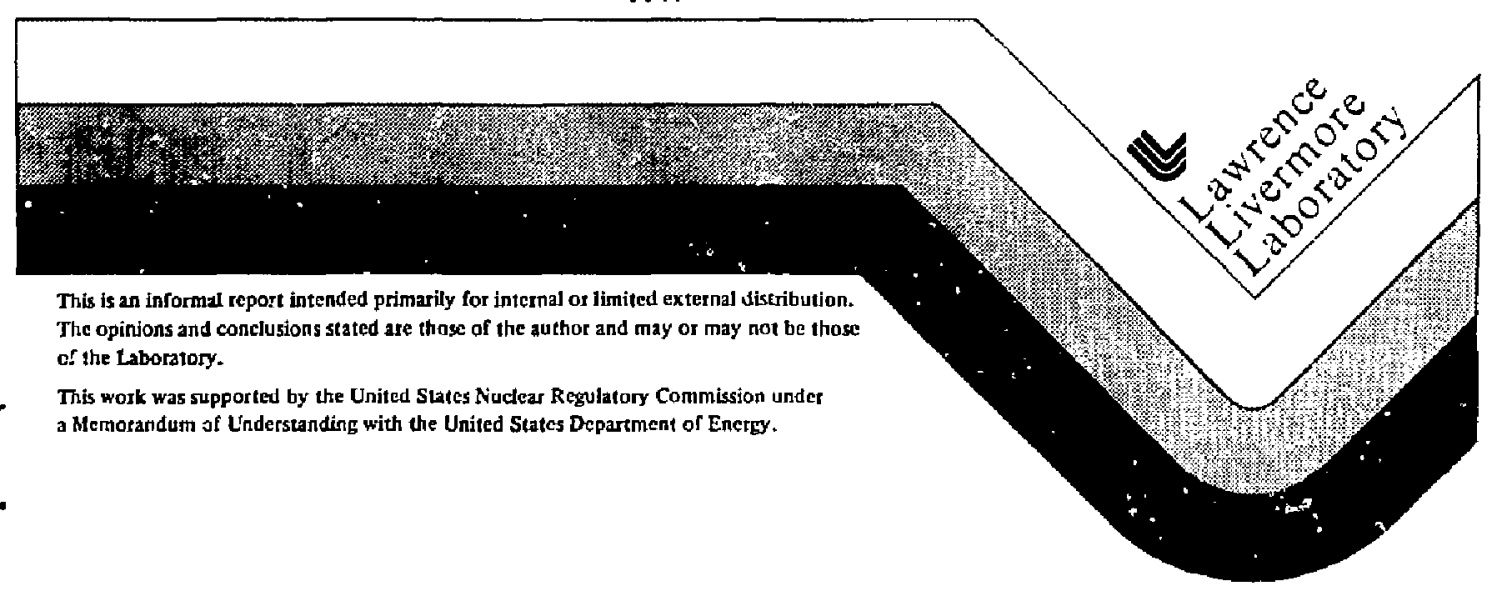

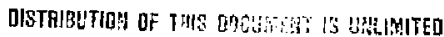


In this report we discuss the application of spatial estination tecnniques or kriging to representative groundwater and geological data sets. Tnis work aas Funded under tne Wuclear Regulatory Commission (NRC) waste Management Prograin and partially oy che Lawrence Livermore Hational Laboratory (LLNL) containnent Test Program. Tile program is primarily concerned with investigating the geologic properties of potential underground repositories wnicn can de used to store nuclear waste material. The first provlen to ue solved is tnat of site cnardcterization, i.e., the determination of various paralleters iike transmissivity, porosity and suosurface structures necessary to evaluate the incegrity of the particular site. Initially exploratory boreholes are orilled at a potential site and this data is evaluated to determine the critical paraneters. Usually contour maps of groundwater flows and other parameters are develuped and site cndracteristics can be derived froin this information. Thus, it is recessary for the dikc to evaluate various tecmiques whicn can oe used to produce reliaole contour maps in order to characterize a site.

Spatial estimariun is a technique to estinate points ur volunes on a grid wren the data is spatially correlated. Once tne grid is generated, contouring follows directly using sinple interpolation techriques. It is the purpose of tmis study to investigate the applicauility of a specific spatjal estinator developed in the mining industry to groundwater and geological data. The investigation consists of applying the estimator to simple groundwater

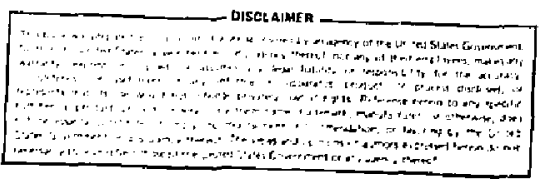


structures and evaluating the results. In one case a model developed by a nydroiogist for a particular aquifer was used to generate a grid which was used as "truth" and the performance of the estjmator given a sparse number of measurements was evaluated. It was snown tnat the estimatar could reliably reproduce the grid for this simple aquifer. The estimator was then applied to more complex geological formations and found to produce reasonale results in this case as well. In summary, we feel that the spatial estimator can be used with confidence to produce reliadle contours if the investigator carefully identifies the proper sratistical model from the data set. 


\section{AUSTRACT}

In tnis report we consider the application of spatial estimation tecnniques or kriging to groundwater aquifers and geological borehole data. We investigate the adequacy of these techniques to reliably develop contour inaps from various data sets.

The estinator is developed tneoretically in a simplified fasnion using vector-matrix calculus. The practice of spatial estimation is discussed and the estimator is then applied to two groundwater aquifer systens and used also to investigate geological formations from dorehole data. It is snown that the estimator can provide reasonable results when designed properiy. 
Page

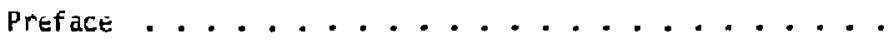

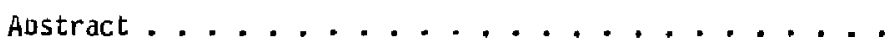

I. Introduction ......................... 1

II. Theoretical Background ................... Iu

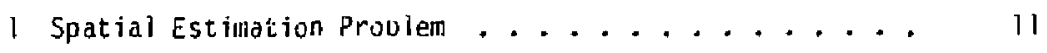

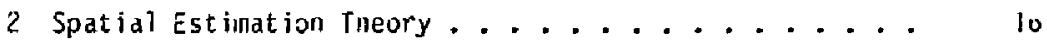

3 Drift Estimation Prodlem ............... 21

4 Orift Estillation Tneary............. ¿ ... ¿s

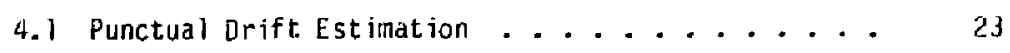

4.2 Regional Drift Estimation ........... 20

111. Practice of Spatial Estimation ............. 27

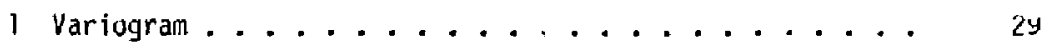

2 Variogram Estination/Identification . . . . . . . 34

3 Variogram Escination in the Presence of Jrift ..... . $4 / 6$

4 Data Displar Tecnniques .............. . 44

1V. Application of Sputial Estinatiur. ........... 40

1 Case Study: Topperisn Creek Basin, rashington ..... 40

2 Case Study: Todo Lake, Natural Fluw Conditions..... . so

3 Case Study: Nevada Test Site, Paleozoic Rock Data . . . 77

v. Sunusary and Future work ................ . . 94

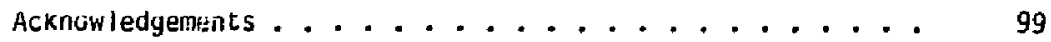

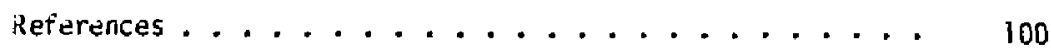

Appendix A Spatial and Urift Estination Theory ...... 105

Appendix B Matrix Calculus Rules ............. 118

Appendix C Derivation of Spatial Estimator Weights . . . . 119 


\section{LIST OF FIGURES}

Figure 1 Spatial Estimation Problem for Grid Generation. . . . . . . 12

Figure 2 Covariance and Variogram. .......................... 31

Figure 3 Experimental Variogram Estimates. . . . . . . . . . . 37

Figure 4 Experimental Drift Estimate. . . . . . . . . . . . . 37

Figure 5 Theoretical Variogram Fit of Estimated Variogram. . . . . . . 37

Figure 6 Successive Estimat ion Technique. . . . . . . . . . . . . 41

Figure 7 Toppenish Creek Basin Raw Data (In Feet). . . . . . . . . 47

Figure 8 Anistropic/Isotropic Estimated Variograms for Toppenish Creek Data. 49

Figure 9 Drift Corrected Anisotropic/Isotropic Estimated Variogram for Toppenish Creek Data................... 50

Figure 10 Est imated NE/SW Variogran for Toppenish Creek Basin, Washington.. . 51

Figure 11 Identified Variograms (Near Origin) Against NE/SW Experimental Variograms far Toppenish Creek Basin, Washington. . . . . . 54

Figure 12 Contour of Groundwater Levels (In Feet) at Toppenish Creek Basin, Washington, Using Spatial Estimation Techniques (Linear Variogram). 56

Figure 13 One Sigma Estimation Error Contours (In Feet) of Toppenish Creek Basir, Washington, Using Linear Variogram. . . . . . . 56

Fioure 14 Orift (Trend) Contours (In Feet) of Toppen ish Creek Bas in, Washington, Using Linear Drift and Spatial Estimation Techniques. . 57

Figure 15 Pseudo-color image of spatially estimated Toppenish Creek Basin, Washington, using linear variogram. ........... 59

Figure 16 Pseudo-color jmage of one-sigma errors for spatially estimated Toppenish Creek data using linear variogram.. . . . . . . . . 59

Figure 17 Todd Lake Regional Map. . . . . . . . . . . . . . . . . . 61

Figure 18 Todd Loke "Truth" Groundwater Level Contour (In Feet).. . . . . . . 63

Figure 79 Todd Lake Groundwater Level Contour Based on 28 Measurements (In Feet). .................. 63

Figure 20 Anisotropic/Isotropic Estimated Variogranis for Todd Lake Data.. . . 64 
Figure 21 Urift-lorrected Anisotropic/Isotropic Variograns for Todd Lake Uata. 65

Figure 22 Estimated NW/jE Variogram for Todd Lake Uata Using 28 Measurements.. 66

Figure $\angle 3$ Estimated iW/SE Variogram for Todd Lake Using 28 weasurenents. . . . 69

Figure 24 Contour of Groundwater Levels (In Feet) at Iodd Lake Using Spatia)

Estination Techniques (Power Variogram\}. . . . . . . . . . 70

Figure 25 Une-Sigina Estimation Error Contours (In Feet) of lodd Lake (Power

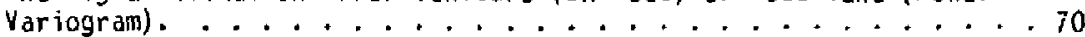

Figure 26 Ident if ied Truth and jjarse for the iw//jE Todd Lake Truth Jata.. . . 71

Figure 27 Relative Error Contours for Todd Lake Spatial Estimation. . . . . 74

Figure 28 Pseudo-color inages of spatially estimated rodd kake. . . . . . 75

Figure $\angle y$ Pseudo-color inage of one-sigma errors for spatially estimated Todd Lake data. . . . . . . . . . . . . . 75

Figure so Map shows principal rock types and studied area at WTj f from damspott ana Howard $(18 \mathrm{j}) . \ldots 79$

Figure 31 Anisotropic Variagrans for Paleozoic kock Uepth at NTs.. . . . . 80

Figure 32 Paleozcic Rock vepth at ITS Froll Model Linear 1 with Fault. . . . . 84

Figure ss Une-sigma Error for Paleozoic kock Ueptn at WTs From rlodel Linear I

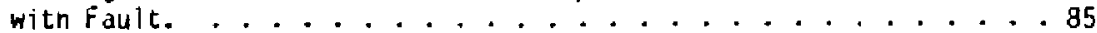

Figure 34 Paleozoic Rock Lepth at NTS froin Model Linear 1 witnout Fault. . . 85

Figure 35 Une-Sigma Error for Paleozoic Rock Vepth at WIS from Model Linear 1

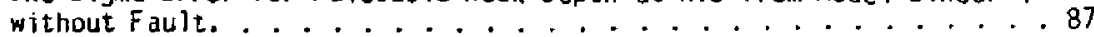

Figure 30 Cross-Section of AA' in Figure 32. . . . . . . . . . . . 88

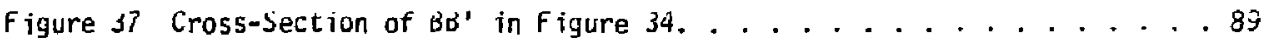

Figure 38 Pseudo-color image of Paleozoic rock depth at the Hevada rest site.. 91

Figure 39 Pseudo-color inage of one-sigina estination erros of paleozoic rock depths at the Nevada Test jite. .................. 9]

$\vec{r}$ igure 40 Anisotropic Varjograns for hesiduals of Urift-Corrected Paleozoic

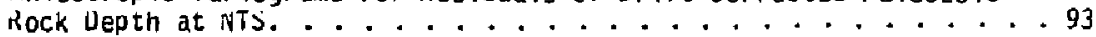


Table 1 Spatial and Drift Estimator Summary. ............. 28

Table II Variogram Models. . . . . . . . . . . . . . . 33

Table III Generalized Covariance Models. ............... 39

Table IV Successive Estimation Validity Test. . . . . . . . . . 43

Table V Toppenish Creek Structural Model Surmary............. 53

Table VI Toppenish Creek Structure Identification/Validation. . . . . . 53

Table VlI Todd Lake Structural Model Summary. . . . . . . . . . . . 67

Table VIII Todd Lake Structure Identification/Validation. . . . . . . . . . 67

Table IX Todd Lake Structural Analysis Using Truth Data.. . . . . . . . 72

Table $x$ NTS Paleozoic Rock Depth Structural Model 5 imary. . . . . . 81

Table XI NTS Paleozoic Rock Structure Ident ification/Validation. . . . . 82 
I. INTRUUUCTIUN

The need for alternate energy sources has propelled the use of nuclear energy as a feasible means for generating power. Huclear tecinolugy nas been utilized in many military and non-lililitary applications sucin as fuel faprication, medicine, weapons, etc. Une perplexing problem has evolved - the disposal of radioactive waste products. It is tne responsibility of the isuclear kegulatory iom(rission (ixh() ta assure that wastes oe disposed in a manner non-Jeterimental to public health and welfare.

Une proposed solution to the disposal problem is to isolate the waste in leep geoloyical repositories. The waste is to be contained until they are no longer radiotoxic. Some elenents will lake a long time to decay - up to a few million years. For tnese sluwly decaying eleilents the prinary contaiment vesset will nave deteriorated and therefore the geological structure of a repository will serve as the uitithdte concainment vessel. The question of concarination of the water supply vecomes of prime concern. The magnitude of the disposal problem can be realized from the fact that only a single curie of ${ }^{90} \mathrm{Sr}$, a cominon fission by-product, if jissolyed in water could render $10^{11}$ liters unacceptable as drinking water according to the U.S. Public Health Service standards [1]. Jisposal praccices depend on the radoactivity of the waste, the general chemical character of the waste, and the 
physical environment in the area of disposal. All plans for terrestrial storage have stressed the need for careful nydrogeologic studies to insure that the wastes will not contaninate existing or future water supplies. Thus, prior to construction and regulation of a repository, a site must be selected, cnaracterized, and evaluated.

The repository site evaluation process consists of two stages: elimination of sites prior to perforinance evaluation and the selection of sites by comparison of predicted perforinance. Unce tile number of candidate sites are screened, the most promising systems must be evaluated by developing a perforinance model, winich ultimately yields as output the radioactive flux dosage to the average man compared to existing radiation standards [2].

Since the most likely release of radionuclides in the long terin will De via the groundwater systeri, it is ocvious tnat nydrogeology will form a major component of any perforinance evaluation model. The geological framework, the output of the repository excavation performance model, and the hydrogeologic paraneters will form tne input to the nydrogeolugical model. During different stages of the process, two types of paraneters will be required: general site characterization parameters during preliminary evaluation and model input parameters for peformance evaluation. Thus prior to site selection, much information about the geological and nydrogeological structures of the site must be ootained. For example, size, shape, 
faults, groundwater properties, and chemical composition - chis process is called site characterization. Tnis ruport addresses itself to the site characterization proulen, i.e., the problen of determining various geological and hydrogeological parameters necessary to characterize a potential repository.

Linfortunately, the evaluation of repository performance invoives considerable uncertainties. These uncertainties arise frum several sources: (i) measurement uncertainty in specifying goological parameters; (ii) spatial variabijity of the subsurface environient, and, (iii) wiartaincy in andytic perfuriance wodels. Any treatinent of repository regulations must account for these uncertainties and therefore, any techni yues used to characcerize a putential site must also give some measure of the potenilal uncertainties in parameters generated.

The determination of hydrogeological parameters reyiires an understanding 0 : the piezonetric surface of a potential site, i.e., the water levels. Water levels measured in wells are conveniently studied by means of inaps and graphs. Most frequenily used are watei-level contour inaps. The elevation to whicn water rises in wells defines the piezonetric surface. The surface may be either adove or below the water table. The piezometric surface is deternilied by ootn water pressure and elevation of the aquifer. Where water levels in wells reliably reflect tne water taule, contour maps of the water 
taple can de drawn. The force potential causing groundwater flow is directiy proportional to the elevation. water levels in wells drilled in aquifers. The general direction of groundwater flow can oe snown on water taole naps. This map indicates the elevation oi the water taole oy ineans of contours. Various nyarogeological parameters can be oatained directly from the contours. Thus, one of the important tasks in groundwater study is to produce reliabie contour llaps of tne water taole.

Information adout nydrogeological parameters can be ootained by borehole sampling. Too many Dorenoles at a site are not only expensive but they can tend to deteriorate the integrity of the site as a possibie repository. Two approacnes are possiole: first, the use of nonintrusive measurements (e.g., seisinic) or second, make statistical inferences on the suitability based on few data poirts. In this report we evaluate a technique which can be used to solve the site characterization problem. The fundanental problem is to generate a grid of control points from a set of sparse, irregular, uncertain, but spatially-correlated, measurements - tnis is called the fundamental spatial estimation problem. Spatial estination techniques can be useful as a statistical interpolation/extrapolation method to derive more information from sparse data sets and tney can also be used to combine different types of data (seismic, depth, gravity, etc.) to give a more complete characterization of geological and hydrogeological parameters. 
Spatial estimation is rooted on ore estimation proulems. In the early 1950's a South African mining engineer, D. G. Krige applied movinyaverage techniques to the problem of ore estimation $[3,4]$. Later a French enginer, G. Matheron formalized the approach in the early 1960's [5]. Matheron introduced the concepc of "regionalized variables" to represent functions whose known values do not follow any simple deterministic function over a wide range. He expanded Krige's empirical odservations into a theory of the denavior of these spatially distributed variables which was applicable to any phenonenon satisfying certain nasic assumptions. Currently, tnis theory nas deen used in mining, meteorology, forestry, llapping of groundwater potentials, air pollution concentrations. geologic surfaces and oil field delineations $[0-12\rfloor$. To nonor Krige for his pioneering work, Matheron referred to tne spatial estimation technigues as "kriging" and later as universal kriging when used to estinate a variable witn a trend in the data. In tnis report, we refer to tne estimator as tne spatial or kriging estimator, interchangady.

Kriging is a particular statistical spatial estination technique similar in principle to the Box-Jenkins approacn of time series analysis [13 J. It makes no attempt to descride the physical mecnanisn of the underlying phemomenon in contrast to the kalman filter approach [14]; instead it models, using statistical principles, the structure of the availdoie spatially-distributed data to estimate contours of geologic phenomenon. Kriging is essentially a stocnastic tecnnique of 
interpolating sparse data assumed to be spatially correlated. It consist:s of two parts: estimation of a variogram, wnich descrions the degree of correlation Detween two observa: :uns as a function of the distance between them, and calculation of the kriging weignts, wnich indicate the relative influence of each of the data ooservations on the interpolations.

A potential geological repository must be evaluated from very sparse data. The relevant questions are: What is the minimum measurement density requirement? What is tne uncertainty assaciated with tne estimate? How is the selection of additional sampling locations optinized? Kriging is a spatial estination tecimique which zan produce answers to these questions. rirst, kriging can be used to produce a contour map of the geological formation (or any other spatialiy-distrisuted phenomena) of a potential site with an associated measure of uncertainty (kriging error). For a given variogram, Dy maneuvering the data set, kriging will provide insignts into the effect of data density on the associated uncertainty of the contour map as well as a rationale for selection of additional sample-locations. Secondly, kriging can oe used to conbine different types of data from a suite of geological and geophysical measurements to produce a mare complete characterization of the geologicai parameters than provided by conventional methods. 
Tre oojective of tou report: : to evaluate the effectiveness of kriging as a potential tool for site characterization of deep geological repositories. The basic criterion for evaluation is now realistically the estimator predicts tne geclogical pnenomenon. This can be judged in two ways: D) romparing the estimate value witn the measured value for tne point wricn is removed from the vata set, or oy comparing tne estinated map with the "real" contour Illap based on other information in addition to the estillated data set. By using representative data sets, the uncertainty in the estilnation of the variogrän can de assessed. Furthermore trie effect of faults on estirution can also oe investigated.

We evaluate kriging by experimenting on representaive data sets. We selected tnree particular data sets to study: (i) Toppenisn Creek Basin, (ii) Todd Lake, and (iti) Nevada rest Site. The first two cases are simple groundwater aquifers and the final set is a complex geological formation.

The Toppenisn Creek Basin, Wasnington is a simple aquifer system. Tne data set consists of 76 water level measurements at various wells in the region during Septemeer 1971. The data was obtained from J. A. Skrivan of the USGS, Tacoma, Wasnington. The main purpose of this study is to evaluate now realistically the spatial estimator could produce contours of a well-known aquifer system. 
The Todd Lake, Pennsylvania data set represents a region well known to a LLNL nydrologist, W. A. Murray. From a set of ten actual we ll-measurements and 18 known water levels (pond, lake, etc.) he was able to develop a groundwater model (partial differential equations) and generate a regular grid of data points for concouring purposes. In tnis case study we assune che grid generated by his model is tne true representation of leyels in the region, nereafter called "truth" grid. Here we would like to deterinine now well tne spatial estinator can reproduce the "truth" grid using the same sparse data set of 28 points.

Finally, we studied the depth to the top af the paleazoic rocks from y3 borenole data from the Nevada Test Site (IIS). The Geologis Data Base from the Nevada Test Site maintained by $[L$ Liv $[7]$ contains parameters describing the location coordinates, the lithologic contacts (alluviuin, volcanic tuffs, and paleozoic rocks), the distance to known and inferred faults, the depth to the water table, etc., from over 1000 drill holes. In addition, there is a data base of 9000 files of processed geophysical data versus deptn from logs anc: samples. Otner geophysical data sucn as seisinic reflections and gravity are also availaole for the area. We also investigated the effect of faults on the estimated depth.

In thi: report, we develop spacial estimators to solve the site characterization prooiem. The estimators are developed simply from 
well-known regionalized variade theory [5] using vector-matrix calculus techniques in Section [1. The practice of spatial estimation is discussed in Section 111 primarily to answer the question of "how"! It is snown in tris section that tne most crucial area of spatial estimation is the development of the statistical strutural model - the variograni and drift. Tecnniques to estinate and identify the underlying variogran dod drift from raw measurement data are discussed along with techniques to validate the model. The spatial estimators are developed for the three representative data sets in Section IV. It will de shown tnat the estimator performs we'l on tne groundwater aquifers, i.e., reasonable contours we pe produced. in the case of the spaise. Todd Lake data, the estimator reproduces the "trutn" grid with a maximun relative error of approximately one percent. Applying the estimator to the complex geological data from the Nevada Test Site produces reasonable maps for subusface paleozoic rock deptn in tne region. Results of the estimator are compared with that obtained from gravity ineasurenents. It will also be snown that image display tecnniques $c$ an be used to interactively investigate properties of regional maps.

We show that spatial estination tecnniques can be used effectively to characterize proposed repository sites from limited data provided that care is taken when identifying the statistical structural model from raw data. Using a statistical nodel the estinator provides reasonable estimates and predicts associated uncertainties from irregularly 
distributed data with geasurement errors and underlying trends. The spatial estimator gives an optimum (ninimum error variance) estimate and $c$ an be used to provide information on the design of optimum sampling networks.

II. THEORETICAL BACKGROUND

In this section we oriefly develop the fundamental tneory of spatial estimation. Matnematical details will de kept to a minimun and deferred to Appendix A. Only the fundamental relations will de presented. Our ultimate goal is to use the spatial estimator to produce a reasonable contour map with some measure of confidence. For the water level data, once the jap is produced other nydrogeological parameters can oe derived.

Construction of contour maps of areally distributed data presents problens because the data are often irregularly located in a region. The first step in contouring is usually to produce a reguiar mesn or grid of contral points tnrough interpolation. The grid may be produced in a variety of ways, ranging from estimates at grid paints based on the nearest observation, to est inates aerived from trend surfaces of all observations. Once tne grid is generated contours or :sopletns (i.e., Jines connecting points of equal value) are produced Dy simpie interpolation oetween grid points. Finaliy, the contours are drawn oy a plotter to yield the desired resuits. 
In tnis section we discuss the development of an "optimal" estimator which can be used to estimate control points on a grid for eventual contouring. In section l, we define the spatial estimation proplen. An estimator to solve this problen is discussed in section 2 . The problem of drift estimation is discussed and solved in sections 3 and 4.

\section{II-1. Spatial Estimation Problem}

In this section we define the spatial estimation probiem and assumptions necessary to obtain a reasonable solution. Recall the most critical part of contour map generation lies in the generation of the grid of control points - this is the fundamental spatial estination problem, simply stated (see figure 1)

GIVEN a set of irregularly lorated measureinent points in a well-defined region, FInó the "oest" (mininum error variance) linear estimates of control points at desired lacations within the region.

Actually spatial estimation can ve thought of as "stocnastic interpolation", since a minimum variance est inator is designed to provide point estimates between and around existing measurenents. 


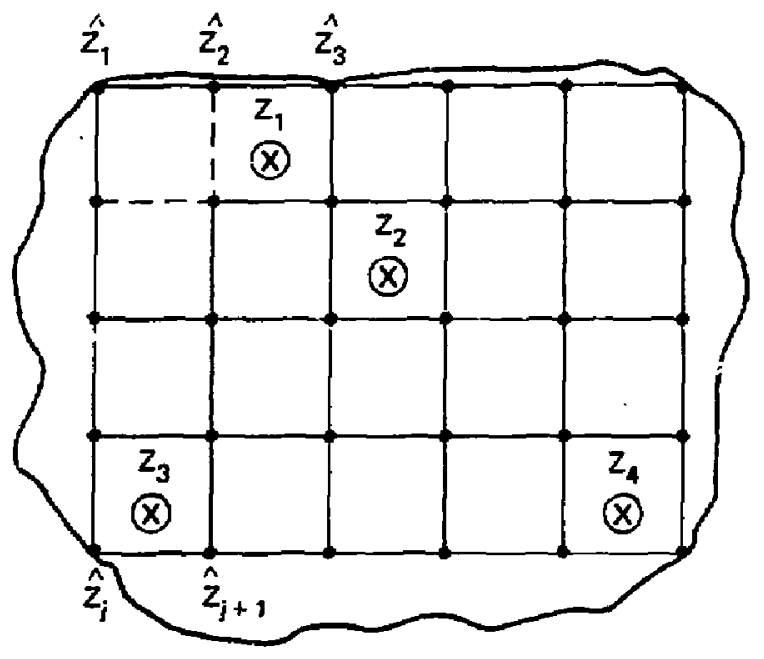

Figure 1. Spatial Estimation Proolen for Grid Generation 
A natural phencinena can oe characterized by the distribtuion in space of one or more variables, e.g. tne distrioution of altitude in a norizontal space characterizes a topological surface. Let $z\left(\underline{x}_{j}\right)$ De the value of the variable $z$ at point $x_{i}$ in space $(1,2$, or 3 dimensional). In the estimation approacn, $x\left(\underline{x}_{i}\right)$ is interpreted as a particular realization of a randon function $2(\underline{x})$. Hore formally, $z\left(\underline{x}_{j}\right)$ is defined as a regionalized varjable, i.e., a function with spatial Jistrioution whicn varies randomly from one location to another. Spatial estination tneory is based on the observation that the variabilities of all regiandized variabius nave a particular structure, i.e., tney are similar and the measure of similarity can de expressed in sone way. For example, if we make three mastsurements of water potenital, two that are in close proximity to one anotier dnd one not as close, we may find that tne close measurements agree and even the third measurement is also related to the other two measurements, to some extent. The statistical measure of similaricy or correlation and continuity between tneasurements as a function of distance between then is called the variograth and it forms the vastic "inodel" which faust oe determined oefore estination can cumnence. Before we get into the practical aspects of spatial estination, let us develop the theoretical dasis of the tecnniques.

In most cases of spatial estination, the number of ineasurements or data points are sparse for a given region, e.g. borenole data in an exploratory ore deposit. Thus, in order to make the technique 
sathematically reasonable we impose the following constraints on the function called the intrinsic nypocnesis. The regionalized variadie satisfies the intrinsic nypotnesis if for all $\underline{n}$ (a spatial distance increnent) the first and second noments of the difference $Z(\underline{x}+\underline{h})-Z(\underline{x})$ depend only on the distance Detween the two points $\underline{x}+\underline{n}$ and $\underline{x}$ and not on their individual locations, i.e. $\lfloor 3,4\rfloor$

$$
E\{z(\underline{x}+\underline{n})-z(\underline{x})\}=m(\underline{n})^{+}
$$

$\operatorname{Var}\{Z(\underline{x}+\underline{n}\}-Z\{\underline{\underline{x}})\}:=E\left\{(Z(Z(\underline{x}+\underline{n})-Z(\underline{x})\}-m(\underline{n})]^{2}\right\}=2 \gamma(\underline{h})$

where $\langle y(\underline{n})$ is the variugran of the aifference. Tnis nypotnesis ineans that the expected value of $Z$ is a constant arid that two different locations separated by the same distance n have the same prodablity distribution. The fritrinsic nypotnesis need only nold over the distance used to make an estimate, not througncul the entire field of interest. This property is called local stationarity.

We def ine the following general measurenent model for the data as

$$
Z(\underline{x})=r(\underline{x})+m(\underline{x})+E(\underline{x})
$$

$t_{E}$ is tne standard expected value operation. 
where

$r(\underline{x})$ is ine residual value at lacation $\underline{x}$;

$m(\underline{x})$ is the systematic error or orift at $\underline{x}$; and

$\epsilon(x)$ is the random measurement error at $\underline{x}$.

in tilis model we relax the assumption of corstant mean fequat ion (2.1)) and assume tnat the orift is a sluwly varying function wnicn can ue approximates oy a polymomial, i.e.,

$$
m(\underline{x})=\sum_{j=0}^{M} a_{j} f^{j}(\underline{x})
$$

where

$$
\begin{aligned}
& a_{j} \text { are unknown coefficients; and } \\
& f^{j} \text { are monomials in the space under consideration. }
\end{aligned}
$$

The residual is aefined to de zero mean with stationary increments as in (L.L). The randon measurement errurs are assulited to ve zero mean, uncorrelated witn $z(\underline{x})$, and itselif, i.e.,

$$
\begin{gathered}
\left.E\left\{\varepsilon \underline{x}_{i}\right)\right\}=v \quad \forall i, \\
\operatorname{cov}\left\{\varepsilon\left(\underline{x}_{i}\right), k\left(\underline{x}_{j}\right)\right\}=\sum_{(A x N)}=v i d g\left[\sigma_{\varepsilon}^{2}(1) \ldots \sigma_{\varepsilon}^{L}(N)\right\rfloor \\
\operatorname{Cov}\left\{\varepsilon\left(\underline{x}_{i}\right), z\left\{\underline{x}_{j}\right\}\right)=U \quad \forall i, \underline{x} .
\end{gathered}
$$


Using the measurement model of (2.3) we can now precisely define true spatia! estimation problem as

GIVEN a set of measurement data $\left\{z\left(\underline{x}_{j}\right)\right\}, i=1, \ldots, N$ and tne measurement model of equations $(2.3-2.5)$

$$
z\left(\underline{x}_{k}\right)=r\left(\underline{x}_{k}\right)+m\left(\underline{x}_{k}\right)+\varepsilon\left(\underline{x}_{k}\right)
$$

FIND the "Dest" linear, unuiaced, minitilum error variance estinate $\hat{z}\left(\underline{x}_{k}\right)$ of $z$ at point $\underline{x}_{k}$.

This coinpletes the Jefinition of the spatial estination prodem in tre next section, we discuss a solution to this proolen.

\section{II-2. Spatial Estimation Tueory}

The spatial estimaticn provlem can de solved using optimization tneory results oy formulating the proolem properly. Here we stow how to solve the froblem using Lagrange muitiplier techniques. To oe more precise, we would like to find the linear estimator

$$
\bar{z}\left(\underline{x}_{k}\right)=\sum_{i=1}^{N} \lambda_{i} z\left(\underline{x}_{i}\right)=\underline{\lambda}^{\top} \underline{z}
$$

wnere $\underline{\underline{x}}^{\top}:=\left[\lambda_{1} \ldots \lambda_{N}\right\rfloor$ and $\underline{z}^{\top}:=\left[z\left(\underline{x}_{1}\right) \ldots z\left(\underline{x}_{N}\right)\right\rfloor$ 
such that

$$
E\left\{z\left(\underline{x}_{k}\right)-\hat{z}\left(\underline{x}_{k}\right)\right\}=0 \quad \text { (unoiased) }
$$

and

$$
\sigma_{k}^{2}=\operatorname{Var}\left\{z\left(\underline{x}_{k}\right)-\hat{z}\left(\underline{x}_{k}\right)\right\} \text { is ininimulil (minimum varidnce). }
$$

The solution to the spatial estimation problan is found ay mininizing tne error variance of (c 9) subject to the constraint of (2.8). The $0:$ timum linear estimuin: of $(2.7)$ is found using Lagrange nultiplier tecnnigues. It is snown in Appendix A trat the estimation prodem can be reduced to solving tre line? , wations

$$
A \underline{\theta}=\underline{b}_{K}
$$

where $A$ is an $(N+M+1) \times(N+M+1)$ matrix with entries specified by the variogran and drift models;

$\theta$ is an $(N+N+1)$ vector of unknown weights and multiplier coeff ic ients, i.e.,

$$
\theta^{\top}:=[\underline{\lambda} \quad \mid \underline{\mu}]^{\top} ; \text { and }
$$


$\underline{D}_{\mathrm{K}}$ is an $(N+M+1)$ vector reflecting distances Detween contro 1 data at position $\underline{x}_{k}$.

It is also shown tnat the associated error variance can be estimated from tne weights as

$$
\sigma_{k}^{2}=\underline{\theta}^{T} \underline{b}_{k}
$$

This error variance is a tneoretical model and it can de interpreted as d preaictian of now inuch different realizations of trle surface cant vary with the sane underlying variugram and orift.

Thus, cne tecnnique yenerates point estinates $\hat{z}\left(\underline{x}_{k}\right)$ and a measure of tue precision $o_{k}^{2}$. Note that if the error is assurned Gaussian, i.e., $(z-\bar{z}) \sim N(0,0)$, then we can construct a y5\% counfiuence interval $\left(\hat{z}\left(\underline{x}_{k}\right)-2 \sigma_{k}, z\left(\underline{x}_{k}\right)+2 \sigma_{k}\right\}$ to evaluate tne estimator quality.

We will examine the practical aspects of spatial estimation jn another section, nere we would like to investigate some properties and extensions of the tecmique.

Property 1: The linear point and variance escilldtor $(\hat{z}, \sigma)$ take into accounc four essential and intuitive facts. 
(i) Geometry (location) of the sample configuration in A;

(ii) A structural (statistical) model of the phenonenon variability cuaracterized by the variogram inooel, $\gamma$;

(iji) Geonetry of the donain to be estimated, $\operatorname{Var}(\alpha-\hat{z})$ expressed in $o_{k}^{2}$; and

(iv) Distances detween control points tu be estimated and samples in $\underline{\Delta}_{k}$.

Property 2: Assume no measurement error $s_{i}$; then $\hat{z}$ is an exact interpolator, i.e., $\hat{z}_{k}=z_{k}$ anu ok $=0$. Thus, the spatial estimates pass directly tnrough the measurement points.

Property 3: The error variance estimate of does not depend on tne particular values of the data $\left\{z\left(\underline{x}_{k}\right)\right\}$ out only the locations $\left\{\underline{x}_{k}\right\}$.

Property 4: The matrix A depends unly on the locations of the samples, i.e., $\left\{\underline{x}_{i}\right\}, j=i, \ldots N$.

This property indicates that two identical sample configurations produce the same matrix $A$. This property is important if we use the sane data set to estinate points on a grid because we need only invert 
A once, since for $\hat{z}\left(\underline{x}_{p}\right)$ and $\hat{z}\left(\underline{x}_{q}\right)$ we solve

$$
\underline{\theta}_{p}=A^{-1} \underline{b}_{p} \text { and } \underline{\theta}_{q}=A^{-1} \underline{b}_{q} \text {. }
$$

It can be shown that the solution $\underline{\theta}$ is invariant under a change of coardinates, $i . e .$, the same weights $\left(\left\{\lambda_{j}\right\},\left\{\mu_{j}\right\}\right)$ result if all sampled points $\left\{z\left(x_{i}\right)-z\left(x_{j}\right)\right\}$ are translated the same amount $\underline{h}_{+}$Thus, if data are collected on a regular pattern, it is noc necessary to solve the equations repeatedly as before. This procedure is usually true when $N$ is sinal1; nowever, for large $N$ a "neighborhooding" technique is applied and $A$ changes for each estimate.

Before we digress fron this discussion, it should be noted that we have been concerned prinariiy witn "punctual" spatial estimation, i.e., minimurn variance estimation of a "point" in space. The general theory [5] has veen developed for the estiulation of $2\left(\underline{x}_{k}\right)$ at location $\underline{x}_{k}$ from samples $\left\{z\left(\underline{x}_{j}\right)\right\}, j=1, \ldots, N$ when

(i) $z_{k}$ is a point value taken by $z$ at $\underline{x}=\underline{x}_{k}$; or

(ii) $z_{k}=\frac{1}{v} \int_{v_{0}} z(\underline{x}) d \underline{x}$ is the average of $z(\underline{x})$ over the block $v_{0}$ of volume $v$ and centered at $\underline{x}=\underline{x}_{k}$; or

(iii) $z_{k}=\frac{1}{V} \int_{V} z(\underline{x}) d \underline{x}$ is the average value or $z(\underline{x})$ over tise whole fialj $V$; or 
(i4) $z_{k}=2\left(x_{1}+\alpha\right) p(\alpha) d \alpha$ is a weignted moving average of $z(x)$; or

(v) $z_{k}=$ grad $z(\underline{x}) \quad \underline{x}=\underline{x}_{k}$ is components of the gradient at $\underline{x}=\underline{x}_{k}$ (i.e., dip and strike of a geological layer).

Thus, spatial estination techniques are not only linited to punctual estimation. In the next section we aiscuss the problem of arift estination and show now it can also be used alternately to solve the spatial estination problem.

\section{1-3. Urift Estimation Proulem}

In cases where tne variable to ve ineasured snows a systematic fluctuation along certain directions we say there is arift present. For example, in hydrology, estimation of water potential in a sloping (linear) plane requires one to account for the large regional systematic trend. urifting can occur in two different manners

(1) regional or slow varying systematic dehavior over a yiven region or large neighbornood; or

(c) punctual or local fluctuations which vary from neignborhood to neighborhood. 
Previously we found it necessary in our measurement model of (L.6) to account for the drift when veriving the spatial estimator. The spatial estinator did not produce estimates of the drift coefficients $\left\{a_{j}\right\}$ of (2.4); however, in some situations it is necessairy to escimate the precise drift nodel and identify these coefficients. The estimation of drift is used to provide residuals for variogram analysis. In this instance we must obtain an analytical expression for drift which is valid over the region under investigation. Urift can also be used for map analysis; i.e., examination of snooth changes or aeneral tendencies of the variable of interest. Punctual estimates are required to contour the drift for this type analysis.

The "regional" and "punctual" arift estimation problen is

GIVEnt a set of measurement data $\left\{z\left(\underline{x}_{i}\right)\right\}, i=1, \ldots, N$ the measurement model of $(2.3)-(2.3)$, and corresponding assuintions, i.e.,

$$
Z(\underline{x})=r(\underline{x})+m(\underline{x})+\varepsilon(\underline{x}) \text {. }
$$

FIND the "nest" linear, unbiased, Ilinimum error variance estimate $\hat{m}\left(\underline{x}_{k}\right)$ of $m(\underline{x})$ at a point $\underline{x}_{k}$ or over the entire data region defined by $\left\{z\left(\underline{x}_{i}\right)\right\}$. 
In the next section, we snow how to solve tnis problem using the sane approach as the spatia! estimator. In fact, we snow tnat after estimating the drift the spatial estination proolem can be soived with a simplified set of linear equat ons which yield results identical to those derived previously. Therefore, drift estimation leads to an alternate approach for soiving the spatial estimation problem as well.

II-4. Drift Estimation Theory

In tnis section, we solve the drift estimation provlen - first, for punctual drift estimates and second for regional drifts. We follow the technique of Lagrange multiphiers used in Appendix A.

\section{II-4. I Punctual Drift Estimation}

As before tnis problen can de formulated as finding the linear, minimum variance, unbiased estimate

$$
\hat{m}(\underline{x})=\sum_{j=1}^{N} \lambda_{j} z\left(x_{j}\right)=\underline{\lambda}^{\top} \underline{Z}^{+}
$$

such that

\footnotetext{
$t_{\text {Here we use tne same notation as Defore to only show the mathematical }}$ similarity of the proolens.
} 


$$
E\{m(\underline{x})-\tilde{m}(\underline{x})\}=0 \quad \text { (unoiased) }
$$

and

$$
\sigma_{M}^{2}=\operatorname{Var}\{m(\underline{x})-\hat{m}(\underline{x})\} \text { is minimum (minimum variance) }
$$

It is easy to snow that the optimal drift estimator can be found oy minimizing the error variance sudject to the unoiasedness constraint. Again using Lagrange inultipliers tne orift estimation proolern reduces to solving tre set of linear equations (see Appendix A for details).

$$
\underline{D}_{\underline{n}}=\underline{\underline{B}}_{K}
$$

where $D$ is an $(N+M+1) \times(N+M+1)$ natrix witn entries speciried by the variogram and drift models;

$\underline{7}$ is an $(\mathrm{N}+\mathrm{M}+\mathrm{l})$ parameter vector given by

$$
\underline{n}^{\top}:=[\underline{\underline{\lambda}}, \underline{\mu}]^{\top} ; \text { and }
$$

$\underline{B}_{k}$ is an $(N+M+1)$ vector at position $\underline{x}_{k}$.

The ascociated error variance equivalent to (2.11) is given by

$$
\sigma_{M}^{2}=\underline{n}^{T} \underline{b}_{K}
$$


It then follows from (2.14) tnat tne desired estimates of tre $\left\{a_{i}\right\}$ of (2.4) can be found as (see Appendix A for details)

$$
\underline{a}=\omega \underline{L}
$$

where $W$ is an $(A+1) \times N$ matrix of weignts, and the associated error variance can also ve estinated ds well.

Thus, witn tne optinal drift coefficients estinated, the residuals can then be calculated at each data point since

$$
\hat{r}(x)=z(\underline{x})-\hat{m}(\underline{x})
$$

For point estimates, not at data points, the residuals must oe estimated from a simple set of linear equations. The optimai spatial estimate is given oy

$$
\underline{z}\left(\underline{x}_{k}\right)=\hat{r}\left(\underline{x}_{-k}\right)+\hat{n}\left(\underline{x}_{-k}\right)
$$

It nas oeen snown oy Matheron, that spatial estimates optained in tnjs fasnion produce identical results to tnose of Section II-2. Tnis equation is the result of the so-called additivity theorem [5] wnich snows that 


$$
\dot{z}\left(\underline{x}_{k}\right)=\hat{m}\left(\underline{x}_{k}\right)+\underline{x}^{\top}(\underline{L}-\underline{\underline{i n}})
$$

\section{II-4.2 Regional Orift Estimation}

Following the sane strategy for "regional" drif $\tau$, i.e., one arift function to model the trend of the entire region, it is possiote to derive similar equations to (2.14). Thus, to estimate drift over a region we must construct

$$
\dot{m}(\underline{x})=\sum_{j=0}^{M} \hat{\alpha}_{i} f^{i}(\underline{x})=\underline{\underline{\alpha}}^{\top} \underline{f}
$$

The relation implies cnat we must calculate tne $\left\{\alpha_{s}\right\}, s=0, \ldots, M$ and $m(\underline{x})$ is the drift of $z(\underline{x})$ for any $\underline{x}_{j}$ sucn that $\underline{\underline{x}}-\underline{x}_{j} \mid \leq \rho$ wnere $\rho$ defines ine regional neighbornood. We assume tnat $\mathrm{N}$ punctual samples of $Z(\underline{x})$ at $\underline{x}_{j}, j=1, \ldots, N$ are orawn. We define $N$ estinates $\hat{\alpha}_{s}$ for each $\alpha_{s}$ which are a linedr combination of the is samples inside the nejghoorhood of radius $r$ around solne $\underline{x}_{k}$, i.e.,

$$
\dot{\alpha}_{s}=\sum_{i=1}^{N} \lambda_{i}^{s} z\left(\underline{x}_{i}\right)=\underline{\lambda}_{s}^{T} Z \quad s=0, \ldots, M
$$

subject to the usual undiased, minimum variance constraints.

After minimizing as in Appendix $A$, we obtain the linear equations 


$$
D_{\Phi_{s}}=\underline{\xi}_{s}, \quad s=0, \ldots, M
$$

where $D$ is given in (2.14) and

$$
\begin{aligned}
& \left.\underline{\Phi}_{s}^{\top}=L \underline{\lambda}_{s}^{\top}: \underline{\mu}_{s}^{\top}\right\rfloor, \quad s=0, \ldots, M \\
& \left.\underline{\xi}_{s}^{\top}=L \underline{u}_{s}^{\top}: \underline{e}_{s}^{\top}\right\lrcorner, \underline{e}_{s}^{\top} \text { a uni } \mathrm{L} \text { row vectur }
\end{aligned}
$$

Tnus solving $\{\angle . \angle U\rangle, \mu+1$ tines we obtain estimates for $\left\{\alpha_{s}\right\}$ and the corresponding error variance is given oy

$$
q_{\alpha_{s}}^{2}=\underline{\Phi}^{\top} \underline{E}_{s}=\mu_{s}^{s}
$$

once the $\left\{\alpha_{s}\right\}$ are estimated the drif can oe removed from sanples and tne residuals can oe estimated using sinple spatial estination techniques as before. This campletes the theoretical discussion on spatial estimation tneory, we sunknarize tne resuits in Tadle I. In the next chapter we discuss the practical issuas involved in spatial estimation.

\section{PRACTICE OF SPATIAL ESTIPATION}

In tnis section we discuss some of the more practical issues involved in spatial estimation. Theoretically, once the variogram and of ift 
TAZLE 1. SPATIAL ANU DRIFT ESTIMATOR SUMAARY

\begin{tabular}{|c|c|c|c|c|}
\hline TYPE & ESTIMATUR & $\lambda$-SOLUTIUN & ERROR VARIAINCE & EUUATIUNS \\
\hline SPATIAL & $\tilde{z}\left(\underline{x}_{k}\right)=\underline{\lambda} \underline{\underline{Z}}$ & $\vec{A} \underline{\theta}=\underline{D} \cdot K$ & $\sigma_{k}^{2}=\underline{\theta}^{\top} \underline{D}_{k}$ & $(2.10,2.11)$ \\
\hline $\begin{array}{l}\text { PUNCTUAL } \\
\text { DRIFT }\end{array}$ & $\begin{array}{l}\hat{m}\left(\underline{x}_{k}\right)=\underline{\lambda}^{\top} \underline{z} \\
\underline{a}=\omega \underline{Z}\end{array}$ & $\begin{array}{l}U_{\underline{1}}=\underline{\underline{b}}_{x} \\
=\end{array}$ & $\begin{aligned} \sigma_{i d}^{L} & =\underline{H}^{\top} \underline{f}_{k} \\
\sigma_{a}^{2} & =\operatorname{Cov}(\underline{a}-\underline{a})\end{aligned}$ & $\begin{array}{l}(2.14,2.15) \\
(2.10)\end{array}$ \\
\hline $\begin{array}{l}\text { REGIUNAL } \\
\text { DRIFT }\end{array}$ & $\begin{array}{l}\hat{i n}(\underline{x})=\dot{s}^{\top} t \\
\hat{a} \\
\hat{a}=\hat{n}^{\top} \underline{L}\end{array}$ & $D \Phi_{5}=\xi_{s}$ & $\sigma_{\alpha_{s}}^{2}=\mu_{s}^{s}$ & $\begin{array}{l}(2.18,2.19, \\
2.20)\end{array}$ \\
\hline
\end{tabular}


are determined, one need only solve a set of linear equations. Besides the numerical difficulties of matrix inversion etc., the major proulen in spatial estination is "identifying" the spatial model variograil and urift. In fact, it is necessary to know the drift in arder to calculate the varioyrall. Typically, chis inpasse is resolves Dy iteration until satisfactory results are acnieved.

We will discuss the provlelil of "fitting" a spatial model tu samples in tnis section. First, we describe properties and procedures to estimate the variogram and drift from samples in sections 1 and 2. Then we discuss sone of the practical aspects of spatid estiflaction wnicn can oe used. Finaliy we discuss some grapnical tecmiques to display tme spatial results.

\section{I-1. Variograls}

In tais section we discuss the pruperties of the variogran - the fundamental spatidl model relating (statisticaliy) the similarily of sanples. Recall tnat the variogran is defined as tne variance in the increment - of regionalized variaotes, i.e.,

$$
r(\underline{n}):=1 / 2 \operatorname{Var}\{z(\underline{x}+\underline{11})-z(\underline{x})\}
$$

where the increments satisfy tne stationarity requirements of the intrinsic hypotnesis of $(2 . L)$. Note tnat in dealing witn tne 
increments rather than the spatial variables tnemselves, the variograin is more general than tne usual covariance because in cases tnat the Cuvariance does not exist the variogram voes (e.g. Wiener process). The variogram is related to the covariance by (see Figure 2).

$$
Y(\underline{n})=C(0)-C(\underline{n})
$$

where $c(h):=\operatorname{Cov}(z(\underline{x}+\underline{h}), z(\underline{x}))$.

Let us examine some of the fundamental properties of the variogran

Property 1: The variogran staris at 0, j.e., $Y(\underline{a})=0^{\dagger}$

Property 2: The variogran is a positive definite, even function, i.e.,

$$
\gamma(\underline{n})=\gamma(-\underline{1}) \geq 0 \quad V \underline{n}
$$

Property 3: When the variance exists, the variogran uas a limit or

$$
\begin{aligned}
& \text { si]l, i.e., } \\
& \lim _{\underline{h} \rightarrow \infty} \gamma(\underline{1})=\operatorname{Var}\{z(\underline{x})\}=i(u)
\end{aligned}
$$

t In sume cases, the variogran may nat start at zero, out some uther positive value tnen iz is sajd to de discontinuous and exnibit the "nugget effect" (see $[4\rfloor$ for details), i.e., $Y(\underline{n})=C_{0}$ for $\underline{n}>\underline{\varepsilon}$ ana $\underline{\varepsilon} \sin a 11$. 
$-31$.

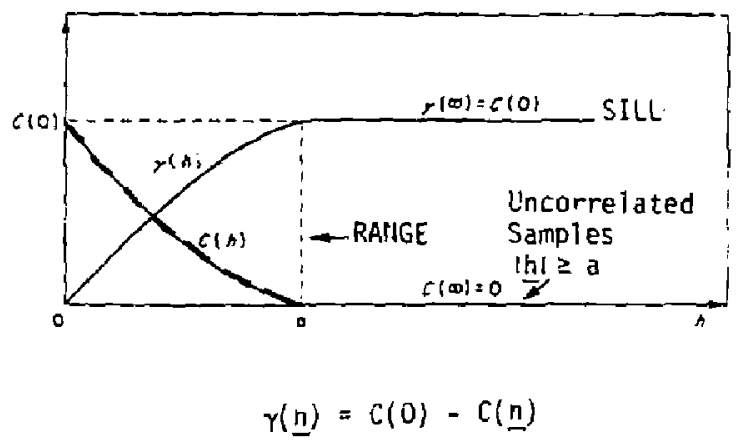

Figure 2. Covariance and Variogram 
Property 4: The variogram possesses a range - the point "a" on the variogram (Figure 2) beyond wricil the samples are no lonyer related or correlated, i.e., there exist an a such that for $\underline{\mid n} \mid \geq a, \operatorname{Cov}(z \underline{x}), z(\underline{x}+\underline{n}))=0$.

Property 5: The variogram grows more slowly than a paradola, i.e.,

$$
\lim \frac{Y(n)}{\ln 1^{2}}=0 \text { when } \ln 1 \rightarrow \infty
$$

The first four properties of the variogram are depicted in Figure 2 along with the corresponding covariance function. Note that for values of $z$ witn $\mid \underline{n} ! \geq \underline{a}$ the samples are uncorrelated. Property $b$ can be used to detect the presence of "drift", if llut satisfied.

Tavle II depicts some of the comnon variograms which satisfy the properties discussed. Note that soine variograns do not possess all of tnese properties (e.g. a linear variugram does not possess a si11).

Finally we note that if the regionalized variables do not exnibit tne Sanie Denavior in every direction (isotropy) they are called anisotropic, i.e., the varioyrans calculated in different directions of space differ. When tney are identical, tne variogram is termed isotropic. Departure from isotropy can be classified as geanetric and zonal - both can be corrected. These classifications evolved from the manner in which the variagrams can be reduced to isotropic 
$-33$.

TABLE 11. YARIOGRAM MODELS

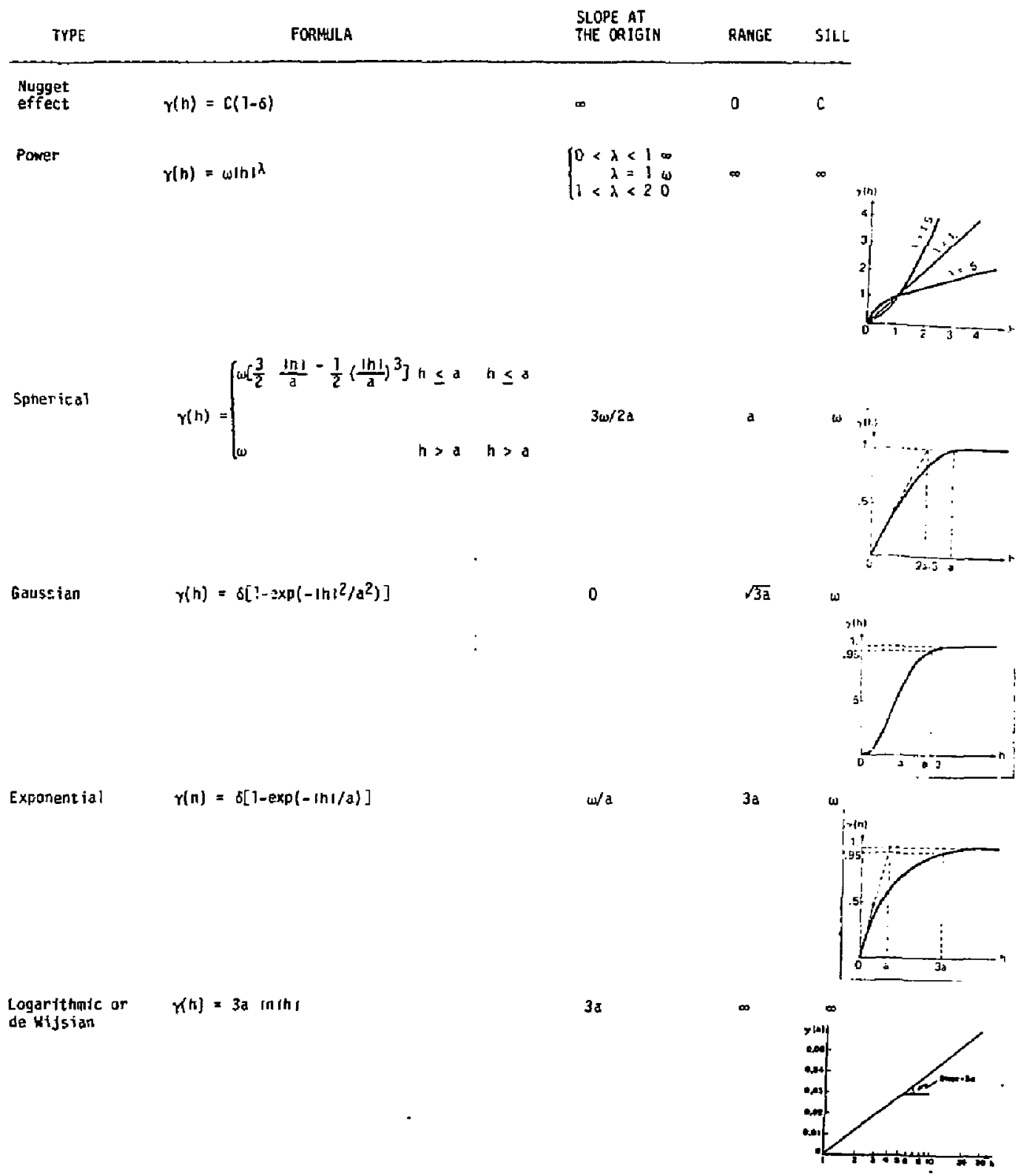


Geametric anisotropy - is the case where anisotropy can be corrected by a linear transformation of coordinates (see $[4]$ ]; and

Zonal aniostropy - the variogram is a nested structure in whicn each component has a variogram of its ow'n structure.

This completes the discussion of variogram properties. In the next section we discuss the proplem of estimating or identifying the variogran from räw sainple data.

\section{III-2. Variogram Estimation/Identification}

Variogram identification from raw data is the most crucial part of the spatial estimation process and probably the least understuod. Prior to the actual estimation, it is necessary to fit an experimental variagram to a theoretical model which will ensure mathematical consistency of the calculations. Thus, the practice of variograin identificaion is concerned with:

(i) estimating the "raw" or experimental variogram and drift from sample Jata;

(ii) fitting a tneoretical variogram and drift to the experinental; and

(iii) checking the validity of the fit. 
An unbiased estimator for the variogran is [9]

$$
\hat{\gamma}^{*}(\underline{h})=\frac{1}{2 N(\underline{h})} \sum_{i=1}^{N(\underline{h})}\left(z\left(\underline{x}_{i}+\underline{h}\right)-z\left(\underline{x}_{j}\right)\right)^{2}
$$

where $N(\underline{h})$ is the number of pairs of points separazed by distance $\underline{n}$.

If orift is present, then it can be shown that (3.3) is a biased ${ }^{\dagger}$ estimator for the variogram. The drift can also be estimated using the experimental drift estimator on the sample data, i.e.,

$$
m^{*}(\underline{n})=\frac{1}{N(\underline{h})} \sum_{i=1}^{N(\underline{h})}\left(z\left(\underline{x}_{i}+\underline{n}\right)-z\left(\underline{x}_{i}\right)\right)
$$

The experimental variogran can then be drift-corrected and $f$ it. The arift corrected variogram is given by

$$
\hat{r}(\underline{h})=\frac{1}{2 N(\underline{h})} \sum_{i=1}^{N(\underline{h})}\left[z\left(\underline{x}_{i}+\underline{n}\right)-z\left(\underline{x}_{i}\right)-\hat{m}^{*}(\underline{h}) j^{L}\right.
$$

An interactive computer algorithin called VARIFIT was developed based on the K6U3 Kriging algorithm developed at USGS, Tacoma [15]. ${ }^{\dagger}$ VARIF IT enables the user to:

If the drift is constant, then it is unbiased. 
(1) Calculate the estimated variogram, drift, and correctedvariogram; and

(2) Interactively fit a theoretical variogram (Table II) to the estimated data; and

(3) Check the validity of the fit.

A typical VARIFIT output is shown in Figures $3,4,5$. In Figures 3 and 4 , we see the estimated variograms and drift calcuiated from the sample data. In Figure 5, we see the result of a theoretical (interactive) fit of a spherical variogram to the experimental variogram of Figure 3. It snould be noted that anisotropic variograns in four directions can also be identified using this algorithm. ${ }^{+}$

Another approach to the orift and structure identification proolem is to make use of an algebraic property tnat nigner order differencing of variables filters out polynomials in the expectation. The original random function $Z(\underline{x})$ is called an intrinsic randon function of order $k$ (abbreviated $k$-IRF) where $k$ is the highest degree polynomial

fiTtered. The purpose of taking increments is to produce a stationary regionalized variable from one with a drift. This is the n-dimensional analog of the box-Jenkins approach to time series

\footnotetext{
T The algorithm is on the cuc 7600 and can be obtained oy typing $.292100:$ SPACEST[VARIFIT].
} 


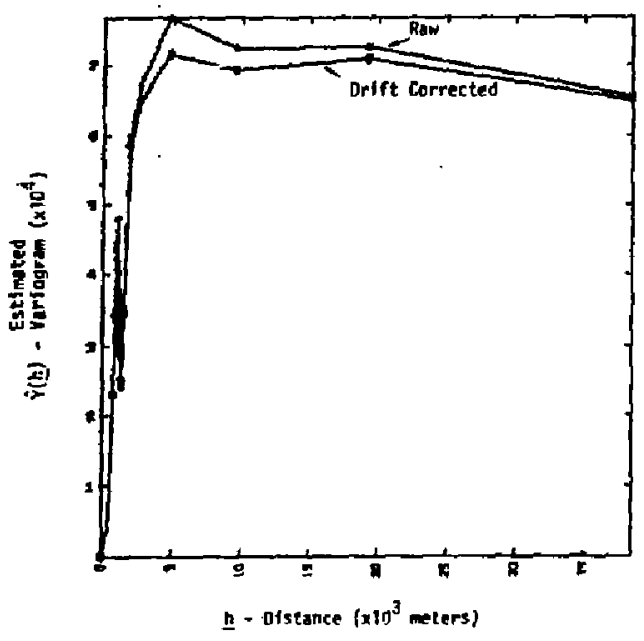

Fipure 3. Experimentol Variogram Estinaces

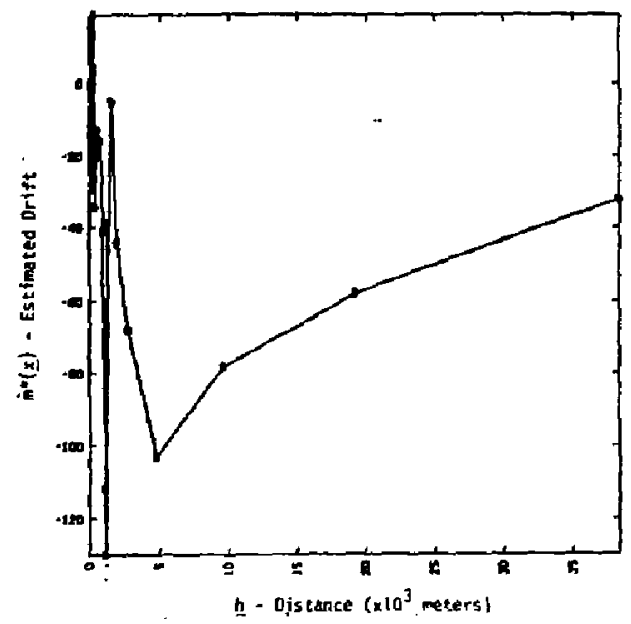

Figure 4. Experinental Drift Estimate

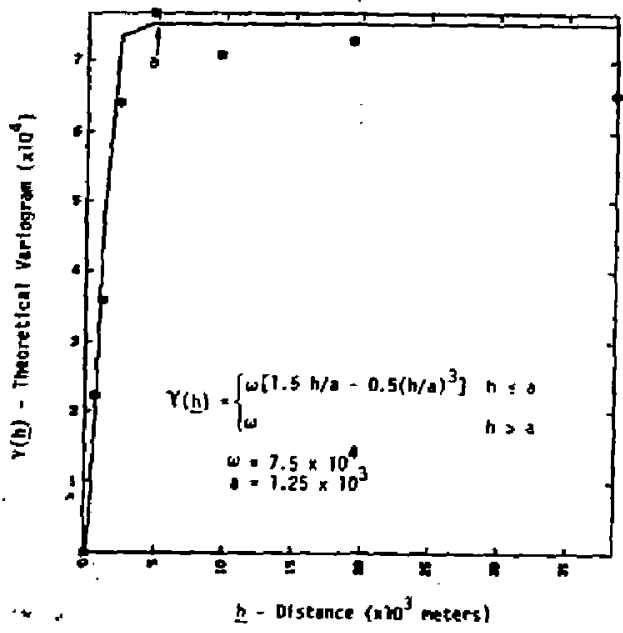

Figure 5. Theoretiçal Voriogrim fit of Estimated Variogram 
analysis [13]. The advantage is that the covariance structure of the spatial variable can de estimated without tne effects of tne drift. This is done by developing the generalized covariance of the $k-I R F$ whicn differs from the variogram, which is only legitimate for tne 0-1RF case.

There are various classes of functions tnat satisfy the conditions of a generalized covariance, but one class witn nice properties for identification purposes (that is, linear in tne coefficients) is the class of polynomial generalized covariances. The form of these generaljzed covariances, which depends on the order of the increnent, is 1 isted in Taole III.

Wote that for $k=0$, the only covariance function is a linear one which is mucn more restrictive tnan the variograns given in Tdole II. How does the generalized covariance compare to the variogram in the 0 -IRF case? Let $Z(\lambda)=Z\left(\underline{x}_{j}\right)-Z\left(\underline{x}_{j}\right)$; then it can oe shown tnat

$$
K\left(\underline{x}_{i}-\underline{x}_{j} l\right)=-x\left(\underline{x}_{j}-\underline{x}_{j} l\right)
$$

Thus, for a non-stationary process, we can produce a stationary one by forming the $x^{\text {th }}$ order increments. He can then estimate, from tne generalized covariance, the covariance structure of the stationary process. It can be snown tnat the estinators jesigned previously are still valid (i.e., same structure equation) with the generalized 
TABLE III. GENERALIZED COVARIANCE MODELS

\begin{tabular}{|c|c|c|}
\hline DRIFT & k & POLYNOMIAL GENERALILED COVARIANCE MUOEL* \\
\hline Constant & 0 & $K(\ln \mid)=C \delta-D_{0}|\underline{\mid n}|$ \\
\hline Linear & 1 & $K(\underline{\ln })=c_{0}-\mathrm{v}_{0} \ln \left|+\mathrm{v}_{1} \ln \right|^{3}$ \\
\hline Quadratic & 2 & $K(\underline{\underline{n}} \mid)=c_{0}-b_{0} \underline{\ln l}+b_{1}|\underline{n}|^{3}-a_{2}|n|^{5}$ \\
\hline
\end{tabular}

*With coefficient constraints:

(Two-dimensional space):

$\mathrm{C} \geq 0, \mathrm{D}_{U} \geq 0, \mathrm{~b}_{2} \geq \dot{\mathrm{U}}, \mathrm{b}_{1} \geq-(10 / 3) \sqrt{\mathrm{D}_{1}^{\mathrm{b}}}-;$

(Three-dinensional space):

$i \geq 0, D_{0} \geq 0, D_{2} \geq 0, D_{1} \geq-10 \sqrt{0_{001}}$. 
covariance replacing the variogran and only a simple systen (no orift equations need be solved (see LbJ for details).

Unce we nave decided on the type of a cneoretical variogram or generalized covariance, we must nake sure that the fit is reasonable. Tests must de perfomed to insure the validity of the variogram and drift models [ll]. The technique employed is the successive estimation of all of the data points, ignoring eacn of thein in turn, one oy one. We then verify that there is no systematic error and compare the calculated errors (difference oetween the estimated and real values) with the tneoretically predicted standard deviations $\left(\sigma_{k}\right)$ Lo assure consistency, A statistical analysis is carried out on tne standard errors, checking that they dre zero mean and unit variance. This technique can ue utilized for comparing several models and determining tne best $f i t$. The first selection criterion is minimum mean squared error and secondly the standard error is close to unity. The successive estimation technqiue is depicted in Figure 0. Here we see tnat data point I has been eliminated from the data set and estimated oased oniy on the remaining data values. The deviation from the actual vaiues, i.e., $\Delta z_{j}=z_{i}-\hat{z}_{j}$ are calculated for the entire data set and then the sample error statistics are estimated. The sample statistics are: 
$-41-$

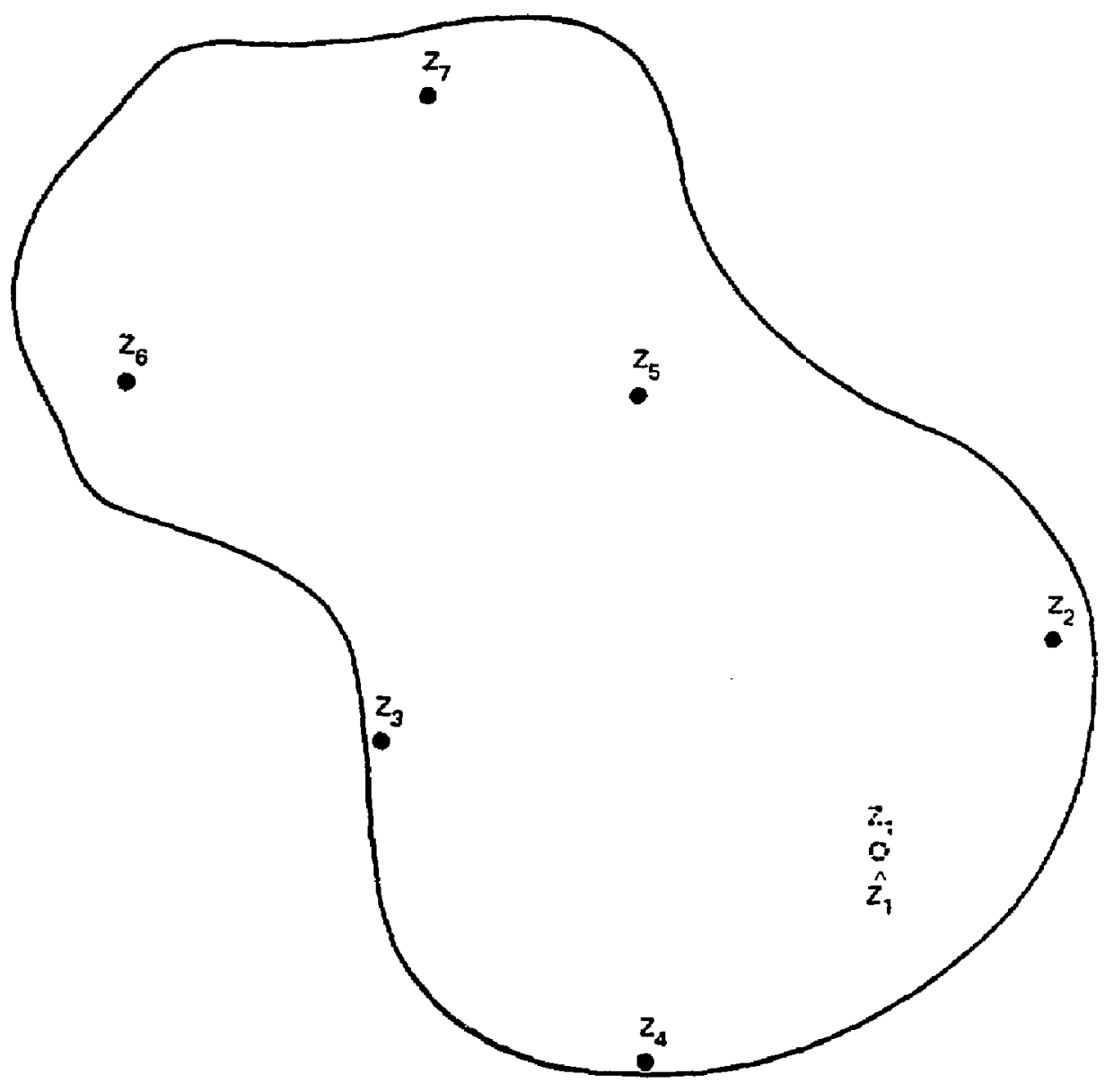

Error $=z_{1}-\hat{z}_{1}$

Figure 6. Success ive Est imation Technique 
(i) Systenatic Error is zero. $\left(E\left(\Delta z_{j}\right)=U\right)$;

(ii) standard Error is unit variance. $\left.\frac{\Delta z}{\sigma_{i}} \sim \|(U, 1)\right)$;

(iii) kuts Error is minimum (min $\sqrt{\Delta z_{i}^{2}}$ )

The validity test results are summarized in Table IV where the practical estimators used to validate the rodels are shown. This completes the discussion of variogram estimation. In the next section we discuss the inore pressing problem - tnat of estimating tne variograms when a orift is present.

IIJ-3. Variograil Estimation In Tne Presence Ui uritc

In this section we oriefly discuss the problem of identifying tne

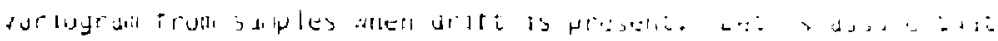

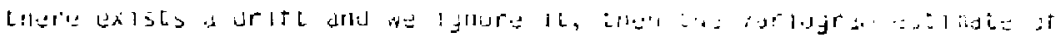
(3.3) is plased jue to the rieyiected ariti, i.t.

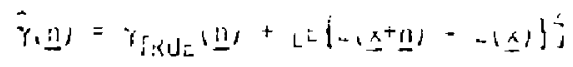

wien there exists a sillple reylulid arift, we an subirde aliaf from (11) to optain the residuals anu identify the rasudal sariogran. it

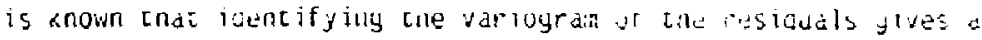
Diased estimate of the true varioyran; nuvever, Lnis jias c.tll be neylected for stiall distances. The closeness of tne resiqual 
$-43-$

TABLE IV. SULLESSIVE ESTIMATIUN VAL IUITY PESi

\begin{tabular}{|c|c|c|}
\hline TEST & ГHEUKY & PRACTILE \\
\hline $\begin{array}{l}\text { SYSTEIAHIC } \\
\text { ERRURR }\end{array}$ & $E\left(\Delta z_{i}\right)=u$ & $\frac{1}{N} \sum_{i=1}^{N} \Delta z, \quad 0$ \\
\hline $\begin{array}{l}\text { SIAHUARLISD } \\
\text { ERRORR }\end{array}$ & $\frac{\Delta z_{i}}{\sigma_{i}}-N(u, 1)$ & $\frac{1}{W} \prod_{i=1}^{d}\left(\frac{\Delta z_{1}}{\sigma_{j}}\right)^{L}=1$ \\
\hline 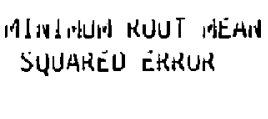 & $\min \left(\sqrt{\Delta z_{j}^{2}}\right)$ & {$\left[\frac{1}{N} \sum_{i=1}^{i} \Delta z_{i}^{2}\right]^{1 / 2}$} \\
\hline
\end{tabular}

where $\Delta z_{j}:=z\left(\underline{x}_{i}\right)-\dot{z}\left(\underline{x}_{i}\right)$ 
varjogram to the true variogram depends on the appropriateness of the functions selected to represent tne drift and variograin as well as the size of the chosen neighoorhood.

A metnod to estinate the drift dnd varioyrain can be summarized [y] as:

(i) Assume a tneoretical variogran and drift function;

(ii) Estimate the coefficients of tne drift polynomial $\left\{a_{i}\right\}$ (2. Iy);

(iii) Using this drift calculate the residuals of (2.3);

(iv) Estimate the variogran of the residuals using (3.3);

(v) Validate tne results using Taule IV; and

(vi) If acceptable, stop. If not go to (i).

Lucal or punctual drift estimation can de performed using the standard spatial estimator setup of section II and then estinating the corresponding arift coefficients. In the next section, we discuss various tecnniques to display the data.

III-4. Datd Disolay Tecinniques

Two-dinensional spatial data ras tradicionally oeen displayed in contour maps, which was the basic idea in introducing the spatial estimation. Skipping ahead, a typical contour map for a particular groundwater aquifer is snown in Figure 12. For sinple structures like 
these dquifiers the contaurs provide an effective theans of displayilg the data. Also, contours are a convenient way of displaying the one-signa error maps (see figure 13) since the investigator can overlay voth maps (estimated and ane sigma) to decide on the regions of nighest conf idence.

Unfortunately, for more complex structures it is sumetines offficult to identify the value represented oy a contour (see Figure 36 ). An alternative to contours are gray or pseudo color indages. The signal and Image Processing Research Group (SIPRG) at LLNL nas tine capduility co generdte aisplays of two dimensiond data eitner ill gray or culor. Representative color indges of the simple aquifier and corresponding ane-sigind error thap is shown in Figures $i b$ and 10 . The advantage of color is that various colors can be assigned to various values of $L$ displayed (see the spectrum shown on the inage) wnicn are easy to interpret. In fact regions of minimurn error can easily be lucated by the black assignments in Figure 10. The SIPRG aiso nas an "interactive" capability which enables the user to dynamically select various coior assignments and rotate them tnrosgn the inage. In the near future, capability will de develuped to generate color inages of the data and overlay tne one-sigina error contours (in white) so that tne investigator can easily andiyze the data. Tnis completes the discussion of display techniques. In the nex section we discuss the application of these tecmniques to representative datd sets. 


\section{APPLICATION OF SPATIAL ESTIMATORS}

In this section we discuss the application of the spatial estimation tecnnqiues to real data sets. We apply the "practice" of spatial estillation to representative measurements of water and geological farmation deptn data in order to evaluate the performance of the estimator and produce contour maps for comarative purposes. First, we evaluate the estinator perfornance on two groundwater aquifer systems and then investigate tne subsurface structure of a geological formation from barehole data. The aquifer system structures are simple, while the rock depth information is mucn more complex. The first aquifer we investigate is located in Topponish Creek, Washington.

\section{IV-I CASE STUUY: Toppenisn Creek Basin, Wasnington}

The purpose of this study is to investigace the performance of spacial estimation techniques on a simple groundwater aquifer system. The data was optained from J. Skrivan, USGS, Tacona, Wasnington. Tne data set is a neasure of the Septemoer 1971 water levels at Toppenisn ireek Basin, Wasnington.

The Toppenisn Creek data is snown in Figure 7 . We see tnat the 70 measurements are djstributed irregularly in the region and contours of the raw data shows that the major hydraulic gradient is from the SE to NW direction. 


\section{FEET}

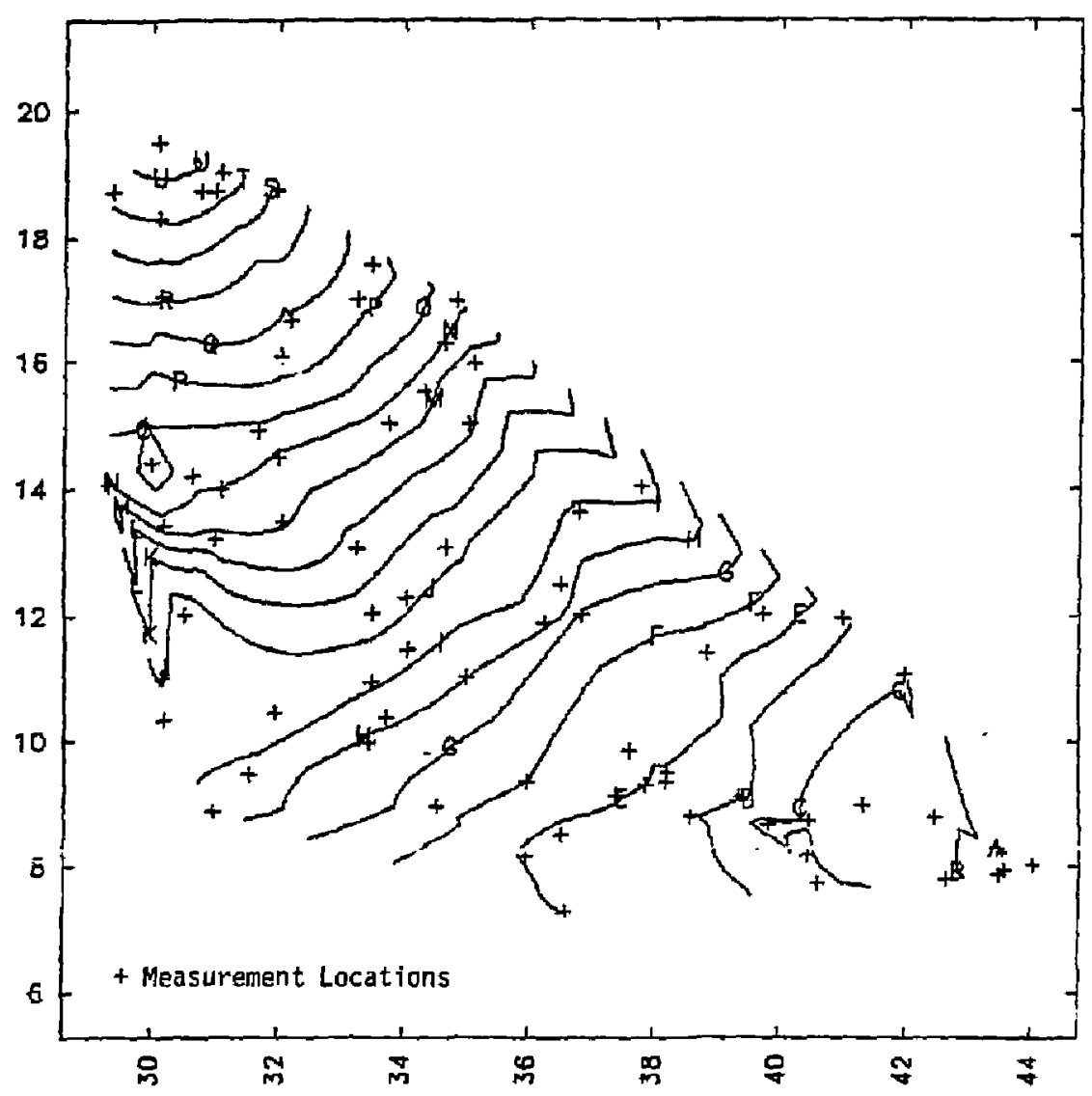

A: $6.90 E+02$

B: $7.00 E+02$

C: $7.10 E+02$

D: $7.20 E+02$

E: $7.30 \mathrm{E}+02$

$F: 7.40 E+02$

G: $7.50 E+02$

$\mathrm{H}: 7,60 \mathrm{E}+02$

1: $7.70 \mathrm{E}+02$

$J: 7.80 E+02$

$K: 7.90 E+02$

L: $8.00 E+02$

$M: 8.10 E+02$

N. $8.20 E+02$

$O=8.30 E+02$

$P: 8.40 E+02$

Q: $8.50 E+02$

R: $8.60 E+02$

S: $8.70 E+02$

$T: 8.80 E+02$

U: $8.90 \mathrm{E}+02$

$v: 9.00 E+02$

Figure 7. Toppenish Creek Basin Raw Data (In Feet). 
The spatial estimator will be applied to generate a grid of $(26 \times 22)$ uniformly spaced sample estimates and then contoured. Note tnat the estimator will be used to "interpolate" between ineasurement points and "extrapolate" in regions without data.

First, we must identify a structural model (variogran and drift) from the data. Following the procedure outilined in section III-2, the estimated variograms $\hat{\gamma}^{*}, \hat{\gamma}$ and Jrift $\hat{m}^{\star}$ are calculated. A set of sample anisotropic/isotropic variograns are estimated and as expected the NW/SE variograin (direction of the hydraulic gradient) increased at a rate faster twan $h^{2}$ (Property of $11 \mathrm{I}-2$ ) indicating the presence of a drift (see Figure 8). Note that the average variogran is doninated by the $N W / S E$ and $W / S$ varioyram. An examination of the estimated drift-corrected variograms (Figure 9) still indicate a Diased estinate (a11 drift not reinoved); therefore we decided to visually fit (using VARLFIT) tne AE/Sw variugram, since it shoula be essentially drift free (appears perpendicular to tne major nydraulic gradient).

The estinated $\mathrm{WE} / \mathrm{SW}$ variogram is shown in Figure 10 . we note that a large number of pairs $(-120)$ are at distances vetweei 0 and 2 feet, which indicates that a careful fit of the initial points snould be made, since the estimator will weight these closest points inost heavily. The drift appears linear; nowever, it could be madeled ejther as linear or a constant since it is not very severe. We used 


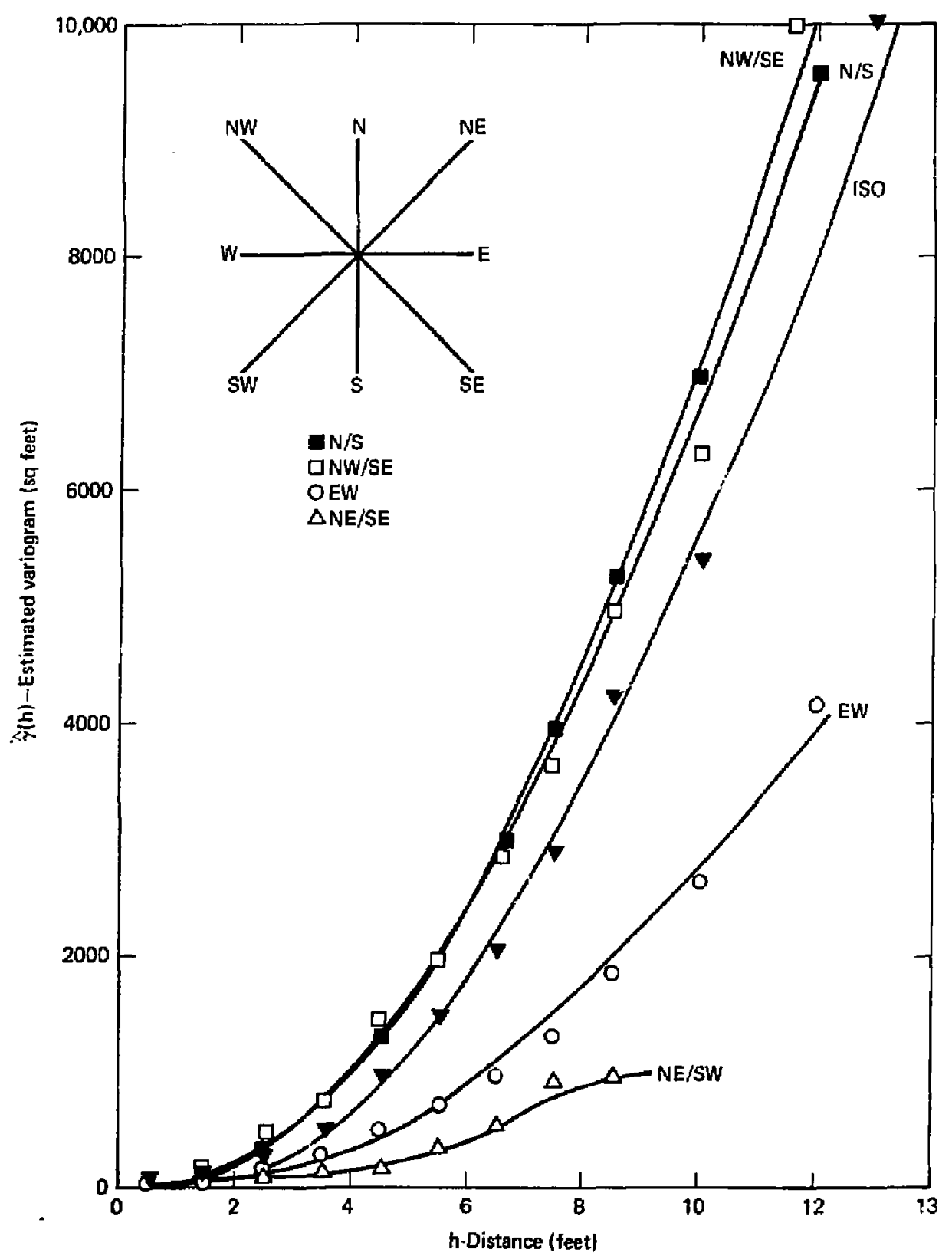

Figure B. Anistropic/Isotropic.Estimated Variograms for Toppenish Creek Data 


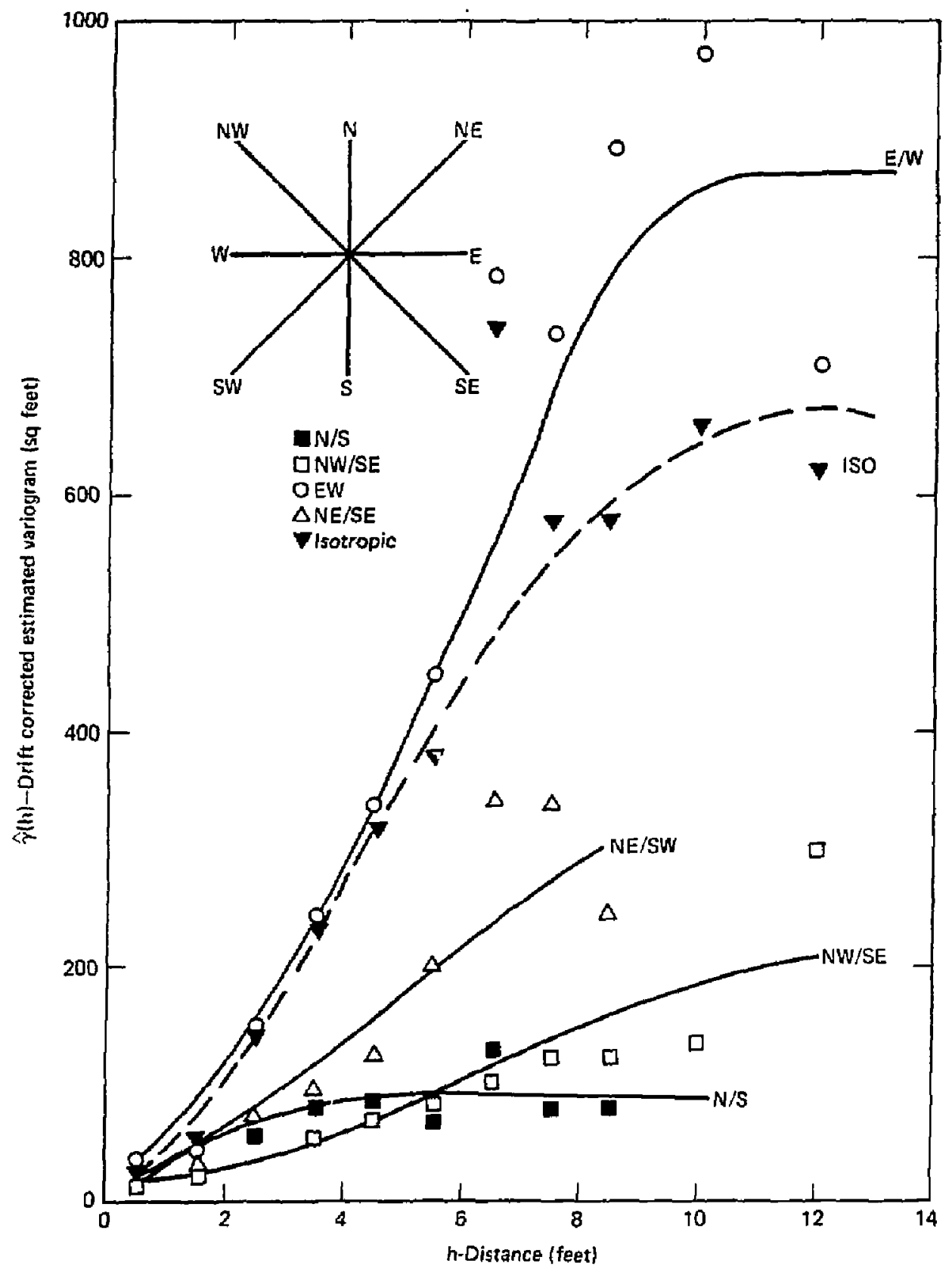

Figure 9. Drift-Corrected Anisotropic/Isotropic Estimated Variogram for Toppenish Creek Data 


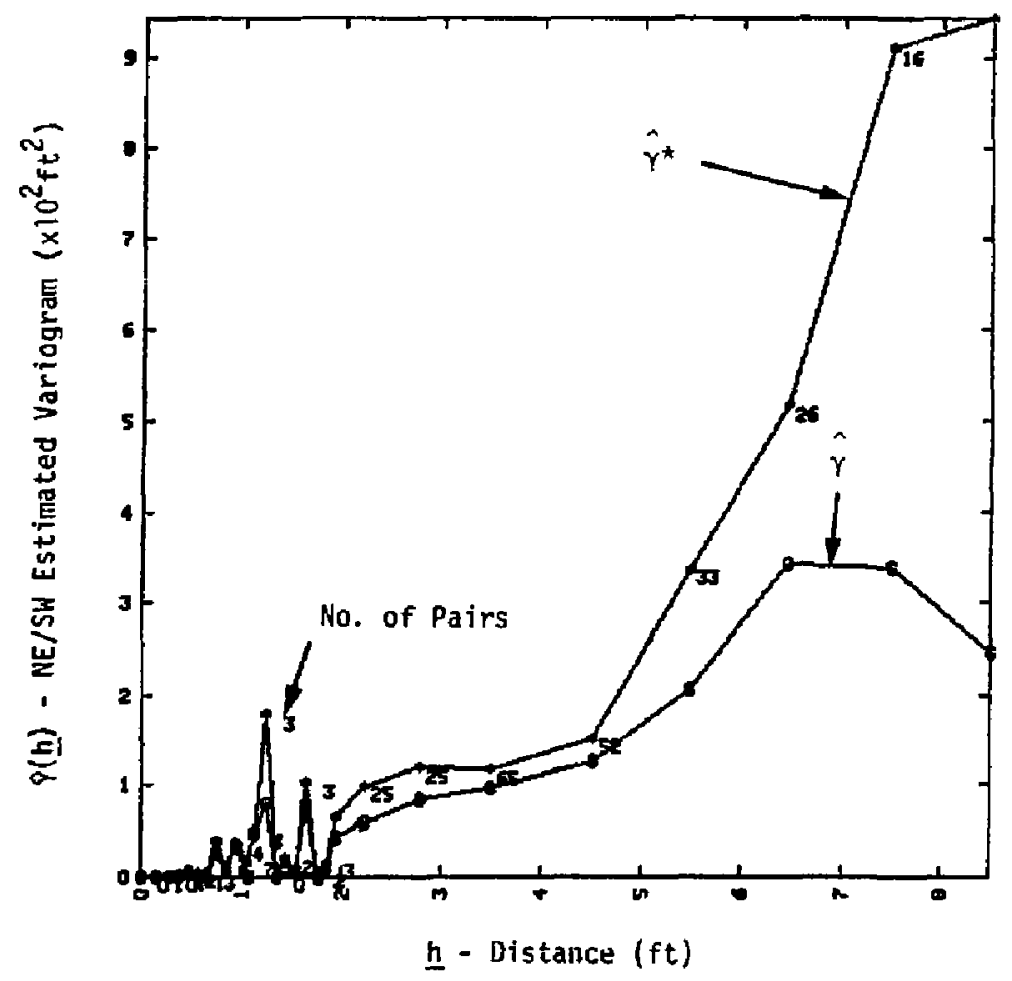

Figure 30. Estimated NE/SN Variogran for Toppenisn Creek Basin, Nasnington 
the automatic (generalized covariance) fit feature of the estimation algorithm ${ }^{\dagger}$ and also selected power function, linear, and spherical variogranls with constant and linear orifts. After fitting these structures visualiy we applied the successive estination method for validation. Each model was fit visually to the estimated NE/SW variogram and then the parameters of each particular structural model were adjusted until the standard error was approximately unity. Those with the smaliest root mean-squared error (RiISE) were retained. These results are suminarized in Tables $V$ and $V I$, we found that the successive estination tecnnique appears to fit the closest points with most pairs. This is apparent when we examine Figure 11 which snows the "best" fits from Tabies $V$ and $V i$ : yeneraljzel" covariance, spherical, and linear variograns with constant urift. Wate that in this figure we plot the "fits" to the Nc/SW variogran since it is approximately arift-free. Wote also that the initial slopes of the linear and spherical are practically identical, taus they yield sinilar validations. We also found that most pairs (range, sill) witn initial slope 25 yielded identical statistics again conf jrming the heavy dependerce on closely spaced pairs.

After the structural identification was completed, the spatial estimator was run over the data set. We chose the linear variagram

t we used the algoritlim dLUEPALK $\lfloor$ loj for our case studies and VARlFIT for tnis variogram identitication. 
TABLE V. TUPPËNISH CREEK STRUCTURAL MUUEL SUMMARY

\begin{tabular}{|c|c|c|}
\hline IYPE & MODEL & DRIFT \\
\hline $\begin{array}{l}\text { GENERAL ILED } \\
\text { COVARIANCE (AUTO) }\end{array}$ & $K(h)=20.50-1.70 \mid \underline{h} \mathrm{I}$ & Linear \\
\hline VARLUGKRAIA 1 & $\gamma(h)=9 j|\mathrm{ln}|^{1.7}$ & Constant \\
\hline 2 & Same & Linear \\
\hline $\begin{array}{r}\text { VAR IULGRAM } 3 \\
4\end{array}$ & 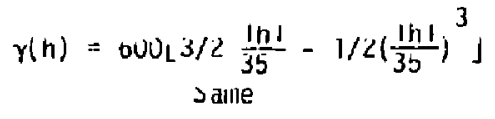 & $\begin{array}{l}\text { Constant } \\
\text { Linear }\end{array}$ \\
\hline VARIULRAM 5 & $\gamma(h)=2 b|h|$ & Constant \\
\hline
\end{tabular}

TABLE VI. TUPPENISH CREEK STRULTURE IUENTIF ICATIUN/VALIUATIUIV

\begin{tabular}{|c|c|c|c|}
\hline TYPE & $\begin{array}{l}\text { STANUARD } \\
\text { ERROR }\end{array}$ & $\begin{array}{c}\text { RUUT MEAN-SQUARED } \\
\text { ERROR }(f t)\end{array}$ & $\begin{array}{l}\text { MEAN } \\
\text { ERROR ( } \mathrm{ft})\end{array}$ \\
\hline $\begin{array}{l}\text { GENERALILEU } \\
\text { COVARIAINCE (AUTU) }\end{array}$ & 0.84 & 4.77 & 0.03 \\
\hline VARIUGRAN $\begin{array}{r}1 \\
2\end{array}$ & $\begin{array}{l}0.96 \\
0.96\end{array}$ & $\begin{array}{l}5.10 \\
5.39\end{array}$ & $\begin{array}{l}0.10 \\
0.10\end{array}$ \\
\hline VARLOGRAM 3 & $\begin{array}{l}0.99 \\
0.98\end{array}$ & $\begin{array}{l}4.67 \\
4.97\end{array}$ & $\begin{array}{l}0.05 \\
0.09\end{array}$ \\
\hline VARIULGRAMI b & 1.02 & 4.00 & 0.00 \\
\hline
\end{tabular}




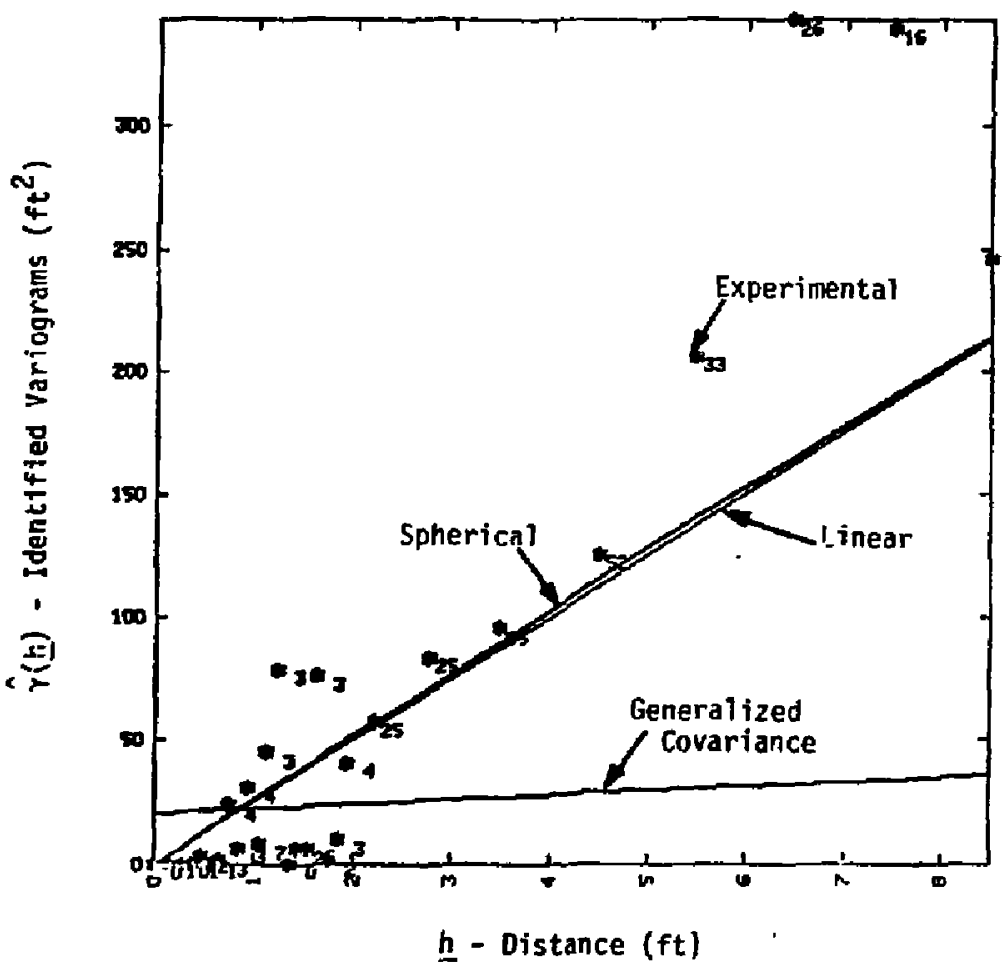

Figure 11. Identified Variograms (Near Origin) Against NE/SW Experimental Varlograms for Toppenish Creek Basin, Washington 
with a constant drift since it had the minimum RMS error and generated the contours snown in Figures 12 and 13 . We could nave selected the generalized covariance, or spherical model as well since the validation statistics were very close. In fact maps generated from tnese inodels were almost identical.

An examination of the resulting contour inap of the Toppenisn Creek Basin, indicates tnat most of the najor features have been maintained. Note that tne nomalized lap coordinates must ve converted back to proolem coordinates and the conversion factors are snown as $(\Delta x, \Delta y)$ on Figures 12 and 13 .

An exanination of the standard errors indicates tnat the sample distribution appears symmetric; thus, a Gaussian approximation is reasonable, so the one-sigina values can be used to construct confidence intervals in various regions of the ared. A close examination of the one-sigma error map in Figure 13 indicates that the upper NE corner and lower SW corners are the InOSt uncertain areas. Tuis is expected since no measurenents are availale in tnose regions.

A contour was also constructed for fitting a linear drift to the data. The results of this run using the linear variogram are shown in Figure 14. The contour represents a simplified fit to the raw data and it is close to the estimated contour of Figure 12 again indicating 


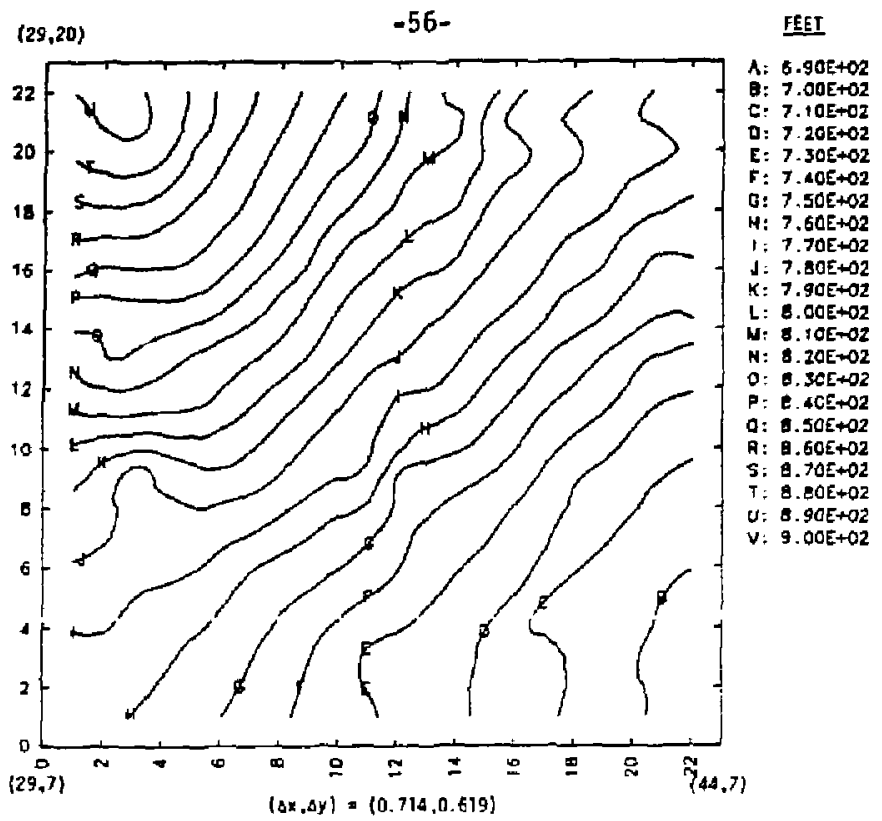

Figure 12. Contour of Groundwater Levels (in Feet) at Toppenish Creek Basin. Washington. Using Spatial Estimation Techniques (Linear Variogram)

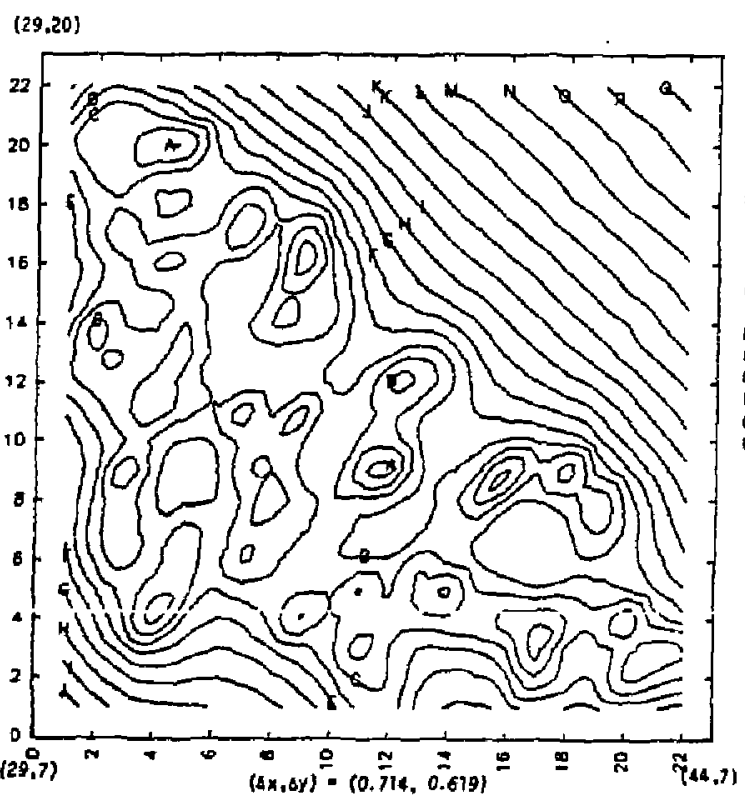

D: $\$ .00 t-\infty$

E: 6. $005+\infty$

$F: 7.00 E+\infty 0$

G: $9.00 E+00$

H: $\mathbf{3} . \mathrm{COE}+\infty \mathrm{OO}$

1: $1.00 E-0:$

$\mathrm{J}: 1.10 \mathrm{~B}+01$

$\mathrm{K}: 1,20 E+0.9$

$L: 1.50 E+01$

$M: 1 . \angle O E+O 1$

N. J SOE+OI

$0: 1.50 E+01$

P. $1.70 E-01$

$0: 1, \triangle 0 E+01$

R: $1.90 E+01$

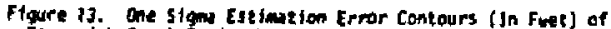
Toppenish Creek Basin. Washington, Using Linest vartonrem 
$(29,20)$

FEET

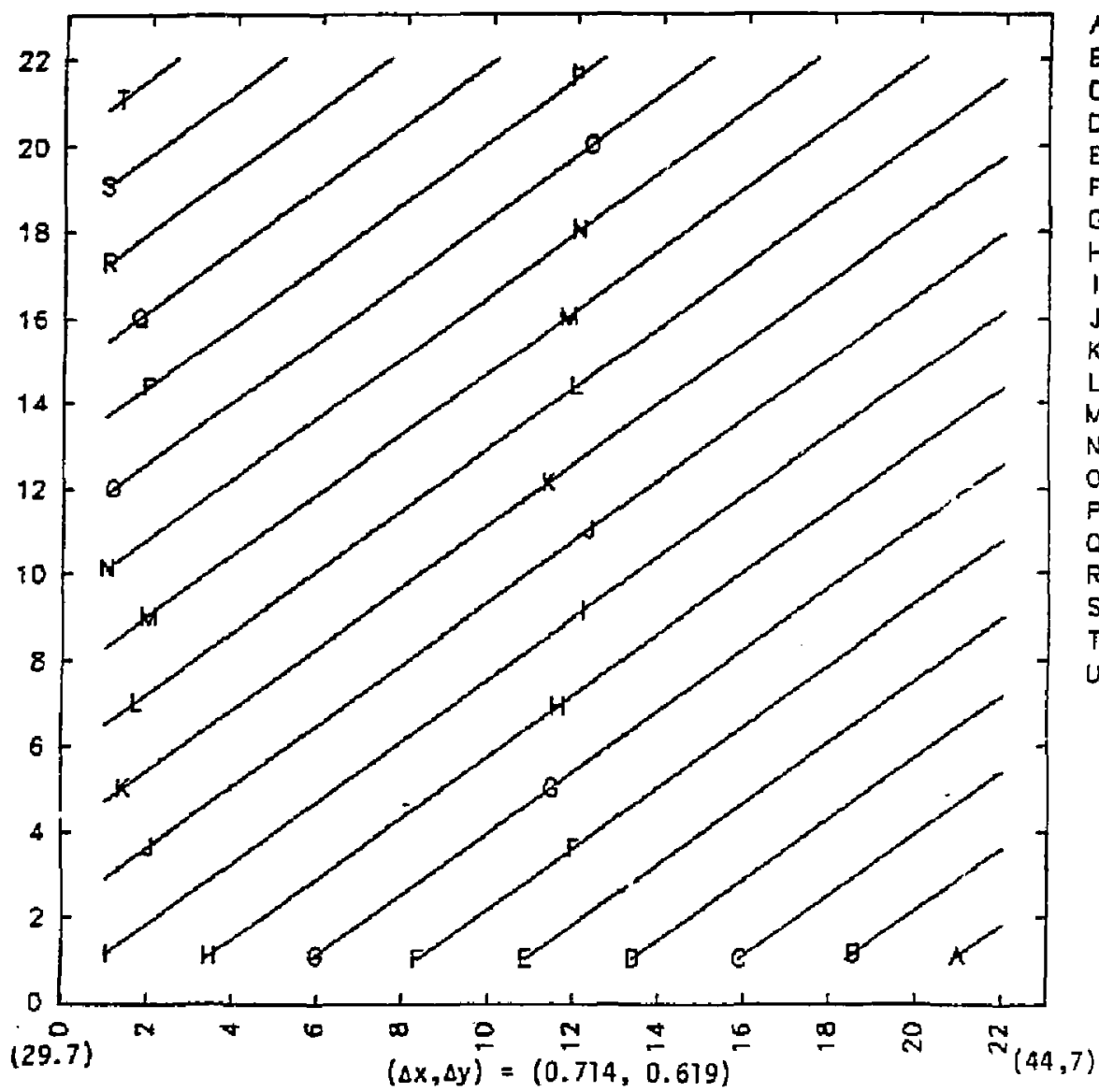

$A: 6.90 \mathrm{E}+02$

$B: 7.00 E+02$

C: $7.10 \mathrm{E}+02$

D: $7.20 \mathrm{E}+02$

E: $7.30 \mathrm{E}+\mathrm{O} 2$

$F: 7.40 E+02$

G: $7.50 E+02$

$H: 7.60 E+02$

I: $7.70 \mathrm{E}+02$

$\mathrm{J}: 7.80 \mathrm{E}+02$

$K=7.90 E+02$

L: $8.00 E+02$

$M: 8.10 E+02$

N: $8.20 E+02$

$0: 8.30 \sqsubseteq+02$

$P: 8 . \angle O E+O 2$

Q: $8.50 E+02$

R: $8.60 E+02$

S: $8.70 E+02$

T: $8.80 E+02$

$U: 8.90 E+02$

Figure 14. Drift (Trend) Contours (In Feet) of 


\begin{abstract}
$-38-$
tne simplicity of tne structure. Pseudo-color inage displays of the estinated region and corresponding one signa error values were generated using SIPRG facility. These inages are snown in Figures 15 and 16 .

Suminarizing the results of this case study, it appears that tne spatial estimator can be used with confidence to reconstruct a regional contour map of a siliple groundwater aquifer systen. In tne next section we consider another simple aquifer; nowever, this time with a limited number of data points.
\end{abstract}

IV-2. CASE STUDY: Todd Lake, Pennsylvania Natural Flow Conditions

Tile purpose of this case study is to investigate tole perforinance of spatial estination tecnniques on a simple groundwater ayuifer system when the data are sparse. Todd Lake data was obtained from W. Murray. a nydrologist at LLNL, who wurkeo on the aquifer. He developed a two-dimensional (partiai differential equation) groundwater mudel of the Todo Lake region which we used as "truth" data to evaluate the perfornance of the spatial estimator over a limited data set. We used a set of 28 ineasurements (ten well measurements and 18 other inferred from tne map/ corresponding to the data derived by the nydrologist from measurements and a-priori knowledge of the region. A general layout of the Todd Lake region is shown in Figure 17. The major landinarks are shown, i.e., the lake, pond, and quarry. We decided to 


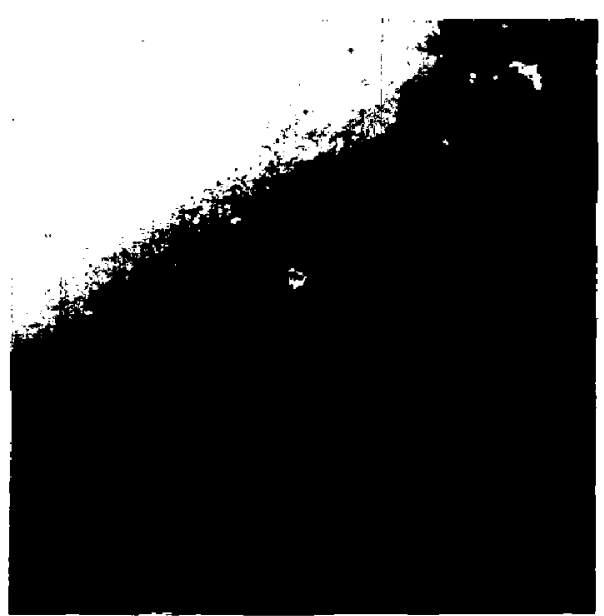

Figure 15. Pseudo color image of spatially estimated Toppenish Creek Basin, Washirigton using linear variogr am.

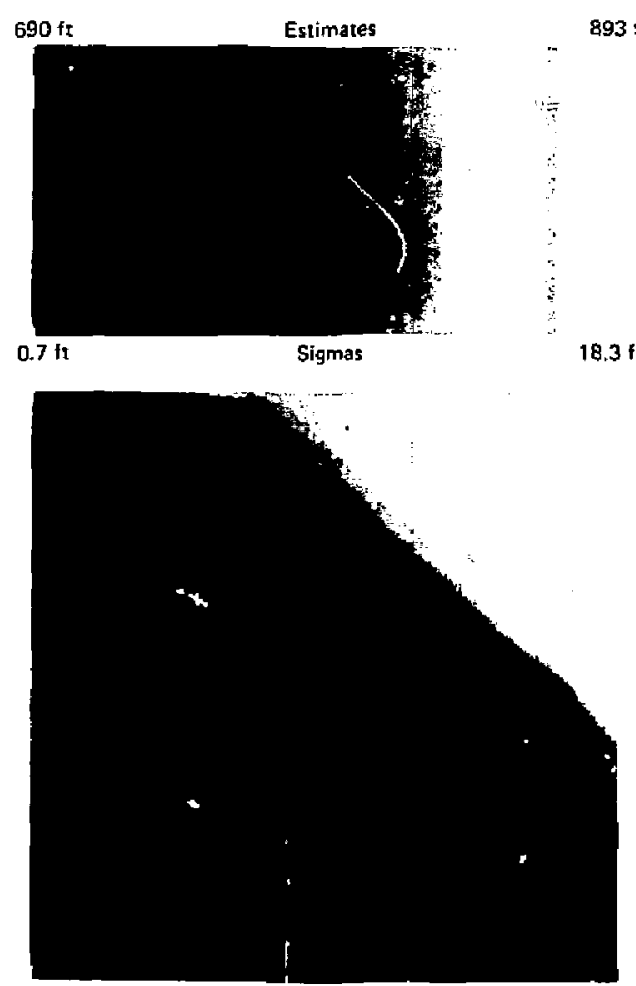

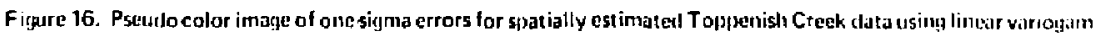


eliminate the quarry, since this data would create unnecessary problems for the estimator. It would require more data to resolve and not really provide anymore useful information for this analysis. The "trutn" contour of the Todd Lake region is snown in Figure la. The major nydraulic gradient appears to be from the SW to the NE. Contours from the measurement set are shown in $\mathrm{F}$ igure 19 for comparative purposes. Again note that the major features are preserved Decause of the particular measurement locations selected.

As Defore, we use the 28 data points and identify a structural model from the data. Anisotropic/isotropic variograns were est inated first indicatinç a drift in the NE/SW direction (nydraulic gradient) as snown in Figure 2U. Again, the estinated drift-corrected variograms (Figure 21) appear biased due to inadequate drift estimation. We chose to use the NW/SE variograin to $f$ it because ic appears perpendicular to the major hydraulic gradient and essentialiy drift-free. The estimated variograin is snown in Figure 22 . Note that the apparent drift-correction is sinall (difference Detween $\hat{\gamma}^{*}$ and $\hat{\gamma}$ curves) indicating the drift-free variogran structure.

The variogram and drift identification were again performed and tne resuiting variograms are given in Tables VII and VIII. After adjusting tne model parameters to yield a standard error of unity, tne "hest" fit is a power variogram with a linear orift (variogram 2 in Taple VIII), since it yields the minimum RMS error. The fit of tnis 


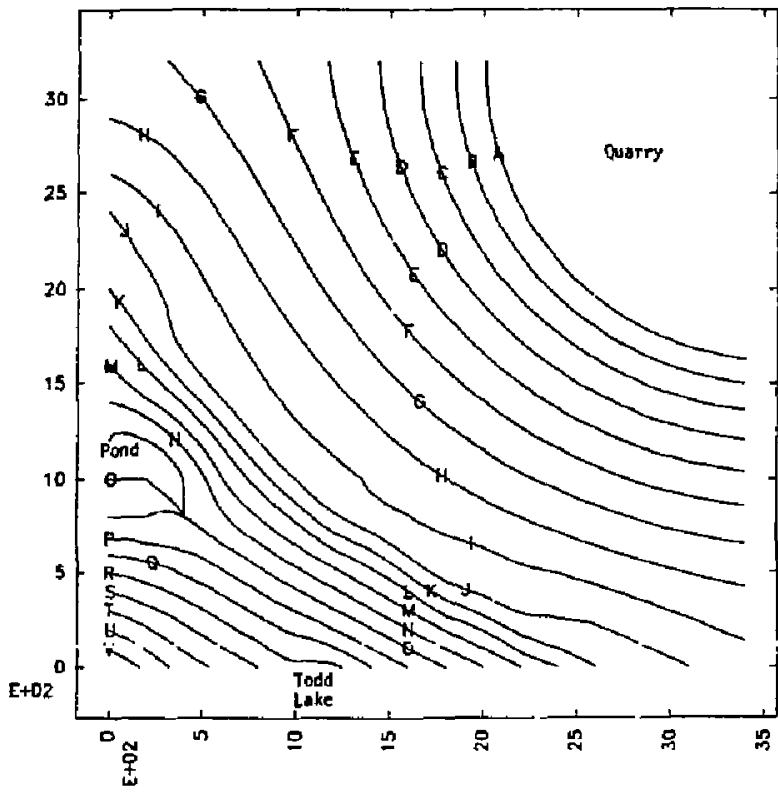

A: $3.60 E+02$

B: $3.65 E+02$

c: $3.70 E+02$

D: $3.75 E+02$

E: $3.80 \mathrm{E}+02$

f: $3.85 E+02$

G: $3.90 E+02$

H: $3.95 \mathrm{E}+02$

1: $4.00 E+02$

J: $4.05 E+02$

K: $4.10 \mathrm{E}+02$

L: $4.15 E+02$

M: $4.20 \mathrm{E}+02$

N: $4.25 E+02$

D: 4.30E+02

P: $4.35 E+02$

Q: $1.105+02$

$\mathrm{R}: 4.45 E+02$

S: $4.50 E+02$

$T=4.55 \mathrm{E}+02$

U: $4.60 \mathrm{E}+02$

V: $1.65 E+02$

$w: 4.70 \mathrm{E}+02$

Figure 1B. Todd Lake "Truth" Groundwater Level Contour (In Feet)

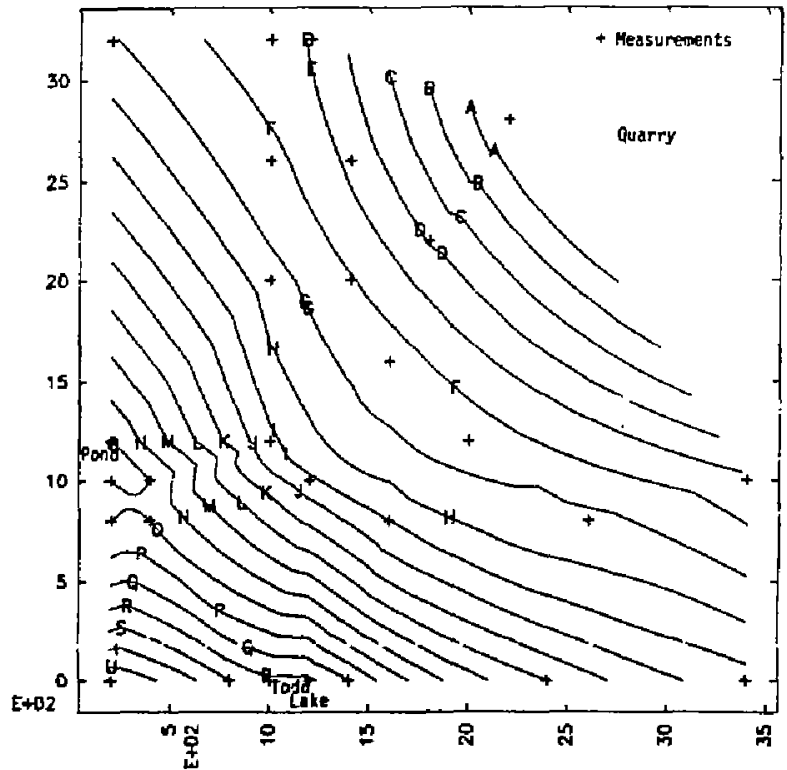

A. $3.60 \mathrm{E}+02$

B: $3.65 E+02$

C: $3.70 E+02$

D: $3.75 E+02$

E: $3.80 E+02$

F: $3.85 E+02$

C: $3.90 E+02$

H: $3.95 E+02$

1: $4.00 E+02$

J: $4.05 E+02$

k: $4.10 E+02$

$L: 4.15 E+02$

$M=4.20 E+02$

$\mathrm{N}: 4.25 \mathrm{E}+02$

$0: 4.30 \mathrm{E}+02$

P: $4.35 \mathrm{E}+02$

Q: $4.40 E+02$

R: $4.4 i[+02$

$5: 4.50[+02$

$T: 4.55 E+02$

U: $4.605+02$

$v_{i} 4,65 E+02$

$W:$ 4.70E+02

Figure 19. Tadd Lake Grouncanater Leye1 Contour Based on 28 measureatints (In Fett) 


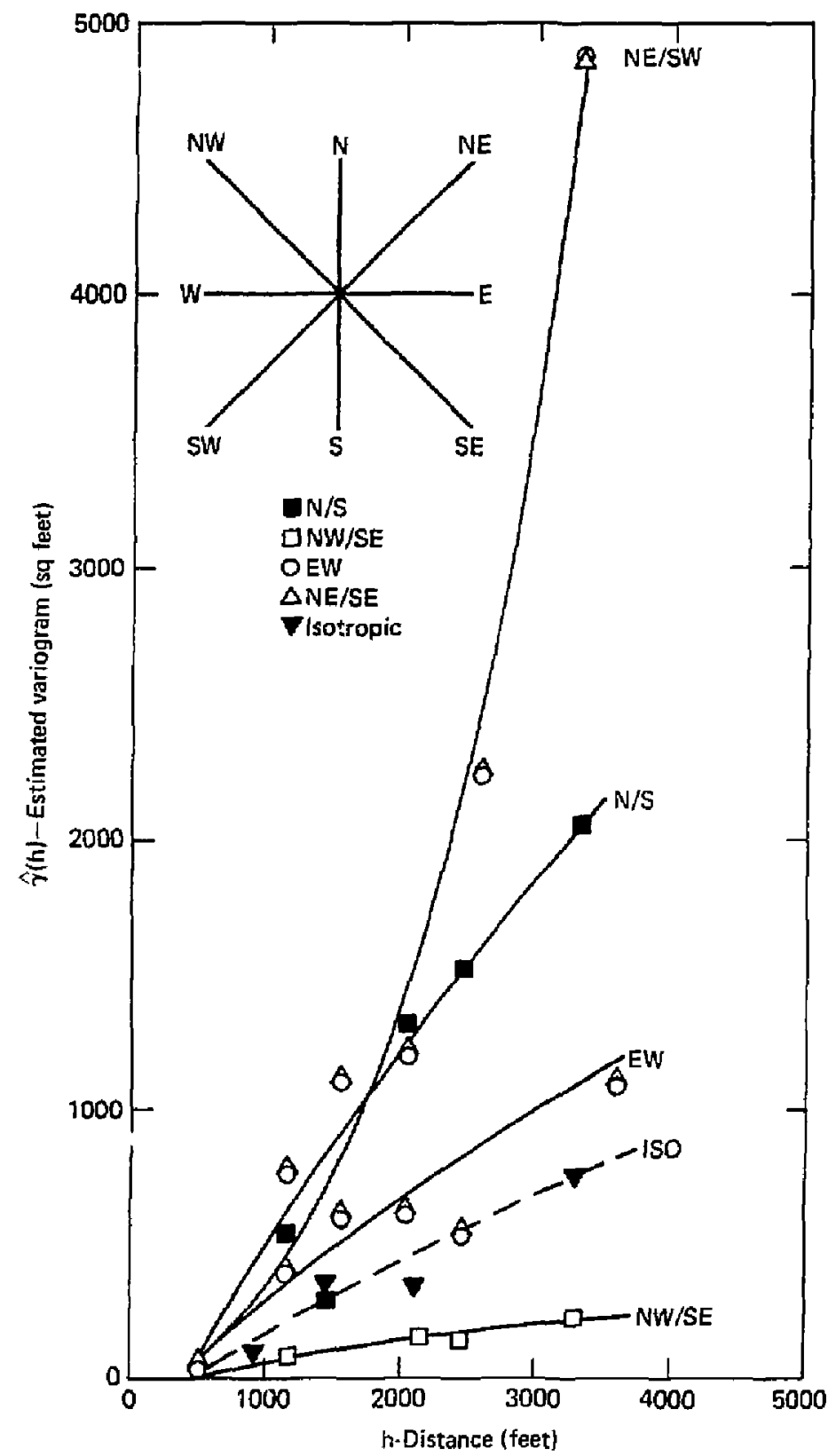

Figure 20. Anisotropic/Isotropic Estimated Variograms for Todd Lake Data 


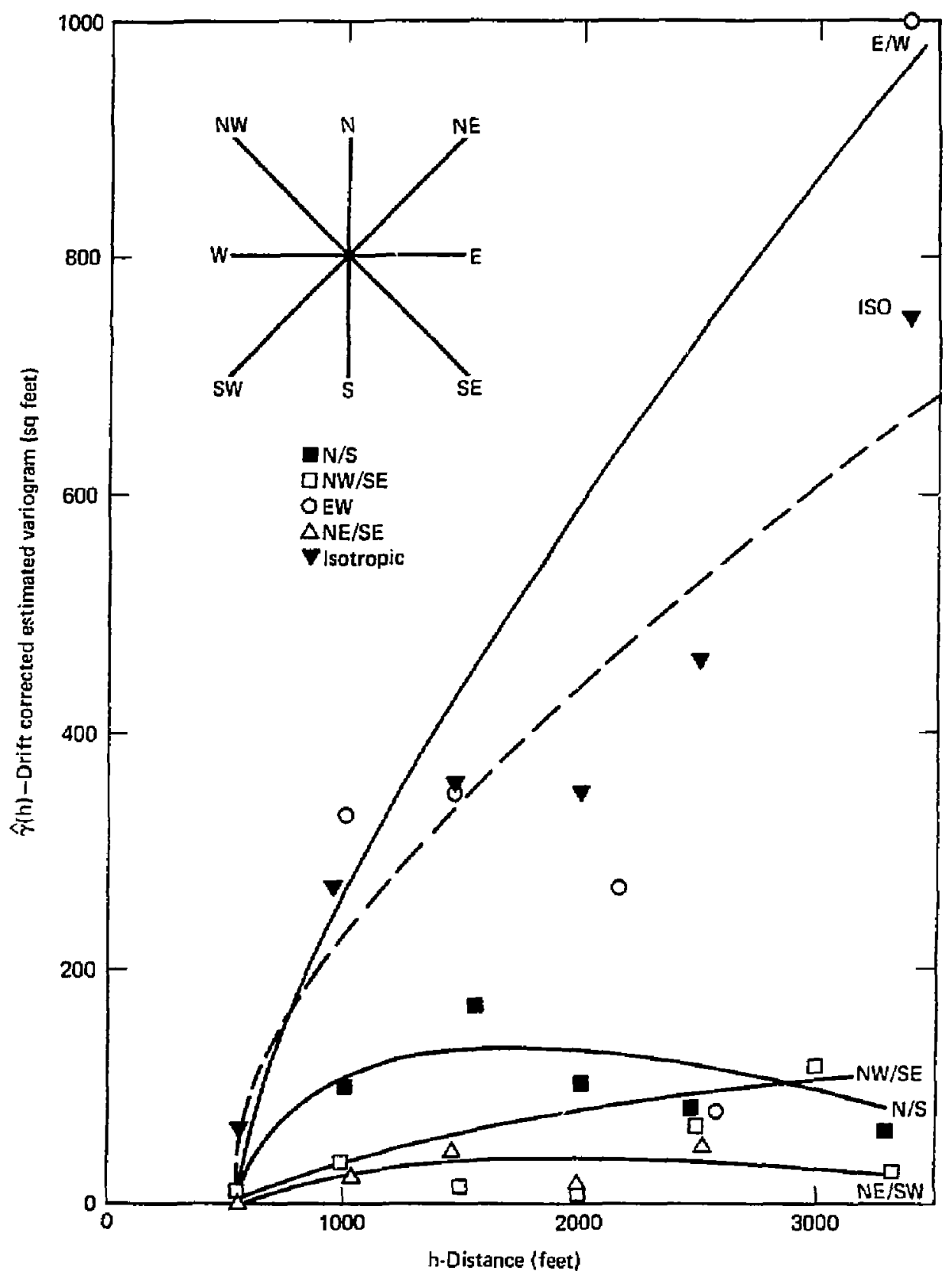

Figure 21. Drift-Corrected Anisotropic/Isotropic Variograms for Todd Lake Data 


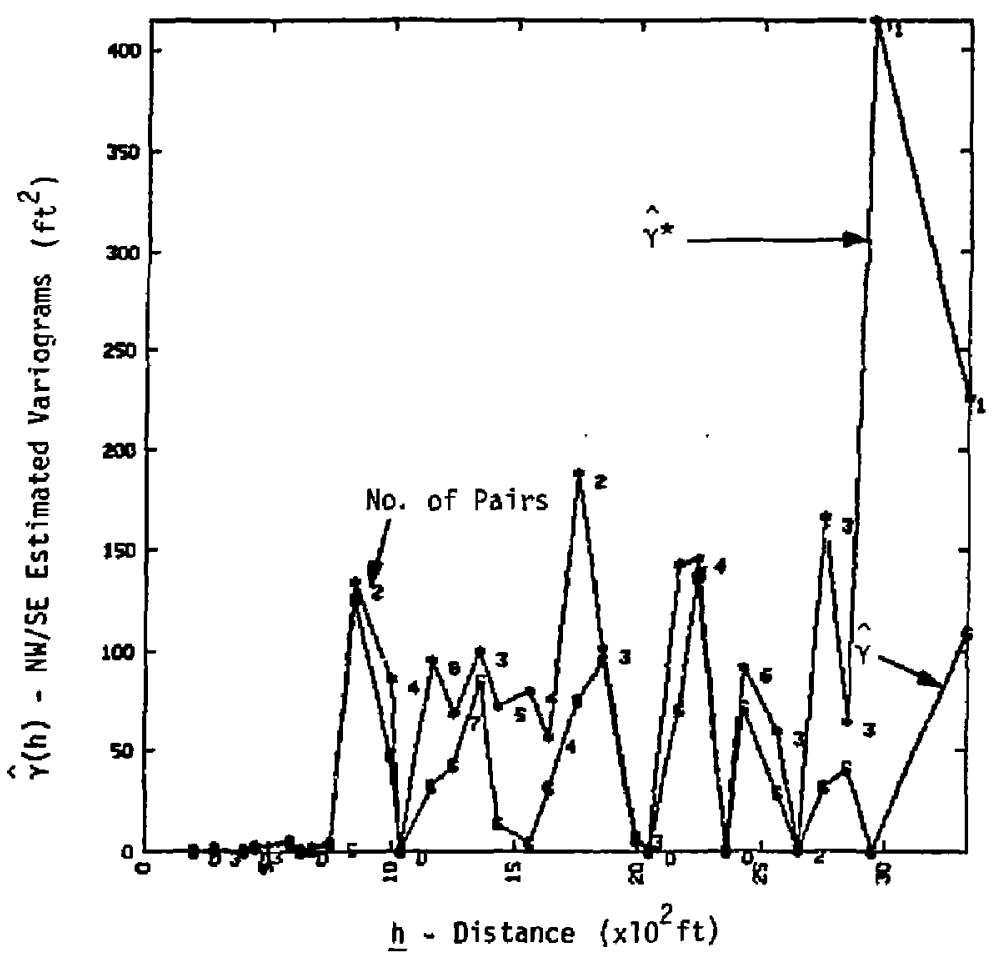

Figure 22. Estimated NW/SE Variogran for Todd Lake Data Using 28 Measurements 
TABLE V11, TODO LAKE STRUCTURAL MODEL SUMMARY

\begin{tabular}{|c|c|c|}
\hline TYPE & MOUEL & ORIFT \\
\hline $\begin{array}{l}\text { GENERALIZEO } \\
\text { COVARIANCE (AUTO) } \\
\text { VARIOGRAM } 1 \\
\qquad 2\end{array}$ & $\begin{array}{l}K(n)=2.17-0.04|n|+6.07 \times 10^{-9} \mid n 1^{3} \\
Y(n)=3.0 \times 10^{-3} \mid 111.45 \\
\gamma(n)=2.3 \times 10^{-3} 1111.45\end{array}$ & $\begin{array}{l}\text { Linear } \\
\text { Constant } \\
\text { Linear }\end{array}$ \\
\hline $\begin{array}{r}\text { VAR IOGRAM } 3 \\
4\end{array}$ & $\begin{array}{l}\gamma(n)=1.4 \times 10^{-2} \ln 1.2 \\
r(n)=8.0 \times 10^{-3} \ln 11.2\end{array}$ & $\begin{array}{l}\text { Corstant } \\
\text { Liruear }\end{array}$ \\
\hline $\begin{array}{r}\text { VARIOGRAM S } \\
\text { b }\end{array}$ & $\begin{array}{l}\gamma(\ln 1)=3.0 \times 10^{-2} \ln 1 \\
\gamma(\ln \mid)=2.7 \times 10^{-2} \ln 1\end{array}$ & $\begin{array}{l}\text { Constanl } \\
\text { Linear }\end{array}$ \\
\hline
\end{tabular}

TABLE VILI. TODD LAKE STRULTURE IDENTIFICAIION/VALIDATION

\begin{tabular}{|c|c|c|c|}
\hline TYPE & $\begin{array}{l}\text { STANDARO } \\
\text { ERROR }\end{array}$ & $\begin{array}{c}\text { RMS } \\
\text { ERROR }(f t)\end{array}$ & $\begin{array}{l}\text { MEAN } \\
\text { ERROR ( } \mathrm{ft})\end{array}$ \\
\hline $\begin{array}{l}\text { GENERALILED } \\
\text { CUVARIANCE (AUTU) }\end{array}$ & 0.51 & 4.12 & $0.70^{\circ}$ \\
\hline $\begin{array}{r}\text { VARJOGRAM } 1 \\
2 \\
2\end{array}$ & 1 & $\begin{array}{l}5.0 \\
3.94\end{array}$ & $\begin{array}{l}0.42 \\
0.02\end{array}$ \\
\hline VARIOGRAM 3 & $\begin{array}{l}0.44 \\
1.04\end{array}$ & $\begin{array}{l}5.6 \\
4.04\end{array}$ & $\begin{array}{l}0.48 \\
0.73\end{array}$ \\
\hline VARIOGKAIM D & $\begin{array}{l}0 . y 7 \\
0 . y_{d}\end{array}$ & $\begin{array}{l}0.48 \\
4.10\end{array}$ & $\begin{array}{l}\text { U.5 } \\
\text { U.d }\end{array}$ \\
\hline
\end{tabular}


variogram to the NW/SE variogram Jata is shown in Figure 23 and it appears quite reasonadle.

Contours of the Todd Lake region were produced using the model identified from tne 28 data points. Tne map as well as the one-sigma errors are shown in Figures 24 and 20 . Again tne maitl features are preserved and the map looks reasonate (visually) when comparing it to the "truth" map of Figure 18 . The errur map indicates the regions of nighest confidence (again closest to aata points) and least confidence (edges).

The perfornance of the "sparse" structurd invel derived from the 28 data points was evaluated on tine set of crutn data and the results are snown in Taple IX. The RMS and inean error are quite simall as conpared to the original statistics (in parenthesis) Dased unly on 28 points; however, the standard error is no longer close to unity. This resuit is expected since tnat structural model was "identified" from the sparse 28 point data set. A "trutin" variogram was fit tu ine trutn data for comparative purposes and the validation results are also shown in Table $I X$. Note that tne error stacistics are invariant out the standard error is now unity. The invariance of the error statistics inplies trlat botn models are functions of the exponent (1.45 fixed) only. Tre truth variogram more closely fits the initial points. This result is cunfirined in Figure 20 . The identified "trutn" variogran was run over the 28 point data and the estimated 
$-69-$

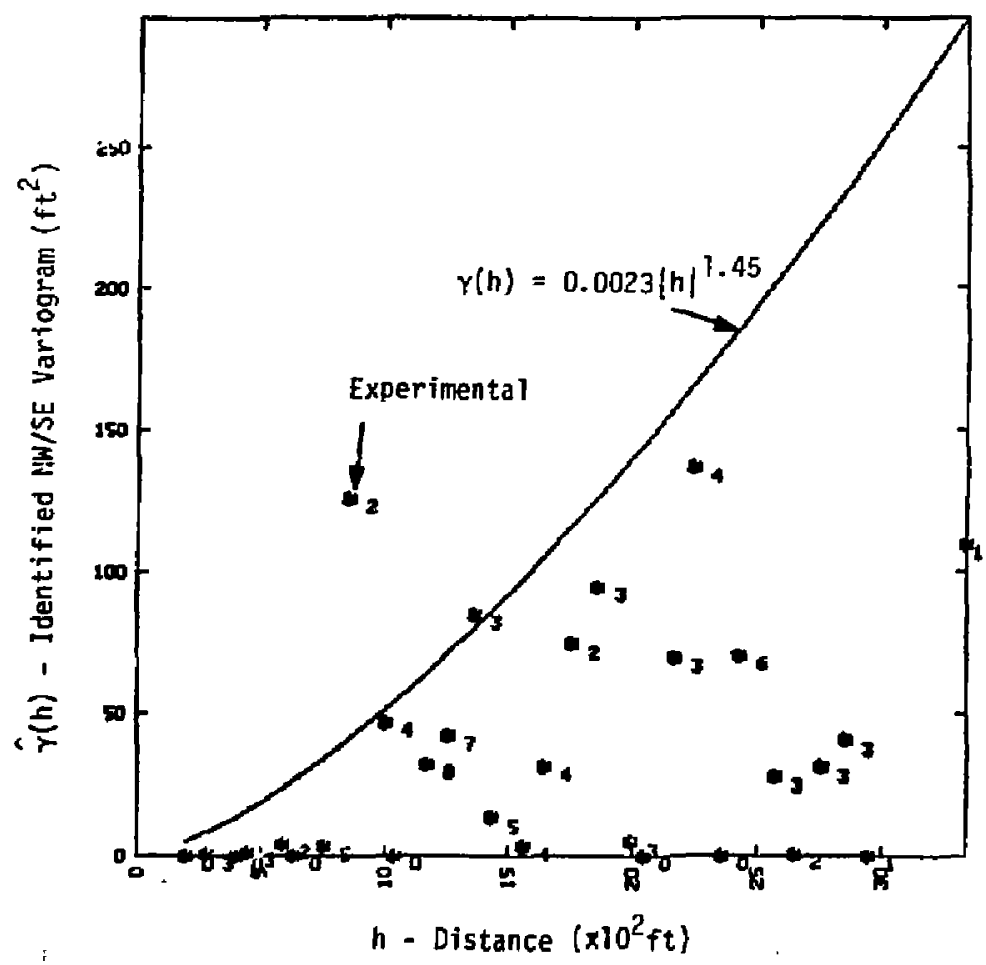

Figure 23. Estimated הiW/SE Variogram for Todd Lake Us ing 28 Measurements 
$\underline{\mathrm{FE}}$

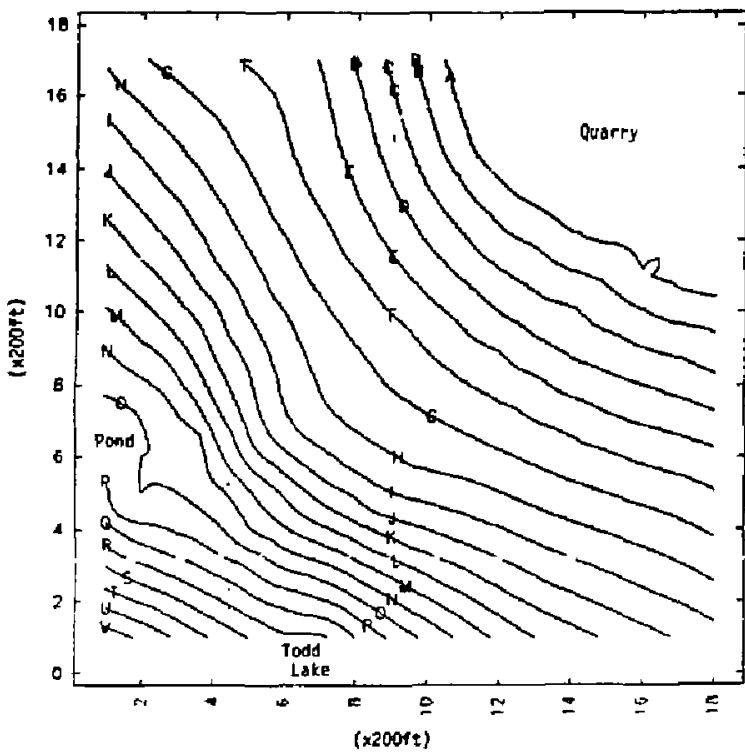

A: 3. $30 E+02$

B: $3.65 E+02$

C: $3.70 E+02$

d. $3.75 E+02$

E: $3.80 E+02$

F: $3.85 E+02$

G: $3.40 E+02$

H: $3.45 E+02$

I: $4.00 E+02$

S: $4.05 E+02$

K: $\triangle 10 E+02$

L: $4.15 E+02$

UI: $205-02$

N: . $25 E+02$

o: 4 . $30 E+02$

P: $4.35 E+02$

$0: 4.0 \mathrm{E}+02$

R: $4.15 E+02$

5: $4.50 E+02$

T. 4. $55 \overline{\mathrm{L}}-02$

U. $4,60 E+02$

$v:$ A. SSE+02

W: A. TOE+02

$x: 43 E+02$

F1gure 24. Contour of Groundwater Levels (In feet) at Todd Lake Using 5pot/dal Est inat ion techniques (Pomer Veriagr ana)

EEET

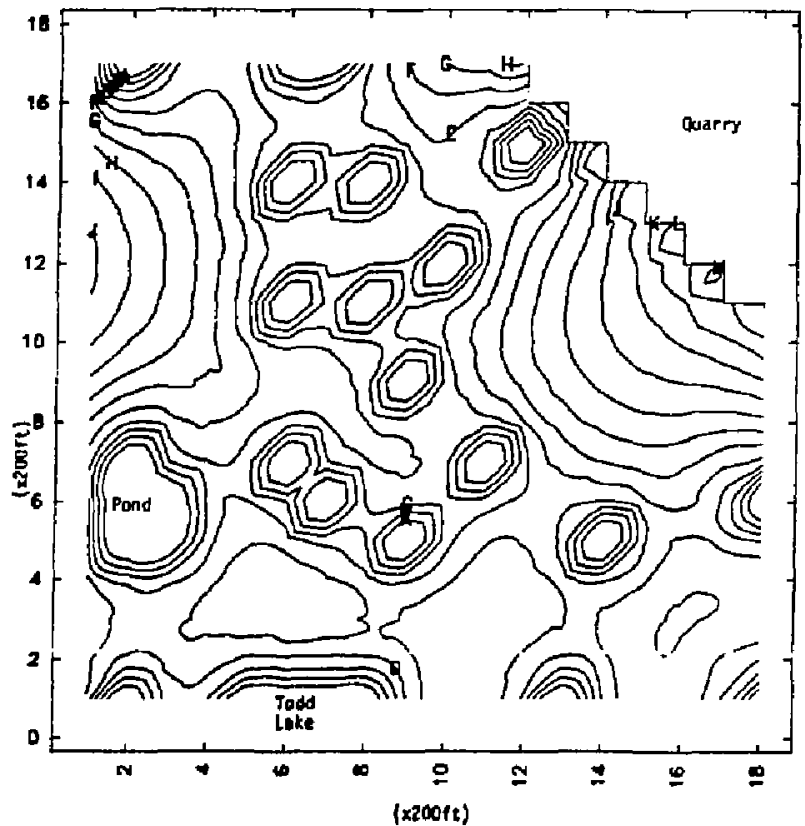

A: $1.00 E+00$

$9: 1.50 E \div 00$

C: $2.00 E+30$

D: $2.50 E+00$

E: $3.00 E+00$

$F: 3.50 E+30$

G: $4.00 E+00$

$\mathrm{H}: 4.50 \mathrm{E}+\mathrm{DO}$

l: $5.00 E+00$

J: $5.50 \mathrm{E}+00$

K: $6.00 E+00$

L: $6.50 \mathrm{E}+00$

$M: 7.00 E+00$

Fipure 25. Omesige Est imtion Error Contours (In Fet) of Todd Like (Power Virlogren) 

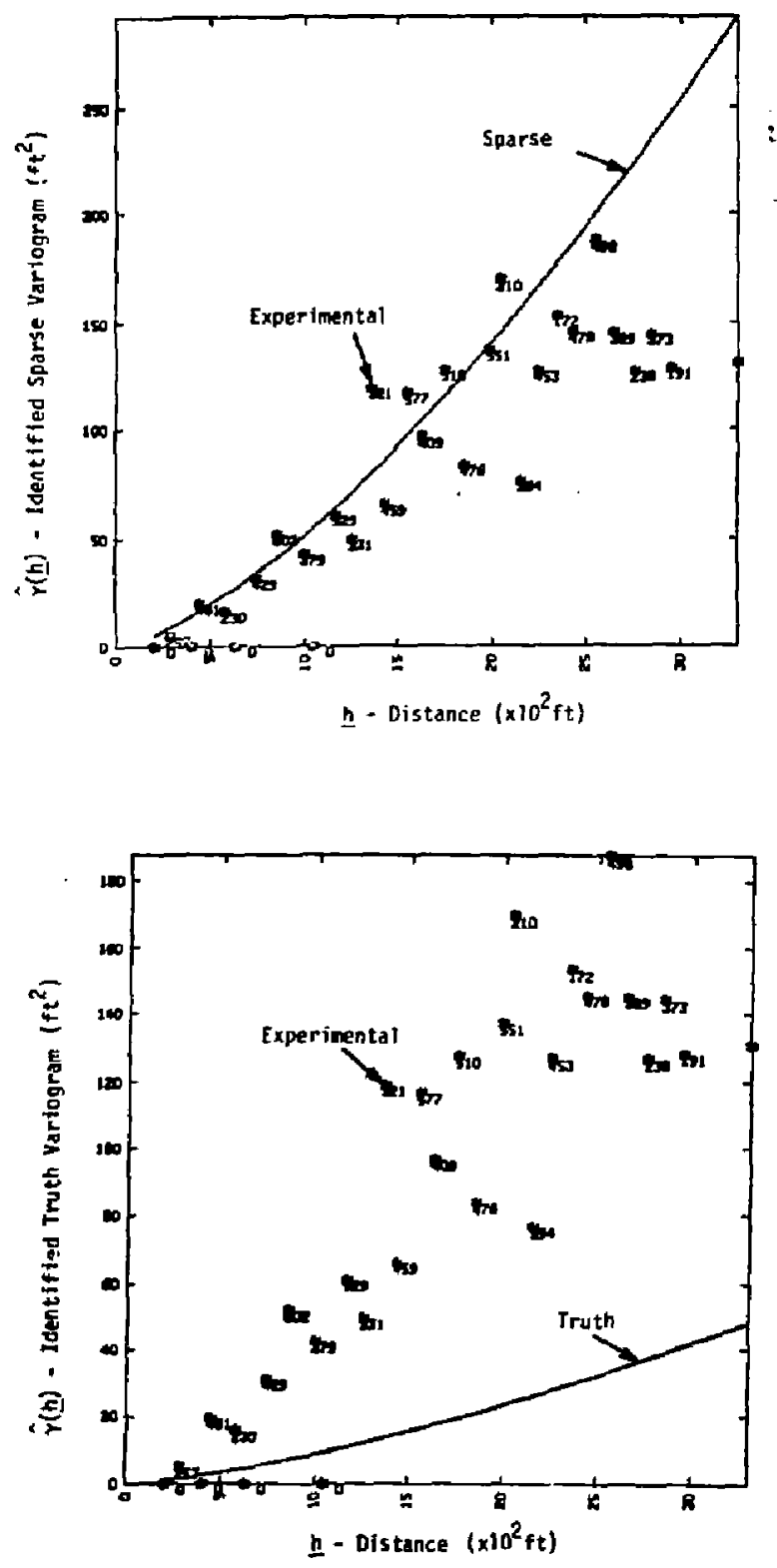

Figure 26. Identified Truth and Sparse for the NW/SE Todd Lake Truth Data 
TABLE [X. TODD LAKE STRUCTURAL ANALYSIS USING TRUTH DATA

\begin{tabular}{|c|c|c|c|c|}
\hline MODEL & TYPE & $\begin{array}{l}\text { STANDARD } \\
\text { ERROR }\end{array}$ & $\begin{array}{l}\text { RMS } \\
\text { ERROR }(\mathrm{ft})\end{array}$ & $\begin{array}{l}\text { MEAN } \\
\text { ERROR }(\mathrm{ft})\end{array}$ \\
\hline $\begin{array}{l}\text { SPARSE } \\
\text { TRUTH }\end{array}$ & $\begin{array}{l}\gamma(n)=2.3 \times 7 v-3 n 1.45 \\
\gamma(n)=3.8 \times 1 v^{-4} n 1.45\end{array}$ & $\begin{array}{l}0.10(0.98) \\
0.98\end{array}$ & $\begin{array}{l}0.03(3.94) \\
0.03\end{array}$ & $\begin{array}{l}0.075(U .6)=* \\
0.015\end{array}$ \\
\hline
\end{tabular}

* Botn wien linear orift.

** Numbers in parenthes is based unly on sparse data ( 28 points) 
values were identical to those ootained from the sparse model. Tnese results confirn again trat the initial fit of close jata puints dominate the perfomance of the estimator.

The final analysis of estimator performance is snown in Figure 27 where relative error ${ }^{\dagger}$ contours are displayed. Here we see tnat tne largest relative error is only adout one percent wnicn is quite good. In fact, the RifS error was only about $4.4 \mathrm{ft}$. with inean error of $-1 . y \mathrm{ft}$. Which is good for this data set. The largest regions of uncertainty appear where tne estimator limst extrapolate and tnere is no measurement data. The estimated values appear to give good estinates for the true values. Psuedu-color illages of Tudd Lake are snown in Figures 28 and $2 y$ for corsparative purposes.

Sumnarizing, it appears that for simple groundwater aquifers tnat reasunable contours can be obtained even witn sparse data. In the next section we investigate a more complex structure - the paleozoic rock depths at the Nevada Test Site.

$$
{ }^{+} E_{\text {REL }}=\frac{z_{\text {TRUE }}-\tilde{z}}{{ }_{\text {TRUE }}} .
$$




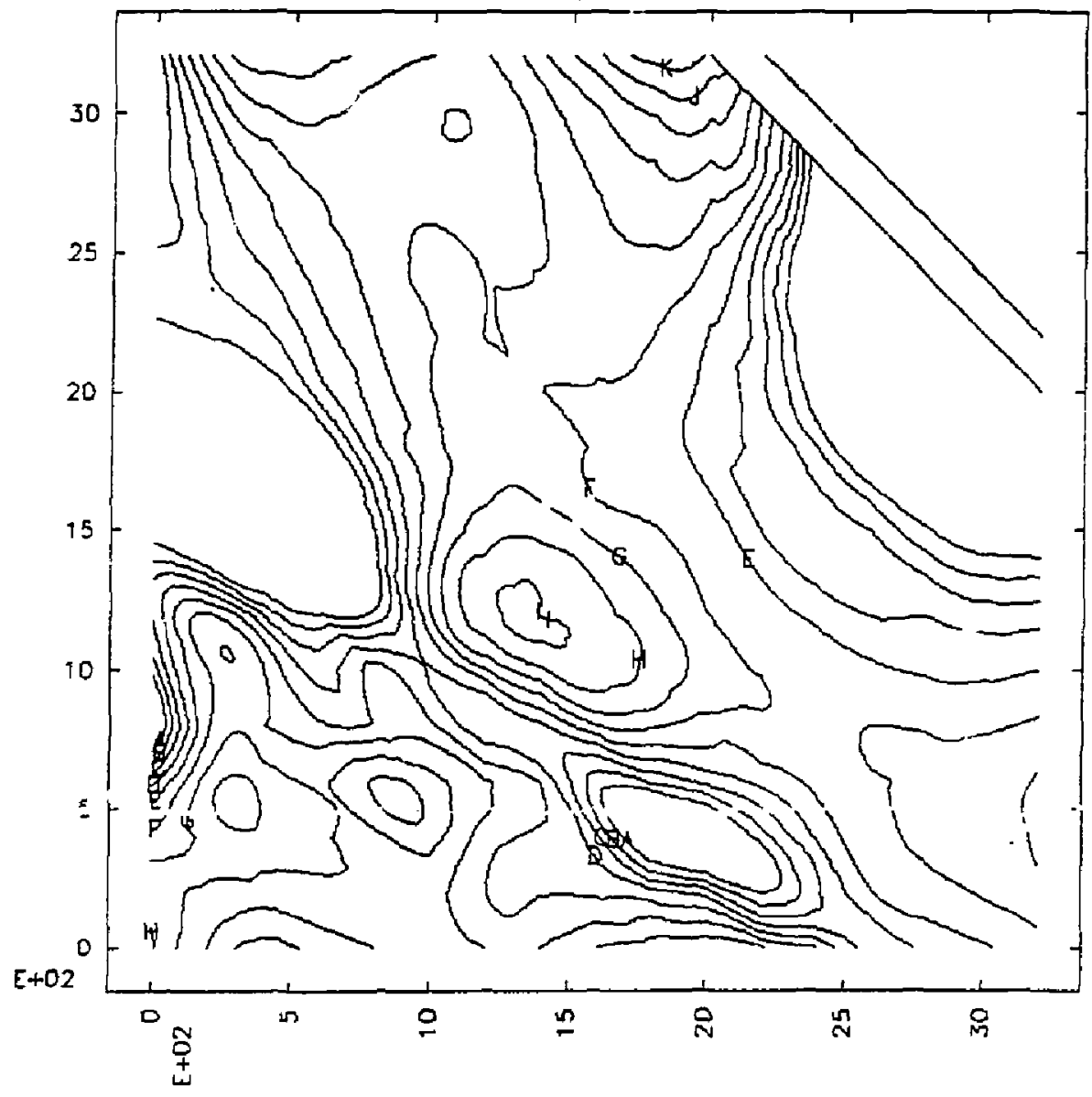

$A:-1.00 E-02$

$B:-8.00 E-03$

$\mathrm{C}:-6.00 \mathrm{E}-\mathrm{C3}$

$0:-4.00 E-03$

$\therefore-2.00 E-03$

$F: 0$.

G: $2.00 E-03$

$\mathrm{H}: 4.00 \mathrm{E}-03$

I: $6.00 E-03$

$\mathrm{J}: 8.00 \mathrm{E} \cdot 03$

$\mathrm{K}: \quad 1.00 \mathrm{E}-02$

Figure 27. Relative Error Contours for Tood Lake Spatiai Estination 
$-75-$

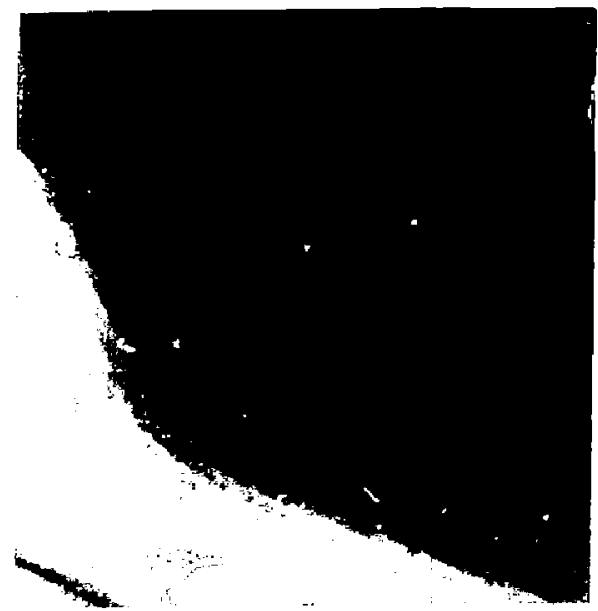

Figure 28. Pseudo-color inages of spatially estimated Todd Lake.
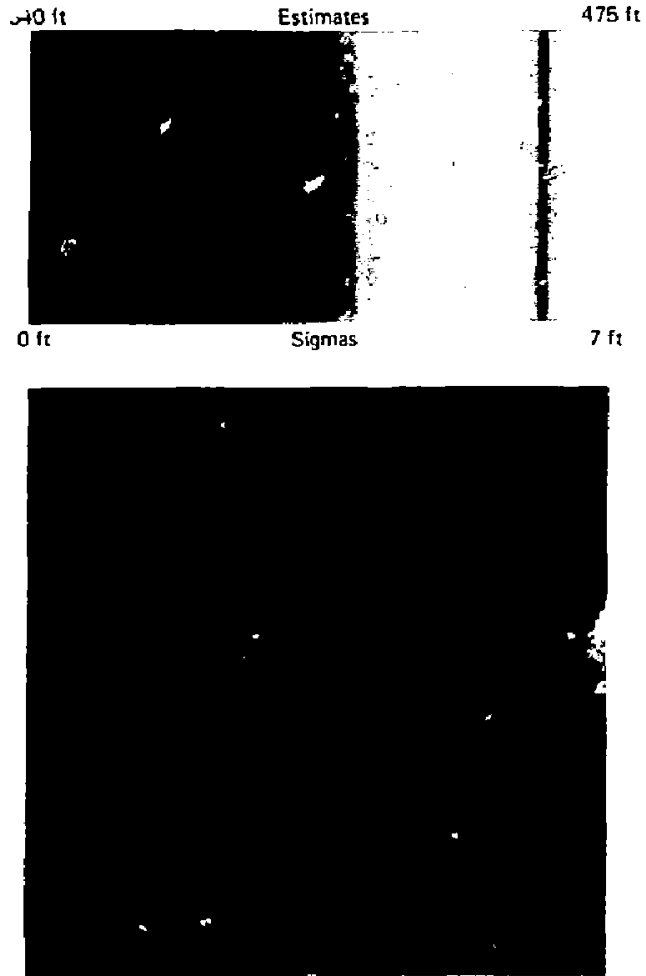

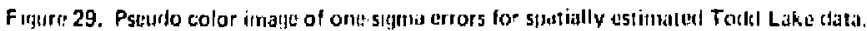


76

1 


$$
2
$$

$-77-$

IV-3 LASE STUUY: Wevada Test site, Paleozoic Rock Forinations

The purpose of this study is to evaluate tne perfornance of the spatial estimator on data from a complex but well known geological formation - the paleozoic rock at the Nevada Test site (NSS).

The l35U square mile NTS is one of the most exhaustively studied areas in existence. The WTS leologic Uata Base maintained ug LLNL contains paraneters describing the location coordinates, the litnoloyic cuntacts (alluviun, volcanic tuffs, and Paleozoic rocks), the distance to known and inferred faults, the depth to the water taole, representative values for pnysiachemical properties of the rocks, etc. from over 1000 drill noles [17]. In addition, chere is a data base of tw00 files of processed geophysical data vs. Jepth from logs and samples. Other geopilysical data such as seismic reflections and gravity are also available for the area. Tnese data are ideal for experimenting with spatial estimation techniques because of the following reasons:

1. being computerized, they are readily available and easily accessible.

2. There is a very large quantity of data.

3. There is quite a variety of types of data.

4. Leneral yeoloyy of the area is well understood. 
5. Uata are for properties similar to those relevant for the gqaluation of a waste repository site, i.e., fault locations, density, lithologic units, baserient depth, and water table location.

We studied the depth to the top of the Paloezoic rocks from 93 borehole data. The prinicpal rock types and the studied area at NTS are shown in Figure 30 . The Yucca $F$ dult running roughly $N-S$ divides the area into two parts. We studied the effect of fault on the estimated depth by considering no fault in the area fo- one case and with fault for another case.

First, we calculated the estimated variogram firom the data following the procedure outlined in section $111-2$. A set of sample anisocropic variogranis are shown in Figure 31 . These varjograms are biased because of the presence of drift in dll airections.

Various tested structural models are sumarized in iable $X$ and the identification and validation results are sumitarized in Tab]e XI. The RIMS errors for those inodels without fault are slightly smaller than those for the equivalent models with fault. There are probably two reasons behind this ouservation. First, the vertical torow due to fault is relatively small as compared with the error. Second, there are fewer data poin.s to estinate with when a fault is present Decause the fault effectively divides the data into two sets and no 


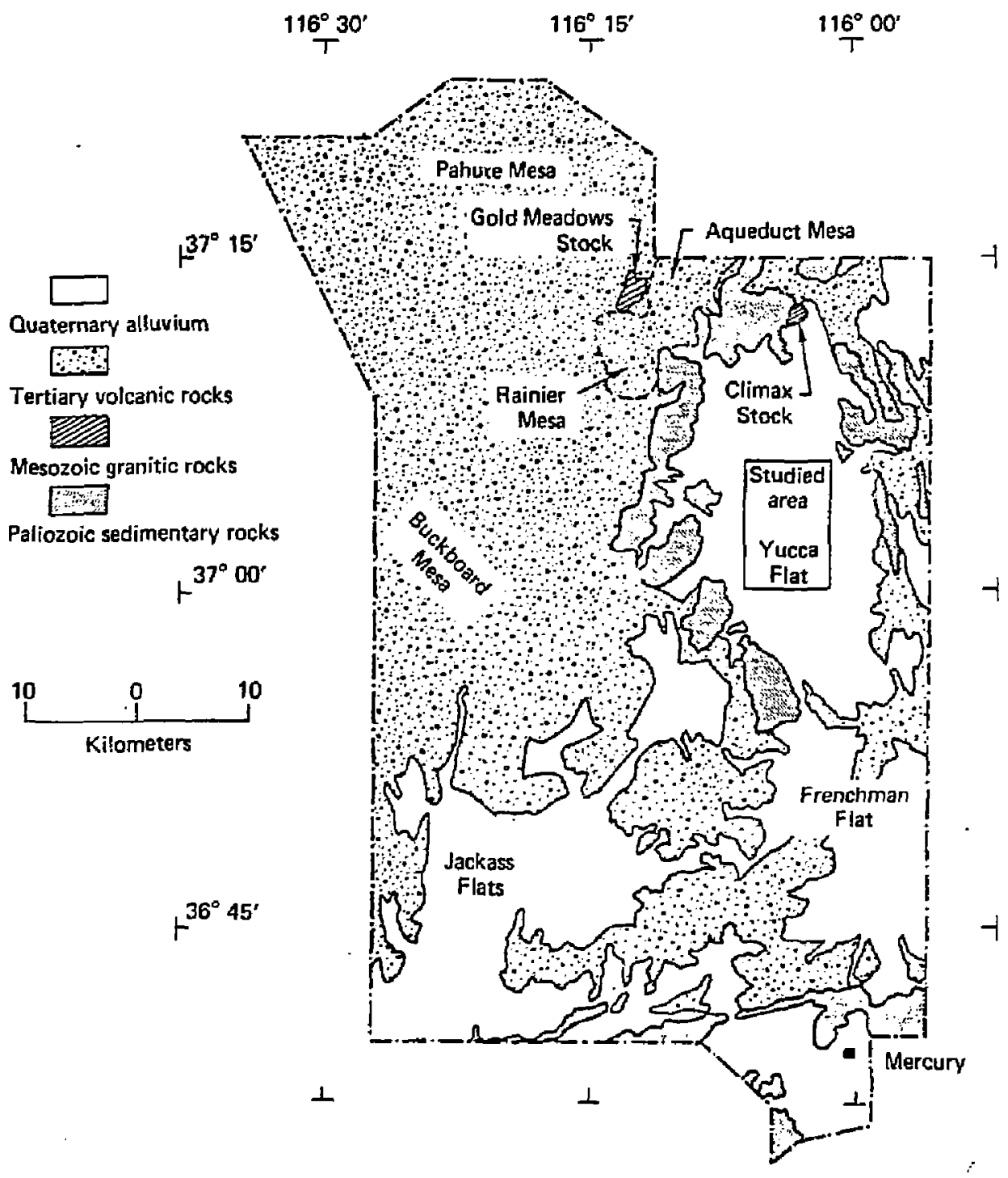

Figure 30. Map shows principal rock types and studied area at NTS.

(From Ramspott and Howard:[18]) 


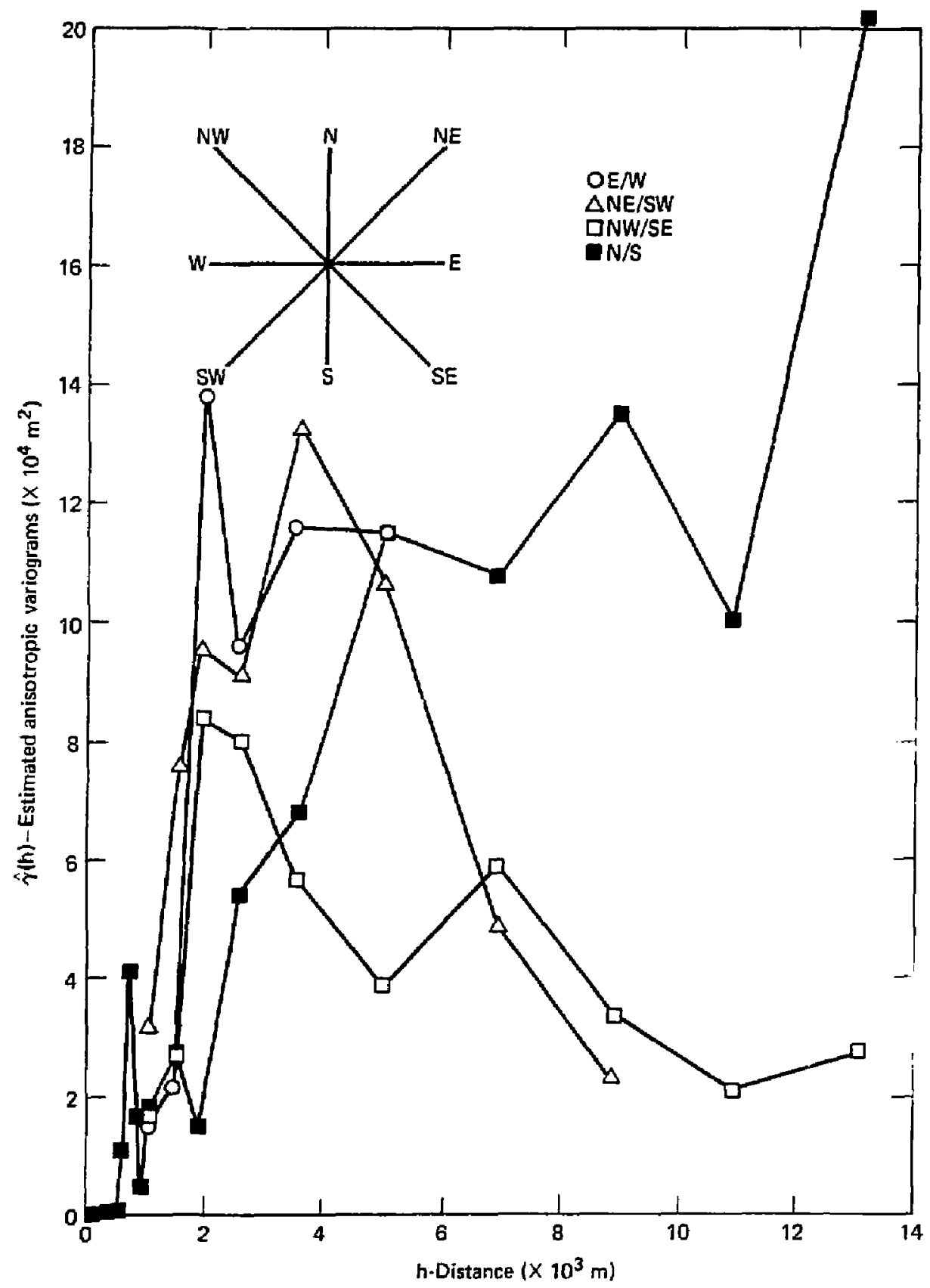

Figure 31. Anisotropic Variograms for Paleozoic Rock Depth at iTS 
TABLE $X$. NTS PALEULOIC ROCK JEPTH STRUCTURAL MUUEL SUMMARY

\begin{tabular}{|c|c|c|}
\hline TYPE & NUUEL & URLFT \\
\hline \multicolumn{3}{|l|}{ HITH FAULT } \\
\hline Generalized & & \\
\hline $\begin{array}{l}\text { Covariance } \\
\text { (Auto) }\end{array}$ & $k(n)=-4.4115 \mathrm{lhd}+2.1088 \times 10^{-6} 113 \mathrm{l}^{\mathrm{J}}$ & Linear \\
\hline $\begin{array}{l}\text { Linear } 1 \\
\text { Linear } 2\end{array}$ & $\begin{array}{l}r(h)=9.1|j| h \mid \\
r(h)=9.15 \ln \mid\end{array}$ & $\begin{array}{l}\text { Lonstant } \\
\text { Linear }\end{array}$ \\
\hline Spherical A] & $\gamma(h)=11700\left[\frac{3}{2} \frac{\operatorname{lh} 1}{2000}-\frac{1}{2}\left(\frac{\ln 1}{2000}\right)\right]^{3}$ & Constant \\
\hline Spherical $A 2$ & $\gamma(h)=11900\left[\frac{3}{2} \frac{\ln 1}{2000}-\frac{1}{2}\left(\frac{\operatorname{lin} 1}{2000}\right)\right]^{3}$ & $L$ inear \\
\hline \multicolumn{3}{|l|}{ WITHUUT FAULT } \\
\hline $\begin{array}{l}\text { Generalized } \\
\text { Covariance } \\
\text { (Auto) }\end{array}$ & $k(h)=-5.0885 \mathrm{IhJ}+2.7081 \times 10^{-6} \mathrm{IhI}^{3}$ & Linear \\
\hline $\begin{array}{l}\text { Linear } 1 \\
\text { Linear } 2\end{array}$ & $\begin{array}{l}x(n)=8.70 \ln 1 \\
x(n)=8.701 n 1\end{array}$ & lonstant \\
\hline Linear 3 & $\gamma(h)=9.15|h|$ & $\begin{array}{l}\text { Linear } \\
\text { Uuadrat id }\end{array}$ \\
\hline Spnerical Al & $\gamma(h)=11100\left[\frac{3}{2} \frac{\ln 1}{2000}-\frac{1}{2}\left(\frac{\ln t}{2000}\right)\right]^{3}$ & Constant \\
\hline Spherical AL & $\gamma(n)=10800\left[\frac{3}{2} \frac{\ln 1}{2000}-\frac{1}{2}\left(\frac{\ln 1}{2000}\right)^{3}\right.$ & Linear \\
\hline Spherical A3 & $r(n)=11200\left[\frac{3}{2} \frac{\ln 1}{2000}-\frac{1}{2}\left(\frac{\ln \mid}{2000}\right)\right]^{3}$ & Quadrptid \\
\hline Spherical 83 & $\gamma(h)=16800\left[\frac{3}{2} \frac{|\ln |}{3000}-\frac{1}{2}\left(\frac{\ln \mid}{3000}\right)\right]^{3}$ & Uuadratio \\
\hline Spherical $C]^{*}$ & $Y(h)=16800\left[\frac{3}{2} \frac{1 h 1}{3000}-\frac{1}{2}\left(\frac{\ln 1}{3000}\right)\right]^{3}$ & Const ant \\
\hline
\end{tabular}

*Orift Removed Residuals 
TABLE XI. NTS PALEOLOIC ROCX STRUCTURE IUENTIF ICATIUIN/VALIDATION

\begin{tabular}{|c|c|c|c|}
\hline TYPE & $\begin{array}{c}\text { STANUARUILEJ } \\
\text { ERROR }\end{array}$ & $\begin{array}{c}\text { RMS } \\
\text { ERROR (田) }\end{array}$ & $\begin{array}{l}\text { MEAN } \\
\text { ERROR }(\Pi)\end{array}$ \\
\hline 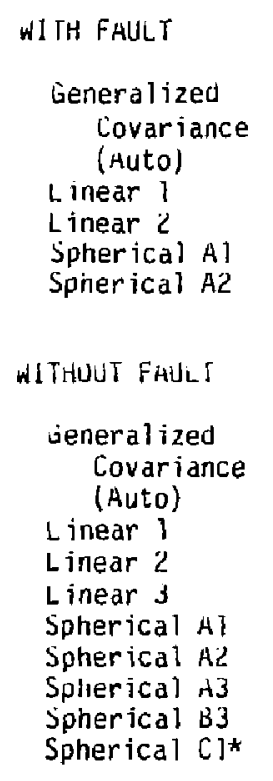 & $\begin{array}{l}0.991 \\
1.003 \\
3.012 \\
1.010 \\
1.004 \\
1.043 \\
1.005 \\
1.075 \\
0.941\end{array}$ & $\begin{array}{l}83 \\
73 \\
74 \\
77 \\
75 \\
73 \\
78 \\
79 \\
69\end{array}$ & $\begin{array}{r}-5.234 \\
-2.089 \\
-5.404 \\
0.508 \\
0.819 \\
-6.711 \\
-0.373 \\
0.332 \\
-0.403\end{array}$ \\
\hline
\end{tabular}

* Drift Removed Residuais 
correlation is assumed between them. Nevertheless, the kMS error from all models are not too different from the kils error of 77.8 il estimated froin gravity data based on 20 measurements of depth between 500 and $1000 \mathrm{~m}$.

The contour maps Dased on the estimated depth for both cases of with and without fault toyether with their uncertaiaty maps are snown in Figures 32 ta $3 b$. Two cross-sections running E-w denonstrate the effect of fault on the estinated depth (Figures 36 and 37) Although the estimated deptns show discontinuity near the fault, the contour routine smooths out these differences. The contour map has the gross features of a tnap based on gravity data, surface geology data as well as the borehole data. The color images of the depths are shown in Figures 38 and 39 . These figures dramaticaliy indicate the presence of the fault in the data.

The contour maps indicate a quadratic orift. We calculated this drift with a spherical variogram of range $3,000 \mathrm{~m}$ and $\mathrm{sill} 10,800 \mathrm{~m}$. The variograms of the drift removed residuals are shown in figure $4 v$. It is evioent that the anisotropy has been greatly reduced. The standard error for the drift removed residues (see Taole $x 1$ ) using the same initial variogram but constant orift is quite good (0.441) indicating that the estinated drfit is correct. 


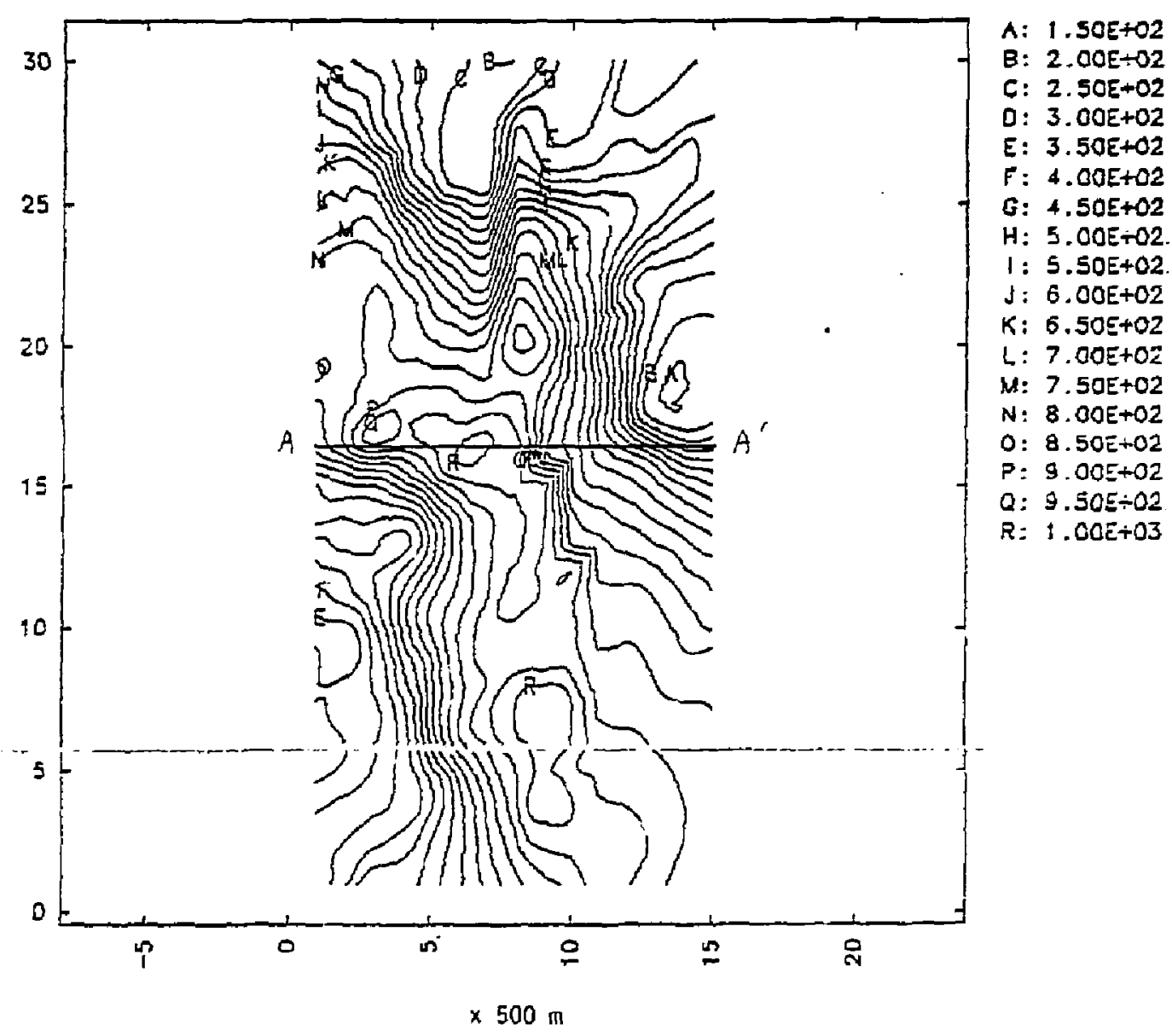

Figure 32. Paleozoic Rock Depth at NTS from Model Linear 1 ditn Fault 


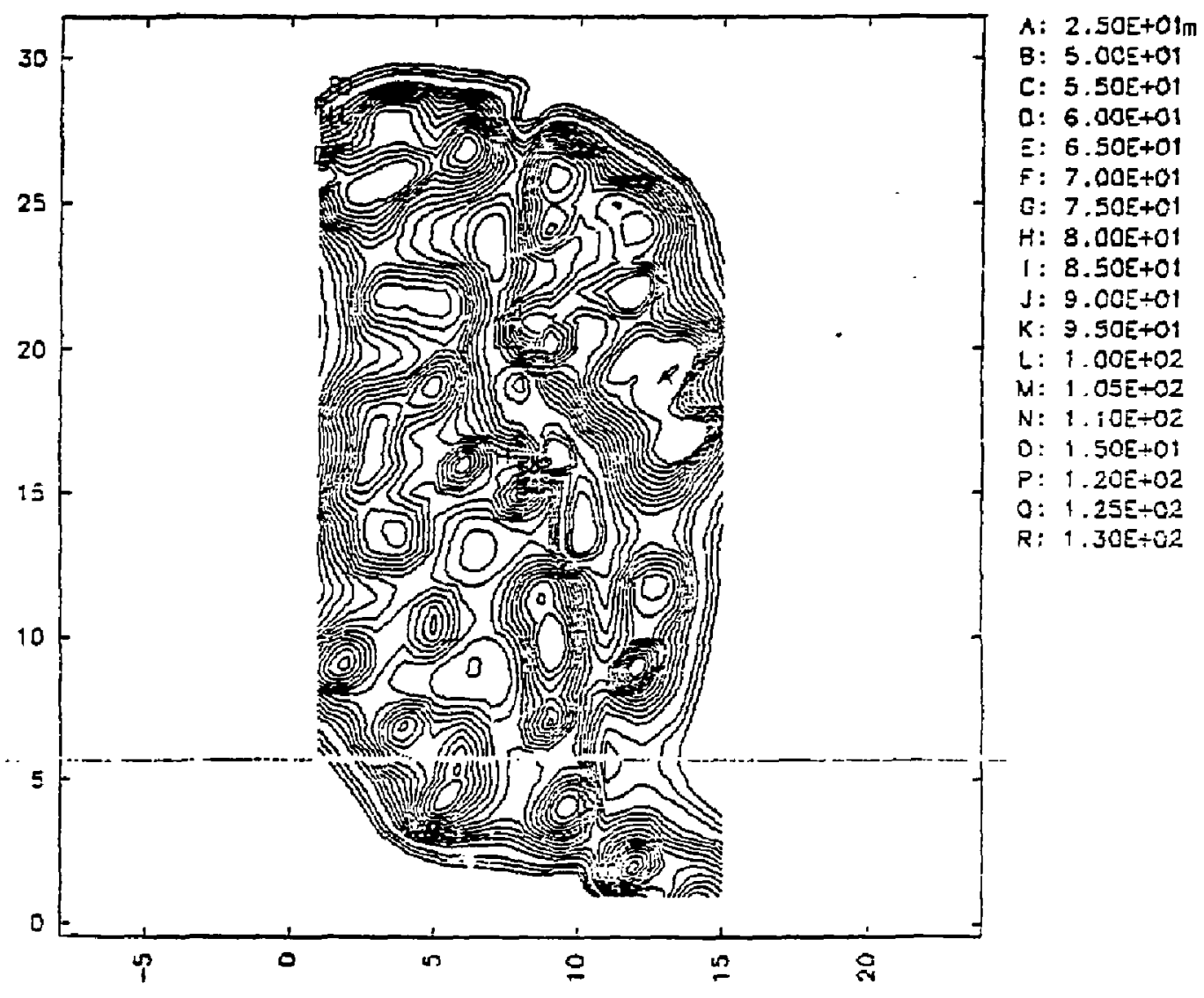

$\times 500 \mathrm{~m}$

Figure 33. One-Sigma Error for Paleozoic Rock Depth at UTS From dodel Linear l witn Faulc 


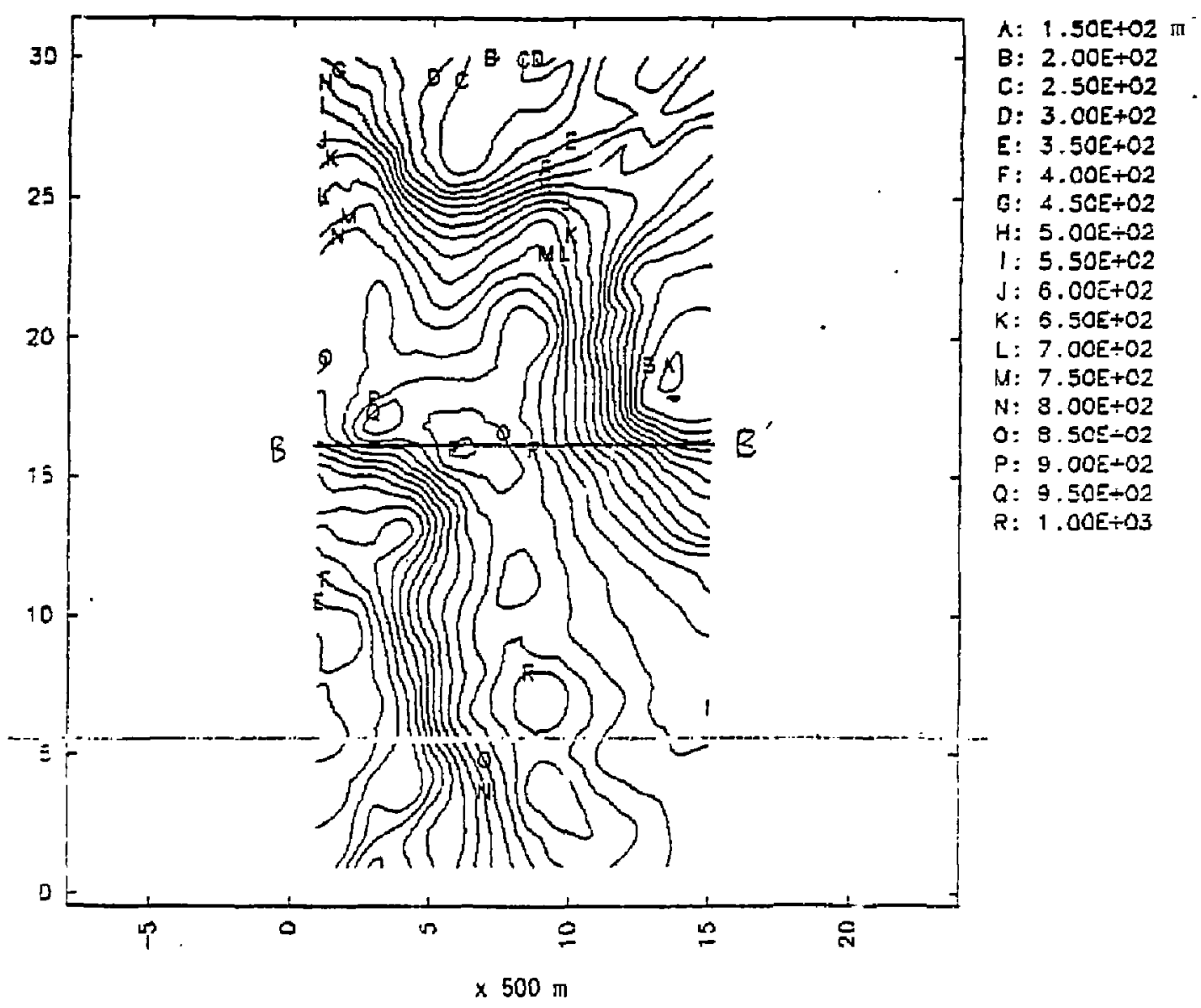

Figure 34. Paleozoic Rock Depth at NTS from Model Linear 1 witnout Faule 


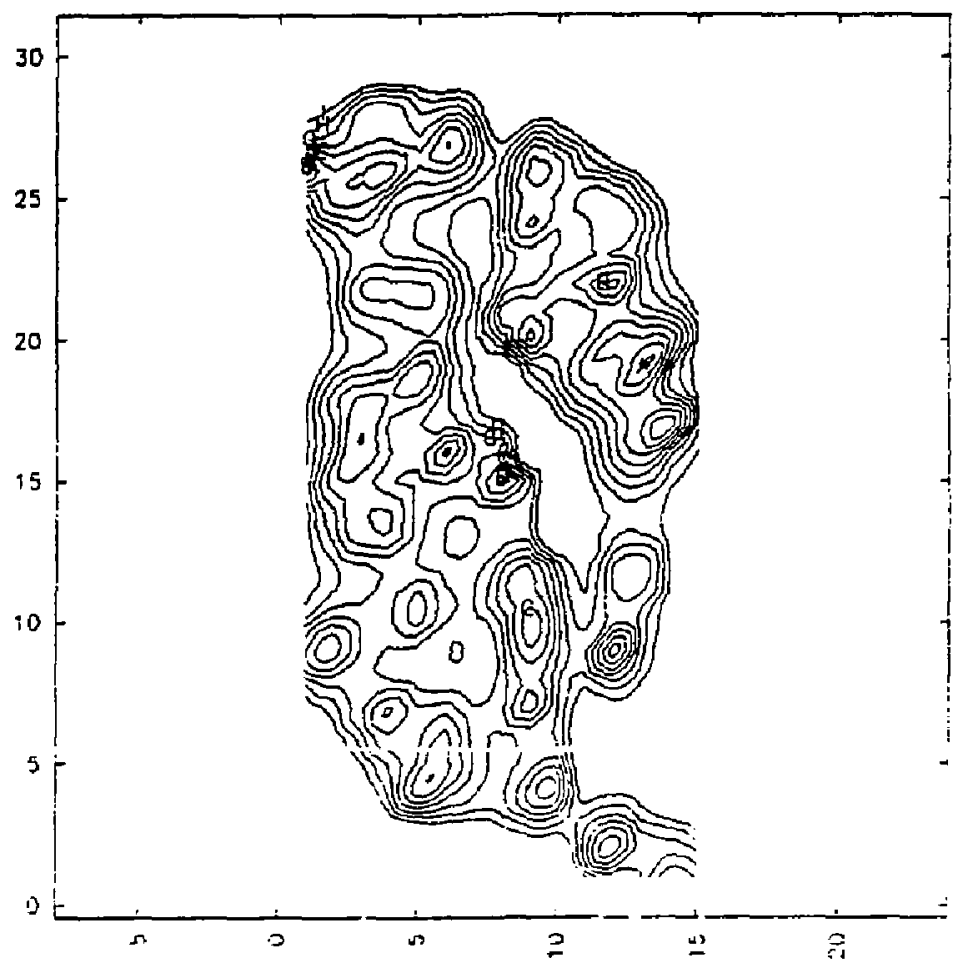

A: $2.50 E+C 1$

B: $3.50 E+01$

C: $4.50 \mathrm{E}+\mathrm{CI}$

D: $5.50 E+01$

E: $6.50 E+01$

$F: 7.50 E+0 i$

G: $8.50 E+01$

H: $9.50 E+01$

1: $1.05 E+C 2$

Figure 35. One-Sigma Error for Paleozoic Rock Depth at iTS from Model Linear I witnout fault 
Figure 36. Cross-Section of $A A^{\prime}$ in Figure 32
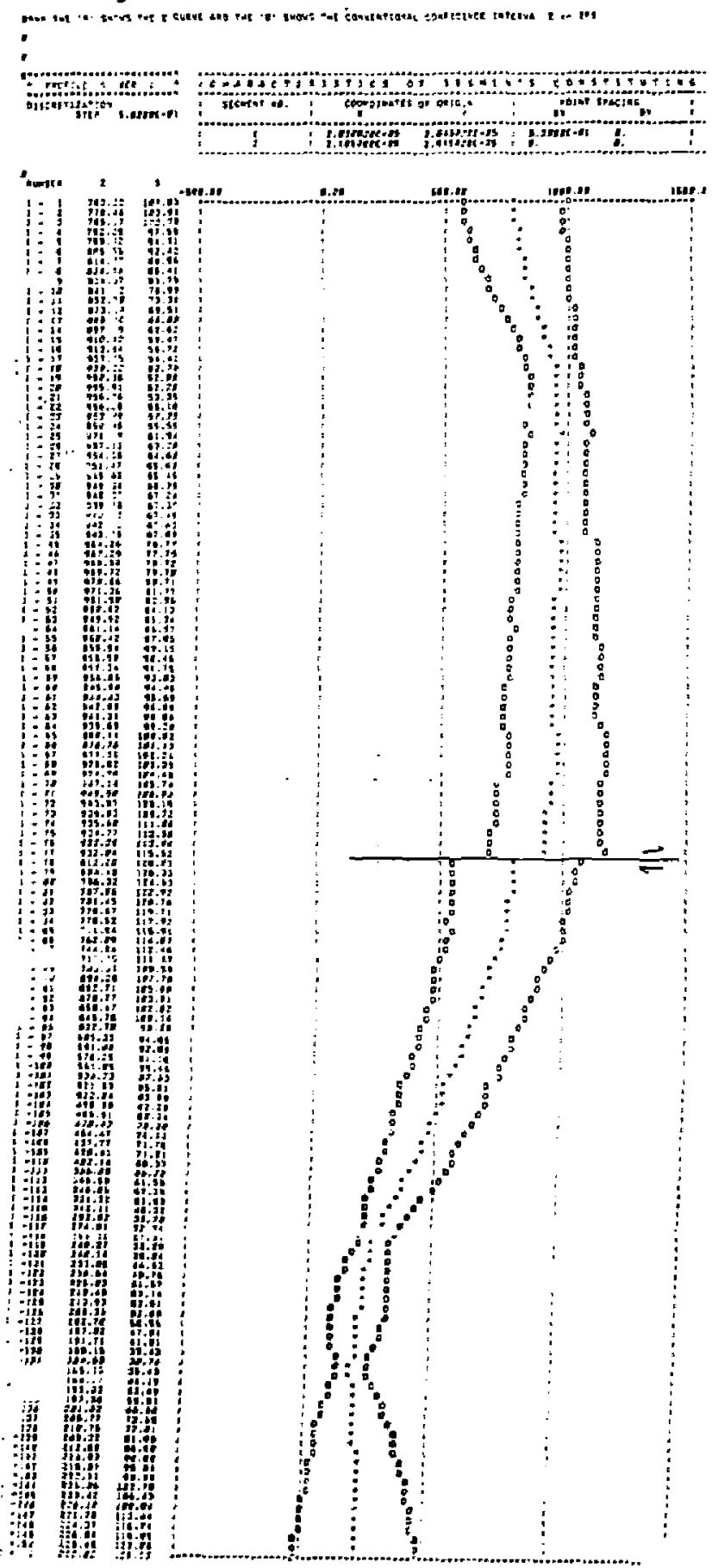
Figure 37. Cross-Section of BA' in Figure 35

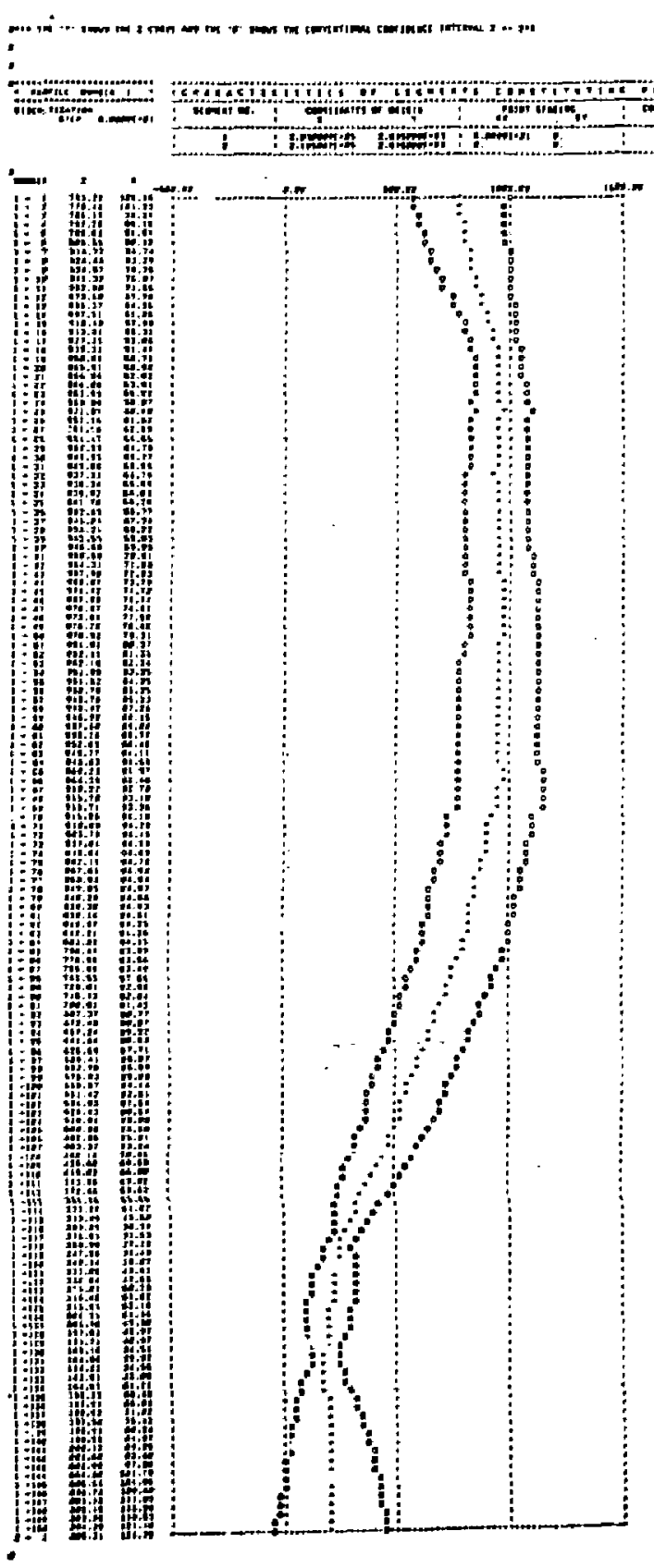


$-91-$

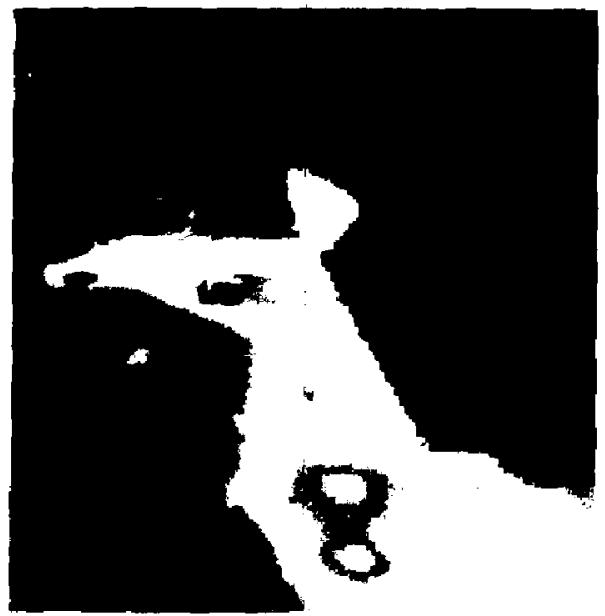

Figure 38. Pseudo-color image of paleozoic rock depth at the Nevada test site.
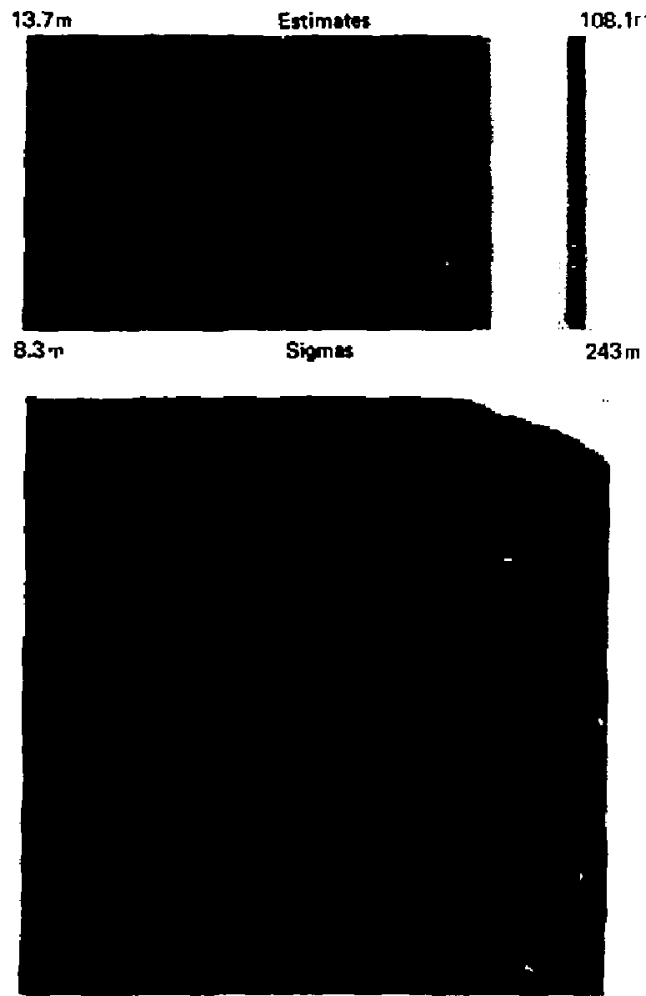

Figure 39. Pseudo-color image of one-sigme estimation errors of paleozoic rock depths at the Nevada test site. 


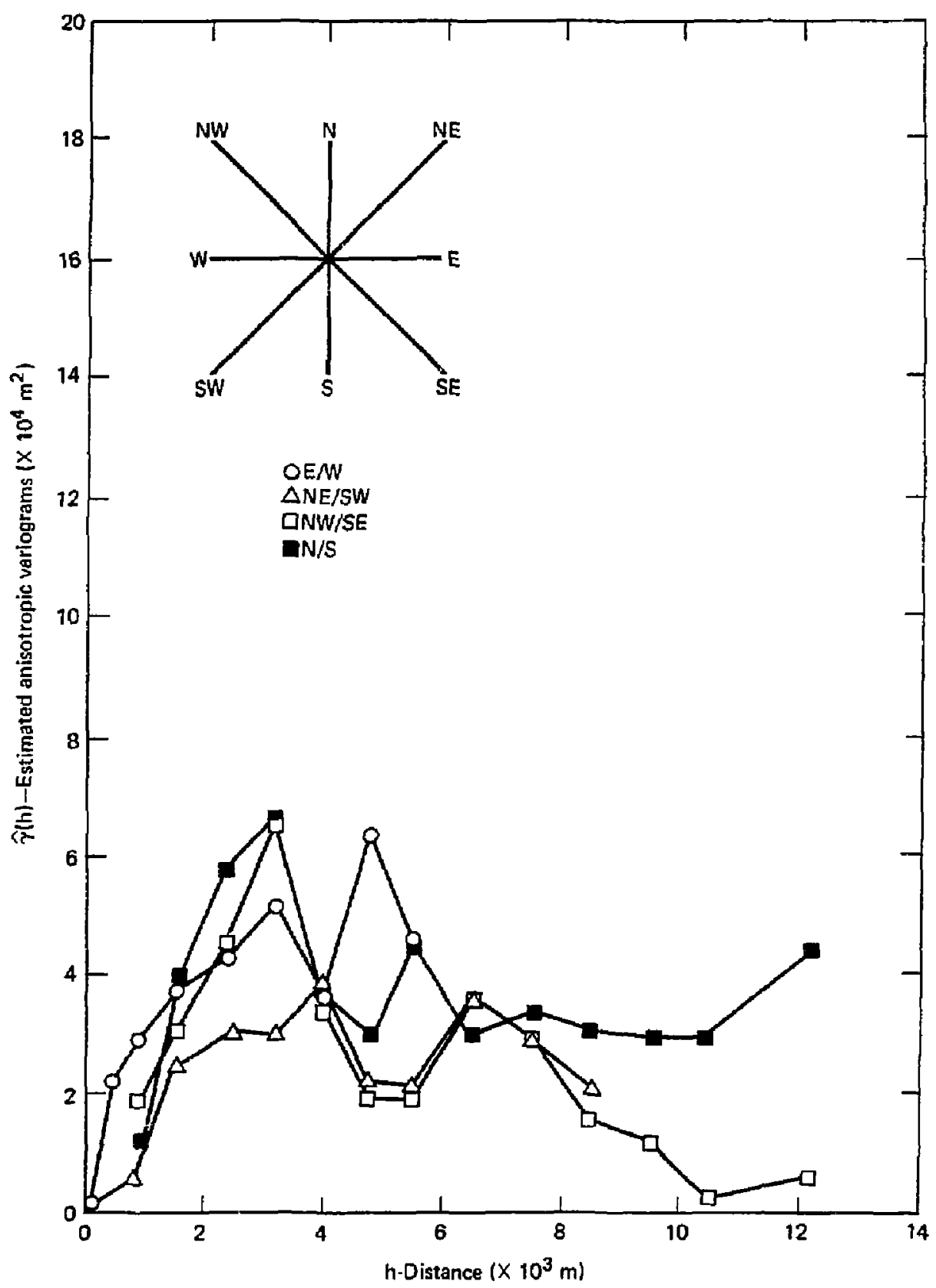

Figure 40. Anisotropic Variograms for Residuals of Drift-Corrected Paieozoic Rock Depth at NTS 
These calculations are prefiminary. They are presented nere to demonstrate the procedures and the potential of the technique. The structure for the rock depth is much more complicated than tnose from the two water level cases studied before. However, with simple linear variogram and constant drift, the Paleozoic rock depth can be reasonably reproduced.

There are many otber parameters in the NTS daca Dank. Furtner researcn of these parameters using the spatial estimation approach is needed. Tnis concludes tne application of spatial estimation techniques to simple groundwater aquifer system and complex geological forinations. In the next section we propose future researcn and application of this approach.

V. SUMMARY AND FUTURE WORK

In this report we developed spatial estimators for correlated data irregularily distributed in a region. Using tne well known reyionalized variade theory we were aole to (simply) develop the estimator using vector-inatrix calcuius techniques. Once the theory was developed, the practice of spatial estination was tnen discussed and it was snown that the most crucial area of spatial estimation is tne identification of the statistical structural mudel - tne variogram and drift. Techniques to estimate and ident ify the underlying yariogran and orift from raw data were djscussed and a valjdation 
teconique discussed. The code VARIFIT available at LLNL was used for tois iuentification.

Tne spatial estimators were applied to three case studies: (i) Toppenisn Creek Basin, (iij) Todd Lake, and (iji) Nevada Test site. Tne first two cases were simple yroundwater aquifers and tre final case was a complex geological formation. The spatial estimator yjelded reasonable contour illas of the reyions under investigation. I7 trie case of Todó Lake sparse ddta was taken froll a known "truth" grid. The estimated grid reconstructed from the sparse data set yields a maximum relative error of approxinately one percent. The complex NTS paleozoic rock deptn tilaps were generated witfl and witinut faules for comparacive purposes. It was snown that tne escimator perforined equally well. kesults of tile estinator aere confirmed of using additional information (gravity measurements). It was also Silown that image display techniques can de used to effectively investigate properties of regional inaps. Spatial estimation tecnniques can ce an effective tool to characterize proposed repository sites fron limbed data; nowever, mucn care must de taken when identifying the structural model from tne raw data.

There is still more work wnicn must ve completed to evaluate tre potential of applying tnis particular spatial estimation technique. The suosequent list snows areas which must de jllvestigated or developed furtner: 
1. Structural model identification;

2. Spatial estimacion conoining various types of ddta;

3. Extension of punctual paraneter estimates to volumetric estimates;

4. Design of optimal measurement netwarks;

5. Grid simulations froul a given data set witn known statistical properties;

o. Development of interactive data display tecnnigues; and

7. Deveiopinent of nydrogeological parameters used model-based estination tecnniques.

The identification of a structural model from various oata sets is the most crucial aspect of Ine spacidl estination tecnnique due to tne need to first identify the orift and cnen cnaracterize tne variogram. The tecnnique using generdiled covariances is a comprolitise ili that models are fit to "arift-free" data after successive differencing. Altinough this technique appears to jive reasonade results most intujcion is lust in the process. The idencification prodten formulated from tne parametric optimization viewpoint fapplying various tneoretical models) may prove to yiela nore satisfying results.

The conoination of more measurement information in the spatial estinlation provlen will yield mure reliable rasults. For example, comoining various measurements i ike borenole data along witn seismic measurements $j n$ the site coldracterizatiun problen snould produce 
better results. Similar provlems nave been approached in different areas and snould be inyestigated further [a].

The extension of punctual paranetric estinates to volumetric estimates flas been investigated tnoroughly and applied to grave estimation in the mining industry $[4]$. These techniques appear quite reasonable in the site characterization problem. For example, the extension of porosity estimated measured in a core can be extended to a olock using the existing theory. We feel that this tecnnique snould be investigatad on a given data set.

The optimization of a measurenent network based on the error variances predicted by tne spatial estimator snould be investigated. In this case the variance of the estinator can de used as an index to determine the optimal location of a possiole additional measurement point $[10\rfloor$. Model-Dased estination tecnniques can also oe used in tnis application and snould also be investigated.

The ability to simulate a given regian. witn the sane structural variaoility passing through the measurenent points can provide valuable information aoout areas where litcle information is presenc 110j. The various simulations depict possible variations of the true area. Generation of many simulations can serve to produce an average of the results and generate more conf idence. 
The development of effective inceractive display tecmiques provide a valuable tool to the NRC site andyst oy proviuing d geologic structure. These cecmiques can de improved furcmer to simultaneuus display estinate grid values and uncertainty maps. Tnis cecnnique would prove very useful when used in conjl:nction witn an optimal measurenent design.

Findily, the feasivility of using mudel-oased estinators to arrectly estimate tne madel paraneters from noisy measurements nas ween demonstrated for temporaly correlated data $L 14 \mathrm{~J}$. These techniques are buite powerful and rep!dce tile scruccurat mudel witı a pnysicai phenomenological model (e.g., gruuldwater flows). We feel tilat tnese tecnniques snould de compared fur a generated data set.

In sumbary, we feel that the application of moderu spatial estimacion cecnniques to spatialiy correlated medsurenent data can provide a useful toor in the akC sice cllaracterizaciun and evaluation process. The spatial estimator applied in cnis report yields reasonable results fur the Jata sets investigaced. Hore ;urk masc de perforned (1) isted above) Defore the final anaiysis can de cumpleted. 


\section{ACKNOWLEDGEMENTS}

We would like to thank Mr. 0. Freeman for nelping us with iluch of the computer work done in this repurt and Dr. W. Hurray wno consulted on the Todd Lake data. We would also like to tnank Mr. J. Shriyan of UjGS for nis kriying algoritnm, Toppenisn Creek data set and Iliany tecnnical discussions on tilis suuject. We would finally out oy no means least like to cnank its. L. Lopez for typing the manuscript. 


\section{LIST OF REFERENCES}

[1] ל. .

[2] U. P. hisnoy at al., "Jerivacion of Paramezers Hecessary for tne Evaluation of Perfurinance oi sites for veep Geological Repositories witn Refurence tu bedded Salt," Lawrence Liverinore National Lavoratory kepork, Jith-lolob, vol, 1, Tyly.

L3. H. Uavia, Geostatiscal Ore Reserve Estimation, Elseviar, the Netmerlarids, 1977.

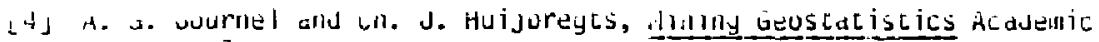
press, 1970.

Loj d. Adenerun, "Tile Tneory of kegiondized Variaules and I miplicatiuns," Les Caniers du Centre de murpmuloyte Matmenatique, $11^{\circ} 5$, ccole idd. sup. Ues lithes de paris, iy/l.

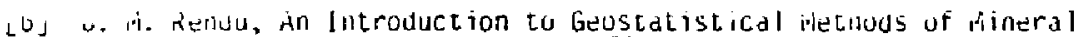

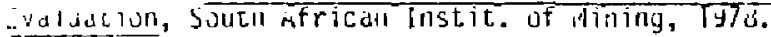

Ll P. Welfiner, "basic Introduction to geostatistics," Cuurse woles, daltella jedct le Researcll Celuter, Octooer ly/y.

Lú J. P. Cniles, P. Delfiner, A. Narecilal, and G, ilatneron, "Speciallzed iecnniques of Geostatistics," Course Nates, Battelle, Seattle kesearcn Center, uctuver lyly.

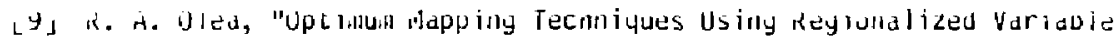
Tneary," Kansas Geological Survey, ly75.

¿ijJ J. P. Jelnumme, "krtiging in tne nydrosciences," Advances in water Resources, vol. 1, 1y/8.

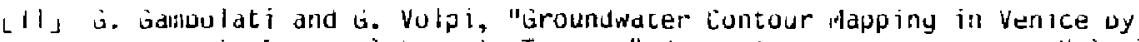
stochast ic Interpolators 1 . Theury," water kesources kesearcn, Vol. 15, $\mid y / y$.

LILJ P. L. Juctur, "Äl Evaluation Jf kriyilly Tecmlyues fur llign Level Kauiuactive Waste Repusicory site inaracterizatiul," Pdcific ild Lad repurt, PNL-LYUSJUL-/U, JyTy.

L13 J G. P. Box and B. H. Jethins, Iume Series Allalysis, Huluen-Day, San irancisto, ly\%o.

Ll4; 3. 6. Azevedo et al., "Paralleter ldentification ill bruundwater Flow: A Feasivility Study, Lawrence Livernore itationd] Lavoratory Report, ULiv-lós7s. isou. 


\section{LIST OF KEFEREANCES (continued)}

[lb] J. H. Skrivan ana M. R. Karlinger, "Semi-Variogram cstimation and Universal Kriging Progran," Water Resources Uivision, UsGS, Tacoma, Washington, 1980 .

Lloj P. Uelfiner, J. P. Uelhome, and J. P. Cniles, BlutePrick, Ecole ivationale superieure les mines de Paris, 1976.

[17」 N. W. Howard, (ly7y), LLL K Jivision Nuclear Test Effects and beoigoical Vata base: Gilossary and Parameters vef initions $\langle V\rangle$, UClD-losuo Part $l$, $71 \mathrm{p.}$

[1J] L. U. Kanspott and W. W. Howard (197J), Average Properties of Nuclear lest mreas and lledia at tne Jscrum Nevaca lest site, UlKL-bly48, $37 \mathrm{p}$.

[19] R. Deutsch, Estimation Theory, Prentice-Hall, N. J., 1965.

[Zu] b. Moble and j. Daniel, Applied Linear Algebra, Prentice-Hall, ì.J., $147 i$. 
$-103-$

APPENDILES 
APPENUIXA

SPATIAL AND BRIFT ESTIMATION THEQRY

In this Anpendix we derive the necessary equations for spatial and drift estination reporteo in Section 11. Here we use tre vector-inatrix calculus techniques of Apperdix $B$ and $C$ to derive the estimators. First we derive the vasic spatial (kriging) estilnator in Section A-l and then the drift est imators in $A-2$ and $A-3$.

\section{A-I. Spatial Estikation Theory}

The spatial estimation problen can de solved using optionization tneory results oy formulating the proolem properly. Hore we show how to sulve the prodem using Lagrange multiplier techniques. To De more precise, we would like to find the inear estimator

$$
\hat{z}\left(\underline{x}_{k}\right)=\sum_{i=1}^{N} \lambda_{i} z\left(\underline{x}_{i}\right)=\underline{\lambda}^{\top} \underline{z}
$$

where $\underline{\lambda}^{\top}:=\left\lfloor\lambda_{1} \ldots \lambda_{\text {fid }}\right\rfloor$ and $\underline{z}^{\top}:=\left\lfloor z\left(\underline{x}_{1}\right) \ldots z\left(\underline{x}_{i v}\right)\right\rfloor$

sucr tnat

$$
E\left\{z\left(\underline{x}_{k}\right)-\hat{z}\left(\underline{x}_{k}\right)\right\}=0 \quad \text { (undiased) }
$$


and

$$
\sigma_{k}^{2}=\operatorname{Var}\left\{z\left(\underline{x}_{k}\right)-\hat{z}\left(\underline{x}_{k}\right)\right\} \text { is mininum (minimum variance) } \text {. }
$$

The unbiased constraint, sometimes called the universality condition (unconditionally unoiasedness) leads to tne following non-bias constraint

$$
\sum_{i=1}^{N} \lambda_{i} f^{j}\left(\underline{x}_{i}\right)-f^{j}\left(\underline{x}_{k}\right)=0^{\dagger} \quad j=0, \ldots, M
$$

which is ootained by solving $(A-2)$ with $(2.6)$ and $(2.7)$ and

$$
E\{z(\underline{x})\}:=m(\underline{x})
$$

To minimize the variance of $(A-3)$ subject to tne constraint of $(A-4)$, we use the Lagrange multiplier tecinique. First, we define the function $\mathrm{d}$ in terns of the Lagrange multipliers $\left\{\mu_{j}\right\}, j=0, \ldots$, M

t It is important to note that tnis constraint is independent of the $\left\{a_{j}\right\}$, $j=0, \ldots, M$ of $(2.4)$ and therefore, the actual drift coefficients need not be estimated! 


$$
\begin{aligned}
& J(\lambda, \mu)=\operatorname{Var}\left(z\left(\underline{x}_{k}\right)-\dot{z}\left(\underline{x}_{k}\right)\right) \\
& -2 \sum_{j=0}^{M} \mu_{j} \sum_{i=1}^{N} \lambda_{j} f^{j}\left(\underline{x}_{j}\right)-f^{j}\left(\underline{x}_{k}\right)=0
\end{aligned}
$$

but

$$
\begin{aligned}
& \operatorname{Var}\left(z\left(\underline{x}_{k}\right)-\hat{z}\left(\underline{x}_{k}\right)\right)=2 \sum_{i=1}^{N} \lambda_{i} \gamma_{i k}-\sum_{i=1}^{N} \sum_{\ell=1}^{N} \lambda_{i} \lambda_{\ell}\left(\gamma_{i \ell}-\sigma_{\varepsilon}^{2}(i)\right) \\
& \text { where } \left.\gamma_{i \ell}:=r \underline{x}_{i}-\underline{x}_{\ell}\right):=\operatorname{Var}\left(z\left(\underline{x}_{i}\right)-z\left(\underline{x}_{l}\right)\right\}=\operatorname{variogran} \text { at }(i, l) \\
& \text { and recall } \sigma_{E}^{2}(i)=\operatorname{Var}\left(\varepsilon\left(\underline{x}_{j}\right)\right)
\end{aligned}
$$

or

$$
\sigma_{k}^{2}=\operatorname{Var}\left(z\left(\underline{x}_{k}\right)-\hat{z}\left(\underline{x}_{k}\right)\right)=2 \underline{\lambda}^{\top} \underline{x}_{k}-\underline{\lambda}^{\top}(\Gamma-\Sigma) \underline{\lambda}
$$

where

$$
\underline{\lambda}^{\top}:=\left[\lambda_{1}, \ldots, \lambda_{N}\right] ; \underline{Y}_{K}^{\top}:=\left[\gamma_{1 k} \ldots \gamma_{M K}\right] ; \text { and } \Sigma=\operatorname{aiag}\left[\sigma_{E}^{L}(1) \ldots \sigma_{E}^{2}(i)\right]
$$




$$
\begin{aligned}
& \text {..108- }
\end{aligned}
$$

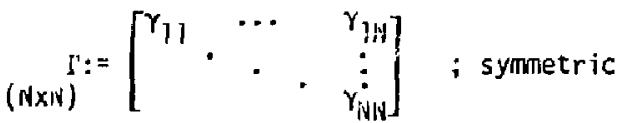

we can also write the constraint $(A-A)$ in vector-matrix form as

$$
F^{\top} \underline{\underline{\lambda}}-\underline{f}_{k}=\underline{U}
$$

where

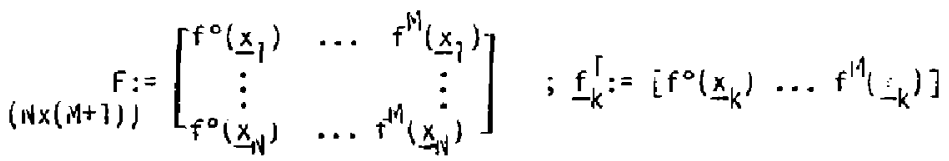

Using $(A-7)$ and $(A-8)$, we can rewrite $(A-5)$ in vector-matrix notation, i.e.,

$$
J(\underline{\Lambda}, \underline{\mu})=2 \underline{\lambda}^{\top} \underline{Y}_{k}-\underline{\underline{\Lambda}}(\Gamma-\Sigma) \underline{\lambda}-\left\langle\underline{\underline{\mu}}\left(F^{\top} \underline{\lambda}-\underline{f}_{k}\right)\right.
$$

and $\underline{\mu}^{\top}:=\left[H_{j} \ldots H_{\mathrm{m}}\right]$

The function $J$ is minimized by differentiating (see Appendix B) with respect to the $\lambda^{\prime} s$ and $\mu^{\prime} s$, setting the results to zero and solving, i.e., 


$$
\begin{aligned}
& \frac{\partial J}{\partial \underline{\lambda}}=2 \underline{I}_{k}-(I-\Sigma) \underline{\lambda}-\underline{2} \underline{\underline{\mu}}=0 \\
& \frac{\partial J}{\partial \underline{\underline{\mu}}}=-2\left(F^{\top} \underline{\lambda}-\underline{f}_{k}\right)=0,
\end{aligned}
$$

a set of $(N+M+1)$ linear equations for $\underline{\lambda}$ and $\underline{\mu}$. Thus, we have to solve for

$$
\mu \underline{\theta}=\underline{D}_{k}
$$

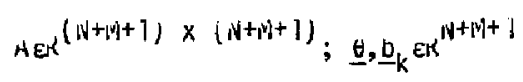

or

$$
\left[\begin{array}{c:c}
\Gamma-L & F \\
\hdashline F^{T} & U_{H+1}
\end{array}\right]\left[\begin{array}{c}
\underline{x} \\
- \\
\underline{\mu}
\end{array}\right]=\left[\begin{array}{c}
\underline{x}_{k} \\
-- \\
\underline{f}_{k}
\end{array}\right]
$$

Solving the linear equation of $(A-11)$ gives the "optimal" weights $\left(\left\{\lambda_{j}\right\},\left\{u_{j}\right\}\right)$ of the spatial estinator. Using tnis relation we can rewrite $(A-7)$ in terms of the optimal solution. Premultiplying the first equation of $(A-11)$ by $\underline{\lambda}^{\top}$ we can replace the second term of (A-7) after substituting the second equation of $(A-11)$ to odtain 


$$
\sigma_{k}^{2}=\underline{\theta}^{\top} \underline{a}_{k}
$$

Thus, a solution to the spatial estimation problem is yiven by the linear, unbiased, minimum variance estimator ${ }^{\dagger}$

$$
\left.\hat{z}\left(\underline{x}_{k}\right)=\sum_{i=1}^{N} \lambda_{j} z \underline{x}_{i}\right)=\underline{\lambda}^{\top} \underline{Z}
$$

where the $\lambda_{i}$ 's are the solution of $(A-11)$ given by

$$
\underline{\lambda}=(\Gamma-\Sigma)^{-1}\left[\left(I+F \Delta F^{\top}(\Gamma-\Sigma)^{-1}{ }_{Y_{k}}-F \Delta f_{k}\right]\right.
$$

and

$$
\Delta=-\left(F(r-z)^{-1} F\right)^{-1}+t
$$

The assocjated error variance is given by $(\dot{A}-12)$. Inus, the technique generates poinc estinates $\hat{z}\left(\underline{x}_{k}\right)$ and a measure or tine precision $\sigma_{k}$.

†Historically this is called the "kriging estimator" in honor of U. G. Krige, a mining engineer who applied statistics to ore estimation. The technique without measurement errors is called "universal kriging," since it removes the trend as well (see $[3,4]$ for details).

tt see Appendix $C$ for details. 
In the next section we discuss the provlem of urift escindtion dna snow now it can also de used alternately to solve tne spatial estimation provlem.

\section{A-II. Drift Estimation Theory}

In tinis section, we solve the drift estination proden - first, fur punctual drift estinates and second for regional drifts. We follow the tecmique of Lagrange multipliers used in Seccion A-I.

\section{A-II-I Punctual Drift Estialation}

As vefore this pronlem $c$ an de formulated as finding the linear, minimum variance, unojased estimate

$$
\hat{n}(\underline{x})=\sum_{j=1}^{N} \lambda_{i} z\left(x_{j}\right)^{\dagger}
$$

such that

THere we use tne same notation as vefore to only snow tnle matnematical similarity of the prodeins. 


$$
E\{m(\underline{x})-\tilde{m}(\underline{x})\}=0 \quad \text { (unoiased) }
$$

and

$$
\sigma_{M}^{2}=\operatorname{Var}\{m(\underline{x})-\dot{m}(\underline{x})\} \text { is minimuln (Ininimum variance) }
$$

The unviasea condition leads to the constraint of (A-4) wnicn can be expressed in vector-matrix notation as before

$$
F^{\top} \underline{\underline{k}}-\underline{f}_{k}=\underline{v}
$$

Similarily, the variance can be expressed as

$$
\sigma_{M}^{2}=\underline{\Lambda}^{\top}(r-\Sigma) \underline{\lambda}
$$

We define tne function to be minimized as a function of the variance and unviased constraint of $(A-16),(A-17)$

$$
L(\underline{\lambda}, \underline{\underline{L}})=\underline{\lambda}^{\top}(\Gamma-\Sigma) \underline{\lambda}-2 \underline{\mu}^{\top}\left(F^{\top} \underline{\lambda}-\underline{f}_{K}\right)
$$

Performing the required minimization $\left(\frac{\partial L}{\partial \lambda}, \frac{\partial L}{\partial \underline{\underline{\mu}}}\right)$ as in Appendix $B$ we abtain the set of linear equations similar to $(A-i B)$ 


$$
\underline{\underline{n}}=\underline{3}_{k}
$$

where

$$
\begin{aligned}
& \mathrm{U}:=\left[\begin{array}{lll}
\Gamma-\Sigma & 1 & \xi \\
& 1 & \\
\hdashline F^{\top} & a_{H+1}
\end{array}\right] ; \\
& \underline{n}^{i}=\left[\underline{\lambda}^{\top}: \underline{\mu}^{\top}\right\rfloor ; \underline{\underline{s}}_{k}^{\top}=\left\lfloor\underline{U}_{l}^{\top}: \underline{f}_{k}\right\rfloor
\end{aligned}
$$

Solving this set of linear equations yield the optinal point orifc estimate

$$
i\left(\underline{x}_{k}\right)=\sum_{i=1}^{N} \lambda_{j} z\left(\underline{x}_{j}\right)=\underline{\lambda}^{\zeta} \underline{L}
$$

winere

$$
\underline{\lambda}=-(I-\Sigma)^{-1} F\left(F^{\top}(I-\Sigma)^{-1}\right)^{-1} \underline{f}_{k}+
$$

with error variance as before

$$
\sigma_{i d}^{2}=\eta^{\top} \underline{B}_{k}=\mu^{\top} \underline{f}_{k}
$$

†ee Appendix $i$ for details. 
Estinates of $\left\{a_{j}\right\}$ can easily ue found from

$$
\hat{n}\left(\underline{x}_{x}\right)=\underline{f}_{k}^{\top} \underline{\hat{a}}
$$

or letting $k=1, \ldots, N$

$$
\underline{i n}=F \underline{a}
$$

Solving $(A-1 d)$ for $d$ it is easy to show that

$$
\underline{\underline{\underline{H}}}=\underline{A^{\top}} \underline{\underline{L}}=\left(\underline{f}_{K}^{T} w\right) \underline{L}
$$

where

$$
W e^{(i M+1) \times W} \text { and } W=\left(F^{T}(T-\Sigma)^{-t_{F}}\right)^{-t_{T}} F(\Gamma-\Sigma)^{-1}
$$

From $(A-2 U)$ and $(A-2 T)$ the orift coefficients can de aotained as

$$
\underline{\hat{a}}=\omega \underline{L}
$$

with 


$$
\operatorname{Cov}(\underline{a}-\underline{a})=\left(F^{\top}(\Gamma-L)^{-1}+\right)^{-1}
$$

This completes the results for punciual drift estimation, in the next section we consider the regional case.

\section{A-II.2 Regional Orift Estimation}

Following the sane strategy for "regional" drif c, i.e., one drift function to model the trend of the entire reglon, it is possiole to derive sinilar equations to $(A-1 B)$. Tnus, to estimate r rift over a region wa must construct

$$
\operatorname{in}(\underline{x})=\sum_{i=0}^{11} \hat{\alpha}_{j} f^{i}(\underline{x})=\underline{\hat{\alpha}}^{\top} \underline{f}
$$

The relation implies that we must calculate the $\left\{a_{s}\right\} s=0, \ldots$, in and $\forall(\underline{x})$ is tne drift of $z(\underline{x})$ for any $\underline{x}_{i}$ sucn that $\left|\underline{x}-\underline{x}_{i}\right| \leq$ $\rho$ where $\rho$ defines tne regional neighoorhoov. We assume that is punctual samples of $2(\underline{x})$ at $\underline{x}_{j}, j=1, \ldots, N$ are drawn. We define $N$ estimates $\hat{\alpha}_{s}$ for eacn $\alpha_{s}$ willich are a linear combination of the $N$ sanples inside tne neignournood of radius $r$ around sune $\underline{x}_{k}$, i.e.,

$$
\hat{u}_{j}=\sum_{i=1}^{N} \lambda_{i}^{s} z\left(\underline{x}_{j}\right)=\underline{\lambda}_{s} \underline{z} \quad s=0, \ldots, i
$$


subject to the usual undiased, minimum variance constraints. The undiasedness condition leads to

$$
F^{T}{\underline{\lambda_{s}}}_{-\underline{e}_{s}}=0 \quad \text { for each } \alpha_{s}, s=0, \ldots, M
$$

and $\underline{e}_{s}$ a unit column vector.

The $\cos \tau$ function Decomes for eacn $s$

$$
\left.R_{S}\left(\underline{\lambda}_{s}, \underline{\mu}_{S}\right)=\underline{\lambda}_{s}^{\top}(]^{\prime}-\tilde{\Sigma}\right) \underline{\lambda}_{s}-2 \underline{\mu}_{s}^{\top}\left(F^{\top} \underline{\lambda}_{s}-\underline{e}_{s}\right), \quad s=0, \ldots, M
$$

After minimizing $(A-2 b)$ as in Appendix $C$, we obtain

$$
D_{\Phi_{s}}=\underline{\xi}_{s}, \quad s=0, \ldots, n
$$

where 0 is given in $(A-18)$ and

$$
\begin{aligned}
& \underline{\Phi}_{S}^{\top}=\left[\underline{\lambda}_{S}^{\top}: \underline{\underline{w}}_{s}^{\top}\right], \quad s=0, \ldots, H \\
& \underline{\xi}_{S}^{\top}=\left[\underline{Q}_{N}^{\top}: \underline{e}_{S}^{\top}\right\rfloor
\end{aligned}
$$

The optimal weignt vector of $(A-24)$ is given by 


$$
\underline{\lambda}_{s}=-(\Gamma-\Sigma)^{-1} F\left(F^{\top}(\Gamma-\Sigma)^{-1} F\right)^{-1} \underline{e}_{s} t
$$

Thus solving $(A-27), M+1$ times we odtain estinates for $\left\{\alpha_{s}\right\}$ and the corresponding error variance is given by

$$
\sigma_{\alpha_{s}}^{2}=\varphi_{s}^{\top} \epsilon_{s}=\nu_{s}^{s}
$$

Once the $\left\{\alpha_{s}\right\}$ are estimated the drift can de removed from samples and the residuals can de estimated using simple spatial estination tectnniques as before. Tnis completes the theoretical discussion on spatial estimation tneory, we sumarize tne results in Table 1.

+ See Appendix $\iota$ for details 
APPEINDIX B

\section{MATRIX CALCULUS RULES}

In tnis Appendix we define tne dasic rules of inatrix calculus which are required in tnis work. These results are taken from Deutsch [y]. First we define the gradient vector operator

$$
\partial /_{\partial \underline{\theta}}^{\top}:=L \partial / \partial \theta_{1} \cdots \partial / \partial \theta_{N} J \text { for } \partial / \partial \underline{\theta} \mathbb{R}^{N}
$$

and $a, v R^{N}, C_{0 R}{ }^{k+i t}$.

The gradient operation on a vectur $\operatorname{ge}^{N}$ dilu inatrix $c$ is

$$
\therefore / \partial \underline{a}\left(\underline{\theta}{ }^{\top} C\right)=C \text { for } C \text { not a function of } \theta
$$

and for a vector $\underline{0}$

$$
\partial / \partial \underline{\theta}\left(\underline{\theta^{\top}} \underline{\theta}\right)=\underline{0} \quad \text { for } \underline{b} \underline{\text { not a function } \theta}
$$

and finally the "cnain rule"

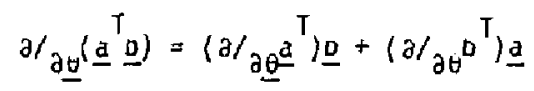

for $\underline{a}, \underline{0}$, functions of $\underline{\theta}$. 


$$
\left.\left.A P^{2-2}\right)\right] \times C
$$

\section{OERIVATION OF SPATIAL ESTIMATOR WEIGHFS}

In this Appendix we use a thecren from linear algebra to explicitly calculate the weights $\lambda$ for the spatial estimators. Tne following theor: rn (Noole and Danjel LZUJ) snows now to calculate the inverse of a partitoned matrix.

Tneoren $C-1$ Let $A$ de a partitioned matrix such tnat

$$
A=\left[\begin{array}{ccc}
p & 1 & 4 \\
-1 & 1 & - \\
\hdashline k & 1 & s
\end{array}\right]
$$

where $P \in R^{N \times N}, S \in R^{M \times N}$ and $A$ and $\mu$ are nonsingular, tnen

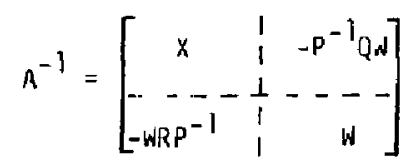

for $W=\left(5-R P^{-1} \cdot 1\right)^{-1}, X=P^{-1}+P^{-1} U W R P^{-1}$.

Proof: This theorem is easily proved using the block baussian elimination cacnnique. Elementary row transforindtions are perforingrd un $A$ until the identiy matrix is odtained, i.e., $T A=1$; thus $T$ is the inve:se of A given oy $(C-1)$. 
If we apply this theorem to the general form of our linear equations for spatial estimation, we obtain the following corollary

Corollary C-1 Let

$$
A=\left[\begin{array}{c:c}
K & L \\
\hdashline L^{T} & 0_{M}
\end{array}\right]
$$

where $K \in R^{N \times N}, L R^{N \times M}, O$ is $M \times M$ nu11 matrix and $A, K$ are nonsingular, then

$$
A^{-1}=\left[\begin{array}{c:c}
Y & -K^{-1} L \Delta \\
\hdashline-\Delta L^{\top} K^{-1} & \Delta
\end{array}\right]
$$

for $Y=K^{-1}+K^{-1} L \Delta L^{X_{X}-1}$ and $\Delta=-\left(L^{K^{-1} L}\right)^{-1}$.

Proof: Using Tneorem $C-1$ with $K=P, L=Q=R, S=0$, we ootain $Y=X$ and $\Delta=w$.

Now if we apply this corollary to our three cases: (i) spatial estimation; (ii) punctual orift estimation; and (iii) regional drift estimation, we obtain the desired results for the optimal weights, $\underline{\lambda}$, i.e., from $(A-10)$ we have 


$$
\begin{gathered}
-12 i- \\
\underline{\theta}=A^{-1} \underline{b}_{k}
\end{gathered}
$$

- Thus, substituting $(\mathrm{C}-2)$ intc $(\mathrm{C}-3)$, we obtain

$$
\left[\begin{array}{c}
\underline{\lambda} \\
-- \\
\underline{\mu}
\end{array}\right]=\left[\begin{array}{c:c}
\gamma & -k^{-1} L \Delta \\
\hdashline-\Delta^{T_{k}}-1 & \Delta
\end{array}\right]\left[\begin{array}{l}
\underline{y}_{k} \\
-- \\
\underline{f}_{k}
\end{array}\right]
$$

or

$$
\begin{aligned}
& \underline{\lambda}=Y_{Y_{k}}-K^{-1} L \Delta f_{-k}=K^{-1}\left[\left(1+L \Delta L K^{-1}\right) Y_{K}-L \Delta f_{-k}\right] \\
& \underline{\mu}=-\Delta L^{\top} K^{-1} \underline{Y k}^{k}+\Delta \underline{f}_{k} .
\end{aligned}
$$

We can now solve our specif ic cases:

\section{Case (i) Spatial Estimator}

Using matrix $A$ of $(A-11)$, we see that with

$$
K=\Gamma-\Sigma \text { and } k=F
$$

so substituting into $(\mathrm{C}-5)$ we have

$$
\underline{\lambda}=(\Gamma-\Sigma)^{-1}\left[\left(I+F \Delta F^{\top}(\Gamma-\Sigma)^{-1}\right) Y_{k}-F \Delta \underline{f}_{k}\right]
$$


and

$$
\Delta=-\left(F^{\top}(I-\Sigma)^{-1} F\right)^{-1} .
$$

Case (ii) Punccual urift Estimator

Using Ilatrix $D$ of $(A-16)$, we see tnat

$$
K=\Gamma-\Sigma, L=F, X_{k}=\underline{0}
$$

so

$$
\underline{\lambda}=-(\Gamma-\Sigma)^{-1} F\left(F^{\top}(\Gamma-\Sigma)^{-i_{F}}\right)^{-i_{I_{k}}}
$$

Case (iii). Regional Drift Estimator

Using 0 of $(A-2)\rangle$, we see tnat.

$$
K=\Gamma-\Sigma, L=F, \underline{Y}_{K}=\underline{0} \text { and } \underline{f}_{K}=\underline{e}_{S}
$$

so

$$
\underline{\lambda}_{s}=-(\Gamma-\Sigma)^{-1} F\left(F^{\top}(\Gamma-\Sigma)^{-\}_{F}}\right)^{-1} \underline{\underline{e}}_{S}
$$

Tnis completes the derivation of explicit expressions for the optina weignt vector, $\lambda$. 